\title{
The state of climate in NW Iberia
}

\author{
M. Gómez-Gesteira ${ }^{1}$, L. Gimeno ${ }^{1}$, M. deCastro ${ }^{1}$, M. N. Lorenzo ${ }^{1}$, I. Alvarez ${ }^{1,2, *}$, \\ R. Nieto ${ }^{1}$, J. J. Taboada ${ }^{3}$, A. J. C. Crespo ${ }^{1}$, A. M. $\operatorname{Ramos}^{1}$, I. Iglesias ${ }^{1}$, J. L. Gómez- \\ Gesteira $^{4}$, F. E. Santo ${ }^{5}$, D. Barriopedro ${ }^{6}$, I. F. Trigo ${ }^{5,6}$ \\ ${ }^{1}$ EPhysLab (Environmental Physics Laboratory), Universidade de Vigo, Ourense 32004, Spain \\ ${ }^{2}$ CESAM, Departamento de Fisica, Universidade de Aveiro, Aveiro 3810-193, Portugal \\ ${ }^{3}$ METEOGAliCIA, Xunta de Galicia, Santiago de Compostela 15707, Spain \\ ${ }^{4}$ CETMAR, Centro Tecnolóxico do Mar, Vigo 36208, Spain \\ ${ }^{5}$ Instituto de Meteorologia, Lisbon 1749-077, Portugal \\ ${ }^{6}$ University of Lisbon, CGUL, IDL, Lisbon 1749-016, Portugal
}

\begin{abstract}
Since 1974, there has been a significant increasing trend in land and sea surface temperatures of 0.5 and $0.24^{\circ} \mathrm{C}$ decade $^{-1}$, respectively, in the NW Iberian Peninsula. Over the same period, annual precipitation does not show any trend, although some tendencies have been detected at seasonal scales. A significant positive trend, on average of $2 \mathrm{~cm} \mathrm{decade}{ }^{-1}$, was also observed in sea level rise from 1943 onwards. Ekman transport perpendicular to the coast (upwelling index) showed a decrease from 1975 to 2008 at both annual and seasonal scales. In addition, the flow of the Miño River (the main river in the area) has also decreased at a mean rate of $18 \mathrm{~m}^{3} \mathrm{~s}^{-1}$ decade $\mathrm{e}^{-1}$ since 1970 . At a synoptic scale, winter cyclone frequency and winter and spring blocking activity have decreased since the 1950s, which may partially explain the winter precipitation decline and the winter and spring temperature increases. These changes in synoptic systems are also in agreement with reported trends in the dominant variability modes of atmospheric circulation affecting NW Iberia, particularly a pronounced positive trend in the North Atlantic Oscillation from the 1970s to the 1990s.
\end{abstract}

KEY WORDS: Climate - Northwest Iberia - Ekman transport - Land temperature $\cdot$ Precipitation · Sea level rise $\cdot$ Sea surface temperature $\cdot$ Synoptic systems $\cdot$ Teleconnection indices $\cdot$ Weather types

\section{INTRODUCTION}

Since 1988 the scientific findings on atmospheric, oceanic, and land changes and the potential for human-induced changes in the Earth's climate have been reviewed and summarized by the Intergovernmental Panel on Climate Change (IPCC) (IPCC 1990, 1996, 2001, 2007). Observational evidence shows that global surface temperature increased during the 20th century. In fact, the increase during the second half of the 20th century is very likely higher than during any other 50 yr period in the last 500 yr (IPCC 2007). The main conclusion of the most recent IPCC report is that this trend is very likely anthropogenically-forced, mainly by the increase in emissions of greenhouse gases and aerosols, changes in land uses, and deforestation. This conclusion has led scientists to define a new geological epoch: the Anthropocene (Falkowski et al. 2000).
The IPCC (IPCC 2007) estimates that the current global temperature is $0.8^{\circ} \mathrm{C}$ above the pre-industrial level, defined as the 1850-1899 average. But this trend has not been temporally homogeneous. The most significant warming has taken place since the mid-1970s, with the highest values occurring in the last 2 decades. Europe has warmed slightly more than the global average. The temperature in Europe is now $1^{\circ} \mathrm{C}$ above pre-industrial levels. Furthermore, on a seasonal scale, Europe warmed most in spring and summer. A particularly significant warming has been observed in the past $50 \mathrm{yr}$ over the Iberian Peninsula, IP (Castro et al. 2005, EEA 2008). The rate of warming over the IP has been estimated to be $0.48^{\circ} \mathrm{C}$ decade $^{-1}$ for the period 1973 to 2005 (Brunet et al. 2007). This increase also implies changes in extreme values (Alexander et al. 2006, IPCC 2007). 
Precipitation is more variable than temperature, both spatially and temporally, and hence precipitation changes have larger uncertainties than those of temperature. Over the period 1900 to 2005, precipitation increased significantly in northern Europe whereas a decline was observed across the Mediterranean (IPCC 2007). In the particular case of the IP this result cannot be confirmed, partly due to the complex patterns of precipitation in the area (Rodríguez-Puebla et al. 1998). For instance, using 10 stations across the IP with reliable precipitation data for the period 1946 to 1998, no significant trend is detectable (Klein Tank et al. 2002). Other studies, taking into account different stations and periods, have observed a general trend towards increasing precipitation in the northern part of the IP and either no discernible trend or a decreasing one for the central and southern regions (EstebanParra 1998, Rodrigo et al. 1999). There is also a significant decreasing trend in spring (Serrano et al. 1999, García et al. 2002, Muñoz-Díaz \& Rodrigo 2004), and it is particularly acute in March (Paredes et al. 2006). Moreover, for the whole IP, the general behavior is a decrease in the daily intensity of rainfall, while the number of wet days does not reveal pronounced changes (Rodrigo \& Trigo 2007). These changes in precipitation and temperature drive concomitant changes in other variables such as river runoff, soil moisture, and drought frequency or intensity (IPCC 2007).

Other aspects of climate such as sea level rise (SLR) or sea surface temperature (SST) show significant trends over the most recent decades. Global average sea level rose at an average rate of $1.8 \mathrm{~cm}$ decade ${ }^{-1}$ over the period 1961 to 2003 (IPCC 2007). Recent results from satellites and tide gauges indicate a higher average rate of global SLR in the past $15 \mathrm{yr}$ of about $3.1 \mathrm{~cm}$ decade $^{-1}$ (Rahmstorf 2007). In Europe, SLR ranged from -0.3 to $2.8 \mathrm{~cm}$ decade $^{-1}$ (Haigh et al. 2009). Along the northern coast of Spain, this rate has been calculated for 3 different tide gauges, all recording similar values (Marcos et al. 2005). Trends in SLR and regional scenarios of SLR and their impacts on coastal habitats have been analyzed throughout the 21st century (Araújo \& Pugh 2008, Chust et al. 2010). Following the well-documented warming of global landmasses, SSTs around Europe have also increased faster than the global average (EEA 2008). On the Atlantic side of the IP, recent research shows that coastal SSTs increased by about $0.2^{\circ} \mathrm{C}_{\text {decade }}-1$ during the period 1985 to 2005 (Gomez-Gesteira et al. 2008). This behavior was put in context by deCastro et al. (2009), who observed an SST increase in the Bay of Biscay of about $0.22^{\circ} \mathrm{C}$ decade ${ }^{-1}$ for the period 1974 to 2007. Those authors also pointed out the existence of different warming-cooling cycles during the last century. Trends and anomalies in SST over the last $60 \mathrm{yr}$ were also analyzed by Goikoetxea et al. (2009) in the southeastern region of the Bay of Biscay.

Changes in the circulation of the atmosphere and underlying oceans are also part of climate change. It is worth noting that the present study region (northwest IP) lies within the mid-latitude belt of the westerlies. Important for the climate of this region is the prevailing westerly circulation that brings the oceanic air masses inland. Stronger advection from the west brings milder and wetter weather and stronger winds, especially in autumn and winter. Weaker and blocked westerly circulation patterns lead to generally colder and drier winters and hotter and drier summers. A general picture of the atmospheric circulation of the North Atlantic includes a poleward shift in storm-track location (Wang et al. 2006), although long-term changes in extratropical storm activity becomes difficult to discern because of the noise present in the observations (IPCC 2007). Blocking activity seems to be less intense over the North Atlantic region throughout the most recent decades, with statistically significant decreases in events and duration (Barriopedro et al. 2006), while cut-off lows, as the other main feature of the circulation, appear to have an inter-annual variability (Nieto et al. 2005). In this general context, the IP climate is strongly influenced by its position within the northern mid-latitudes, and its location between the Atlantic Ocean and the Mediterranean Sea, as well as the existence of 2 important mechanisms of atmospheric moisture and instability - the precipitation regime in the northern and western edges of the IP is strongly affected by the location of the Atlantic storm tracks, whereas the interior and the eastern half of the IP is affected by both large-scale synoptic systems from the Atlantic and convective precipitation originating over the Mediterranean (Trigo et al. 1999, Trigo \& DaCamara 2000, Castro et al. 2005). The orography of the IP has a strong influence on the way that baroclinic perturbations and convective systems affect the local climate. Furthermore, the IP has 2 further characteristics that influence precipitation variability across the region, namely: (1) its location toward the southern margin of the Atlantic westerly belt (Zhu \& Newell 1998), the main large scale feature providing moisture at mid-latitudes, and (2) its location in southwestern Europe, which results in the variability of precipitation in some parts of the IP reflecting the connection to the large-scale North Atlantic atmospheric circulation (von Storch et al. 1993, Serrano et al. 1999, Trigo \& Palutikof 2001).

Variability modes of the atmosphere are of paramount importance to the study of regional climate change. The most important mode of variability in the North Atlantic area is the North Atlantic Oscillation (NAO, e.g. Trigo et al. 2002). NAO is a large-scale fluc- 
tuation in atmospheric pressure in the Atlantic Ocean between high pressure near the Azores and low pressure near Iceland. This mode of variability exerts a dominant influence on climate over many parts of Europe (e.g. Hurrell 1995). In the decades from the 1960 s to the 1990 s, NAO had a positive trend that some authors related to an anthropogenically induced climate change (Feldstein 2002), but in the last decade, NAO values have declined to near the long-term mean (IPCC 2007). Other teleconnection patterns appearing in the North Atlantic and also affecting climate variability over the IP are the Scandinavian (SCAND), Eastern Atlantic (EA), and Eastern Atlantic-Western Russia (EA-WR) patterns, which increases the complexity of climate-change studies. Thus, recent studies have proved that atmospheric and oceanic phenomena such as precipitation, river discharge, and upwelling should be explained in terms of $>1$ teleconnection pattern (Lorenzo \& Taboada 2005, deCastro et al. 2006a, 2008a).

Although climate change is global in nature, greater knowledge is required on smaller scales to more accurately identify its spatial structure and impacts. Within this context, detailed studies of regional tendencies of climatic parameters become particularly relevant. This information is necessary to identify the climatic parameters that are most representative regionally, and for local policy-makers and resource managers to evaluate the risks associated with regional-scale climate change.

With this aim, a detailed study of the climate in NW Iberia is presented in this paper. The analysis will consider both average conditions and periods of significant change during the period from the second half of the 20th century to the beginning of the 21 st century.

\section{AREA AND METHODOLOGICAL APPROACH}

\subsection{Description of the area}

The area under scope covers the northwestern part of the IP, including territories of both Spain and Portugal (Fig. 1a). It corresponds to the Spanish region of Galicia and northern Portugal. The area extends approximately from 41 to $44^{\circ} \mathrm{N}$ and from 6.5 to $9^{\circ} \mathrm{W}$ and is surrounded by the Atlantic Ocean and the Cantabrian Sea. The highest mountains are located within Spanish territory, although they hardly reach $2000 \mathrm{~m}$ (Fig. 1b). A secondary and smaller mountain chain acts as a natural border between both countries.

Although there are $>20$ rivers in the area with a mean run-off over $4 \mathrm{~m}^{3} \mathrm{~s}^{-1}$, the Miño River and its main tributary (Sil River) constitute the main freshwater source in the region, with a catchment area of $17081 \mathrm{~km}^{2}$ and a run-off of $\sim 13 \mathrm{~km}^{3} \mathrm{yr}^{-1}$. The river acts as a natural border between Spain and Portugal over its last $75 \mathrm{~km}$. The other large river in the region is the Douro, with a catchment area of $97682 \mathrm{~km}^{2}$ and a run-off on of $22 \mathrm{~km}^{3} \mathrm{yr}^{-1}$. In spite of the Douro River having a larger run-off than the Miño River, only a small part of the catchment area lies inside NW Iberia and does not reflect the dominant climate features of the area.
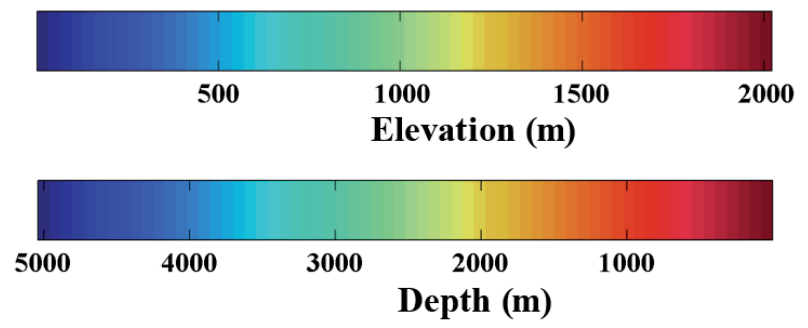

a)

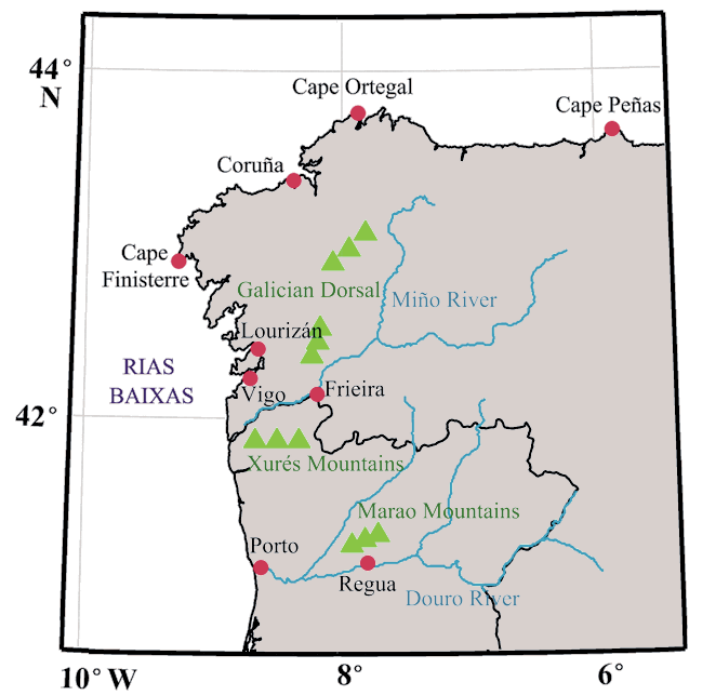

b)

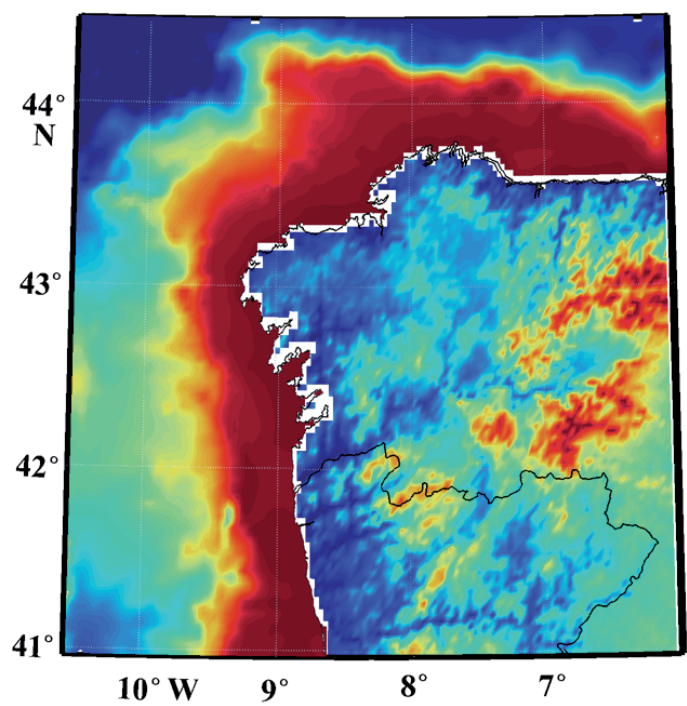

Fig. 1. Maps of the area in NW Iberia. (a) Main locations (•) and geographical features $(\Delta),(b)$ altimetry and bathymetry 
The continental shelf in the area is relatively short and the basin becomes deeper than $1000 \mathrm{~m}$ in just a few tens of kilometers (Fig. 1b). Three different coastal zones can be identified (Fig. 1a): the western coast from Douro River to Cape Finisterre with an approximate angle of $90^{\circ}$ relative to the equator, the middle coast from Cape Finisterre to Cape Ortegal with an approximate angle of $55^{\circ}$, and the northern coast from Cape Ortegal to Cape Peñas, approximately parallel to the equator.

Climatologically, the intensity of winter precipitation is influenced by orography, since incoming fronts from the Atlantic Ocean are affected by the presence of mountains near the coastline, which act as barriers that hinder the movement of the fronts to the interior areas. In general, the coastal and adjacent areas are characterized by a maritime climate with mild summers and rainy winters, whereas the interior part of the region is characterized by a continental climate with dry summers and cold winters.

Atmospheric circulation in the area, within the middle latitudes of the North Atlantic, is governed by 2 main centers of activity: an anticyclonic zone south of $40^{\circ} \mathrm{N}$ centered near the Azores (Azores High) and a low-pressure area centered around $60^{\circ} \mathrm{N}$ near Iceland (Iceland Low). In summer, the Azores High moves northwestward. A thermal low develops over the IP from April to September, giving rise-along with the Azores High - to equatorward coastal winds.

In winter, the difference between the warm waters of the Gulf Stream and the cold waters of Labrador gives rise to a surface weather front (the so-called Polar Front). This difference in temperature enhances the formation of pronounced depressions over the ocean. A typical winter situation corresponds to the presence of an anticyclone over the continent and a low-pressure area over the Atlantic, which gives rise to southwesterlies along the western coast, although the northern coast may become less affected due to the presence of landmasses that deflect the winds.

Important for the climate of this region is the prevailing westerly circulation that directs the oceanic air masses inland. Stronger western advection brings milder, wetter weather and stronger winds, especially in autumn and winter. Weaker and blocked westerly circulation causes generally colder, drier winters and hotter, drier summers. Therefore, due to its location, the region is a transition area, which complicates the study of climate change in the IP. Recent studies have proved that atmospheric and oceanic phenomena such as precipitation and coastal upwelling should be explained in terms of $>1$ teleconnection pattern (Lorenzo \& Taboada 2005, deCastro et al. 2006a, 2008a).

From an oceanographic point of view, the dominant process affecting coastal upwelling in spring and sum- mer is the position and intensity of the Azores High (Wooster et al. 1976, Fraga 1981, Blanton et al. 1984, Tenore et al. 1984, Alvarez-Salgado et al. 1993, Pérez et al. 1995, Gomez-Gesteira et al. 2006). In winter, the coastal behavior is influenced by the presence of a warm poleward-flowing slope current (Frouin et al. 1990, Haynes \& Barton 1990). In addition, the buoyant plumes associated with the outflow of the Miño and Douro rivers also control coastal dynamics in winter, especially the surface waters. As river water is colder than seawater during winter, thermal inversions sustained by haline stratification are commonly observed over the shelf.

\subsection{Methodological approach}

We considered the state and evolution of several atmospheric and oceanographic variables, as well as different spatial scales according to the nature of the particular variable under investigation. Thus, land temperature, precipitation, SST, and Ekman transport were treated as mesoscale phenomena. In addition, other variables such as river discharge or SLR were studied at discrete gauge points. Finally, cyclones and anticyclonic blocking were analyzed at synoptic and larger scales. Despite the varying extent of influence of such features, we focused on the IP area. Also, the length of the series was different due to the different sampling strategies associated with each particular variable. In addition, the definition of season was dependent on the variable. Thus, for example, winter was defined throughout the text as DJF (December to February) for land temperature, precipitation, and $\mathrm{SST}_{;}$an extended wet season (November to March) was considered for Ekman transport; and cyclone activity was analyzed for the period DJFM (December to March). This apparent inconsistency is due to 2 main causes: (1) the different nature of the variables made certain monthly groupings more suitable than for the rest of the analyses, and (2) for the sake of comparison we decided to consider the definition of season most commonly adopted in previous research.

\section{LAND TEMPERATURE}

\subsection{Methods}

There are many different databases containing global gridded temperature data sets over land (Jones et al. 1999), covering at least the last century. However, the resolution of those data is too coarse for regional studies, especially when dealing with areas where topography changes abruptly. Thus, observa- 
tion-based temperature data sets were considered in the present study to reflect the spatial variability of temperature patterns. The main difficulty for this approach comes from the fact that the area under study corresponds to the territories of 2 different countries (Spain and Portugal). Thus, the different administrations have historically considered different sampling strategies, whereas data series should normally be homogenized prior to analysis.

The data set corresponding to the Portuguese territory comprises the daily maximum and minimum temperature for the period 1941 to 2006. Data from 7 climatological weather stations were retrieved from the archive of the Portuguese Meteorological Office. The position and elevation of the stations are listed in Table 1 (Stns P1 to P7). These particular stations were chosen to obtain the best spatial distribution with the highest quality in terms of continuity of the data series.

The Spanish data set was obtained from 2 databases, Agencia Estatal de Meteorología (AEMET) and METEOGALICIA (Xunta de Galicia), with stations distributed throughout the territory. Data from 11 stations were considered (Stns G1 to G11 in Table 1).

Data from both countries underwent a quality-control procedure (with substitutions made for potential outliers and some missing data) similar to the one used in the National Climate Data Center, National Oceanic and Atmospheric Administration (NOAA) for Global Historical Climate Network database (Peterson et al. 1998). Quality control for these data series resulted in $<1 \%$ of missing data and $90 \%$ correlation between neighboring stations.

Maps were created with a $0.01^{\circ} \times 0.01^{\circ}$ mesh using both data sets. Temperature $(T)$ was interpolated at all points considering a Gaussian distribution with a correction $(C)$ in latitude $\left(l\right.$, in $\left.{ }^{\circ} \mathrm{N}\right)$ and elevation $(h$, in $\mathrm{m})$ following:

$$
\begin{aligned}
& T_{i, j}= \\
& \frac{\sum_{k=1}^{\mathrm{N}} C_{l}\left(l_{k}-l_{i, j}\right) C_{h}\left(h_{k}-h_{i, j}\right) \mathrm{e}^{-\left(d_{i, j}^{k} / \sigma\right)^{2}} T_{k}}{\sum_{k=1}^{\mathrm{N}} \mathrm{e}^{-\left(d_{i, j}^{k} / \sigma\right)^{2}}}
\end{aligned}
$$

Table 1. Stations used for land temperature and precipitation data in Galicia and North Portugal. G1-G11: Spanish stations; P1-P7: Portuguese stations;

\begin{tabular}{|c|c|c|c|c|c|}
\hline Stn & Weather station & $\begin{array}{l}\text { Latitude } \\
\qquad\left({ }^{\circ} \mathrm{N}\right)\end{array}$ & $\begin{array}{c}\text { Longitude } \\
\left({ }^{\circ} \mathrm{W}\right)\end{array}$ & $\begin{array}{l}\text { Elevation } \\
\quad(\mathrm{m})\end{array}$ & Period \\
\hline G1 & As Pontes & 43.45 & 7.86 & 343 & 1948-2006 \\
\hline G2 & A Coruña & 43.37 & 8.42 & 58 & $1948-2006$ \\
\hline G3 & Santiago de Compostela & 42.90 & 8.43 & 364 & $1961-2006$ \\
\hline G4 & Salcedo & 42.41 & 8.64 & 40 & $1950-2006$ \\
\hline G5 & Lourizán & 42.41 & 8.66 & 60 & $1958-2006$ \\
\hline G6 & Vigo & 42.22 & 8.63 & 255 & 1961-2006 \\
\hline G7 & Lugo & 43.01 & 7.55 & 450 & 1966-2006 \\
\hline G8 & Sarria & 42.77 & 7.41 & 550 & $1943-2006$ \\
\hline G9 & Pobra do Brollón & 42.59 & 7.41 & 400 & $1951-2006$ \\
\hline G10 & Ponteareas & 42.18 & 8.49 & 50 & $1938-2006$ \\
\hline G11 & Xinzo de Limia & 42.06 & 7.72 & 600 & $1947-2006$ \\
\hline $\mathrm{P} 1$ & Montalegre & 41.82 & 7.78 & 1005 & 1941-2006 \\
\hline $\mathrm{P} 2$ & Bragança & 41.80 & 6.73 & 690 & $1941-2006$ \\
\hline P3 & Braga & 41.55 & 8.40 & 190 & 1941-2006 \\
\hline $\mathrm{P} 4$ & Régua & 41.17 & 7.80 & 65 & $1941-2006$ \\
\hline P5 & Porto & 41.13 & 8.60 & 93 & 1941-2006 \\
\hline $\mathrm{P} 6$ & Penhas Douradas & 40.42 & 7.55 & 1380 & $1941-2006$ \\
\hline P7 & Coimbra & 40.15 & 8.47 & 141 & $1941-2006$ \\
\hline A & Fene & 43.46 & 8.19 & 30 & 1961-2006 \\
\hline $\mathrm{A}$ & As Pontes & 43.45 & 7.86 & 343 & 1961-2006 \\
\hline $\mathrm{A}$ & Betanzos & 43.28 & 8.21 & 38 & $1961-2006$ \\
\hline A & San Andres & 43.21 & 8.44 & 200 & $1961-2006$ \\
\hline $\mathrm{A}$ & A Coruña & 43.37 & 8.42 & 58 & 1961-2006 \\
\hline $\mathrm{A}$ & Montaos-Ordes & 43.04 & 8.42 & 306 & 1961-2006 \\
\hline A & Santiago & 42.90 & 8.43 & 364 & 1961-2006 \\
\hline B & Coron & 42.58 & 8.80 & 20 & 1961-2006 \\
\hline B & Salcedo & 42.41 & 8.64 & 40 & 1961-2006 \\
\hline B & Fornelos G.C. & 42.33 & 8.45 & 360 & $1961-2006$ \\
\hline B & Vigo & 42.22 & 8.63 & 255 & 1961-2006 \\
\hline B & Ponteareas & 42.18 & 8.49 & 50 & $1961-2006$ \\
\hline B & Paramos & 42.06 & 8.61 & 45 & 1961-2006 \\
\hline $\mathrm{C}$ & Lugo & 43.01 & 7.55 & 450 & $1961-2006$ \\
\hline $\mathrm{C}$ & Sarria & 42.78 & 7.41 & 550 & $1961-2006$ \\
\hline $\mathrm{C}$ & Cruz De Outeiro & 42.53 & 7.13 & 790 & $1961-2006$ \\
\hline $\mathrm{C}$ & Ponte Lor & 42.51 & 7.34 & 400 & 1961-2006 \\
\hline $\mathrm{C}$ & Pobra Do Brollón 'Veiga' & 42.59 & 7.41 & 400 & $1961-2006$ \\
\hline $\mathrm{D}$ & Castiñeira & 42.19 & 7.23 & 1046 & $1961-2006$ \\
\hline $\mathrm{D}$ & Rabal & 42.30 & 7.39 & 950 & $1961-2006$ \\
\hline $\mathrm{D}$ & Aciveiros & 42.34 & 7.33 & 978 & 1961-2006 \\
\hline $\mathrm{D}$ & Edrada De Parada Do Sil & 42.33 & 7.55 & 860 & 1961-2006 \\
\hline $\mathrm{D}$ & Ourense 'Granxa Deput' & 42.33 & 7.86 & 143 & $1961-2006$ \\
\hline $\mathrm{D}$ & Maceda 'E. Cap. Agraria' & 42.27 & 7.65 & 600 & 1961-2006 \\
\hline $\mathrm{D}$ & Allariz & 42.17 & 7.80 & 766 & 1961-2006 \\
\hline $\mathrm{D}$ & Viladerrei & 42.02 & 7.60 & 657 & $1961-2006$ \\
\hline $\mathrm{D}$ & Xinzo De Limia & 42.06 & 7.72 & 600 & $1961-2006$ \\
\hline $\mathrm{E}$ & Montalegre & 41.82 & 7.78 & 1005 & 1961-2006 \\
\hline $\mathrm{E}$ & Bragança & 41.80 & 6.73 & 690 & 1961-2006 \\
\hline $\mathrm{E}$ & Penhas Douradas & 40.42 & 7.55 & 1380 & $1961-2006$ \\
\hline $\mathrm{F}$ & Braga & 41.55 & 8.4 & 190 & $1961-2006$ \\
\hline $\mathrm{F}$ & Régua & 41.17 & 7.8 & 65 & 1961-2006 \\
\hline $\mathrm{F}$ & Porto & 41.13 & 8.6 & 93 & 1961-2006 \\
\hline $\mathrm{F}$ & Coimbra & 40.15 & 8.47 & 141 & 1961-2006 \\
\hline
\end{tabular}
A-F: different clusters of stations (see Section 4.1) 
where $\mathrm{N}=$ number of meteorological stations, $C_{l}=$ $0.59^{\circ} \mathrm{C}$ per degree of latitude, $C_{h}=0.004^{\circ} \mathrm{C} \mathrm{m}^{-1}$, and $\sigma=$ 0.5. $d_{i, j}^{k}$ represents the distance in degrees between station $k$ and the gridded point $i, j$. The value of the parameters $C_{l}$ and $C_{h}$ was fitted using the temperatures measured at the different locations. In general, interpolated data were only used to create maps. The rest of the calculations (as temperature trends or percentiles) were calculated at the stations.

Climate extremes have attracted the interest of the scientific community because the impact of climate changes is felt more strongly through changes in extremes. These extremes have been analyzed at different spatial scales (Brunetti et al. 2000, Moberg et al. 2000, Tuomenvirta et al. 2000, Klein Tank \& Können 2003, Klein Tank et al. 2006). The definition of the extreme indices was taken from the joint CCl/CLIVAR/JCOMM Expert Team on Climate Change Detection and Indices (ETCCDI) (Peterson et al. 2001, Klein Tank \& Können 2003). Here, we used the following indices based upon TN (nights) and TX (days):

TN10 (cold nights) represents the days with TN < 10th percentile. Let $\mathrm{TN}_{i j}$ be the daily minimum temperature on day $i$ in period $j$ and let $\mathrm{TN}_{\text {in }} 10$ be the calendar day 10th percentile centered on a 5-day window for the base period 1961 to 1990. Then, the number of days with $\mathrm{TN}_{i j}<\mathrm{TN}_{i n} 10$ is counted.

TX10 (cold days) represents the days with TX $<10$ th percentile. Let $\mathrm{TX}_{i j}$ be the daily maximum temperature on day $i$ in period $j$ and let $\operatorname{TX}_{\text {in }} 10$ be the calendar day 10th percentile centered on a 5-day window for the base period 1961 to 1990 . Then, the number of days with $\mathrm{TX}_{i j}<\mathrm{TX}_{i n} 10$ is counted.

TN90 (warm nights) represents the days with TN > 90th percentile. Let $\mathrm{TN}_{i j}$ be the daily minimum temperature on day $i$ in period $j$ and let $\operatorname{TN}_{\text {in }} 90$ be the calendar day 90th percentile centered on a 5-day window for the base period 1961 to 1990. Then, the number of days with $\mathrm{TN}_{i j}>\mathrm{TN}_{i n} 90$ is counted.

TX90 (warm days) represents the days with TX > 90th percentile. Let $\mathrm{TX}_{i j}$ be the daily maximum temperature on day $i$ in period $j$ and let $\mathrm{TN}_{i n} 90$ be the calendar day 90th percentile centered on a 5-day window for the base period 1961 to 1990 . Then, the number of days with $\mathrm{TX}_{i j}>\mathrm{TX}_{\text {in }} 90$ is counted.

The meteorological stations used to calculate the indices were P1, P2, P3, P4, and P5 and G1, G2, G3, G6, G8, and G9 (Table 1). This particular subset of stations was selected for stability reasons. In particular the study was focused on those stations with a negligible number of missing data and outliers. Trends in the indices of temperature extremes were calculated by ordinary least-squares fits. Trend significance $(p<0.1)$ was tested using a Student's $t$-test.

\subsection{Results}

The Portuguese and Spanish databases mentioned in Section 3.1 were used to create temperature maps for the period 1961 to 2006. The standard meteorological seasons are used: December to February (DJF) is winter, March to May (MAM) is spring, June to August (JJA) is summer, and September to November (SON) is autumn.

Fig. 2 represents the maximum seasonal temperature on land. A marked difference between coastal and continental temperatures can be observed in summer, when at the same latitude, maximum continental temperatures are $\sim 2^{\circ} \mathrm{C}$ higher. In winter, this effect is even more remarkable, with continental temperatures $\sim 5^{\circ} \mathrm{C}$ lower than the coastal ones. Deviations from this general pattern are mainly due to orographic effects (see Fig. 1b). The presence of orographic barriers along the coastline is also responsible for the rapid transition from a maritime climate at the coast to a continental climate at distances $<100 \mathrm{~km}$ from the coast. Similar patterns can be observed for minimum land temperatures (Fig. 2). The lowest temperatures always correspond to the continental part of Galicia, where the highest mountains are located.

The temperature difference between coastal and interior regions can be observed in Fig. 3, where points located at approximately the same latitude are compared for the period 1961 to 2000. In particular, the coastal point Stn G5 (blue line) (see Table 1) is compared to the interior point located at $42.43^{\circ} \mathrm{N}, 7.83^{\circ} \mathrm{W}$ (red line). This last station was not included in Table 1 because it was only operative until 2000. The same analysis (Fig. 3) was carried out over northern Portugal (Stns P4 [interior, black line] and P5 [coastal, green line] in Table 1). The summer and winter temperatures are at least $1.5^{\circ} \mathrm{C}$ lower and $1.5^{\circ} \mathrm{C}$ higher, respectively, at coastal locations than at interior locations. Thus, the thermal amplitude is $\sim 11^{\circ} \mathrm{C}$ near the coast and $\sim 15^{\circ} \mathrm{C}$ in the interior regions.

Fig. 4 shows land stations (black squares) used in the present study, and Fig. 5 shows the evolution of land temperature at different stations (located within the study area) from 1940 to 2008. In all cases, temperature decreased from mid-century until the 1970s and increased from then on. Although the local minimum temperature was not the same at all locations, 1974 appears as a common starting point for this temperature increase. This starting point was estimated by averaging the local minimum temperature at Stns G1-G11 and P1-P7 shown in Table 1. Data were linearly fitted at every station to determine the temperature trend. On average, the annual trend of maximum temperature for the period 1974 to 2006 was positive at all stations (Table 2 ), with values ranging from 0.28 to 

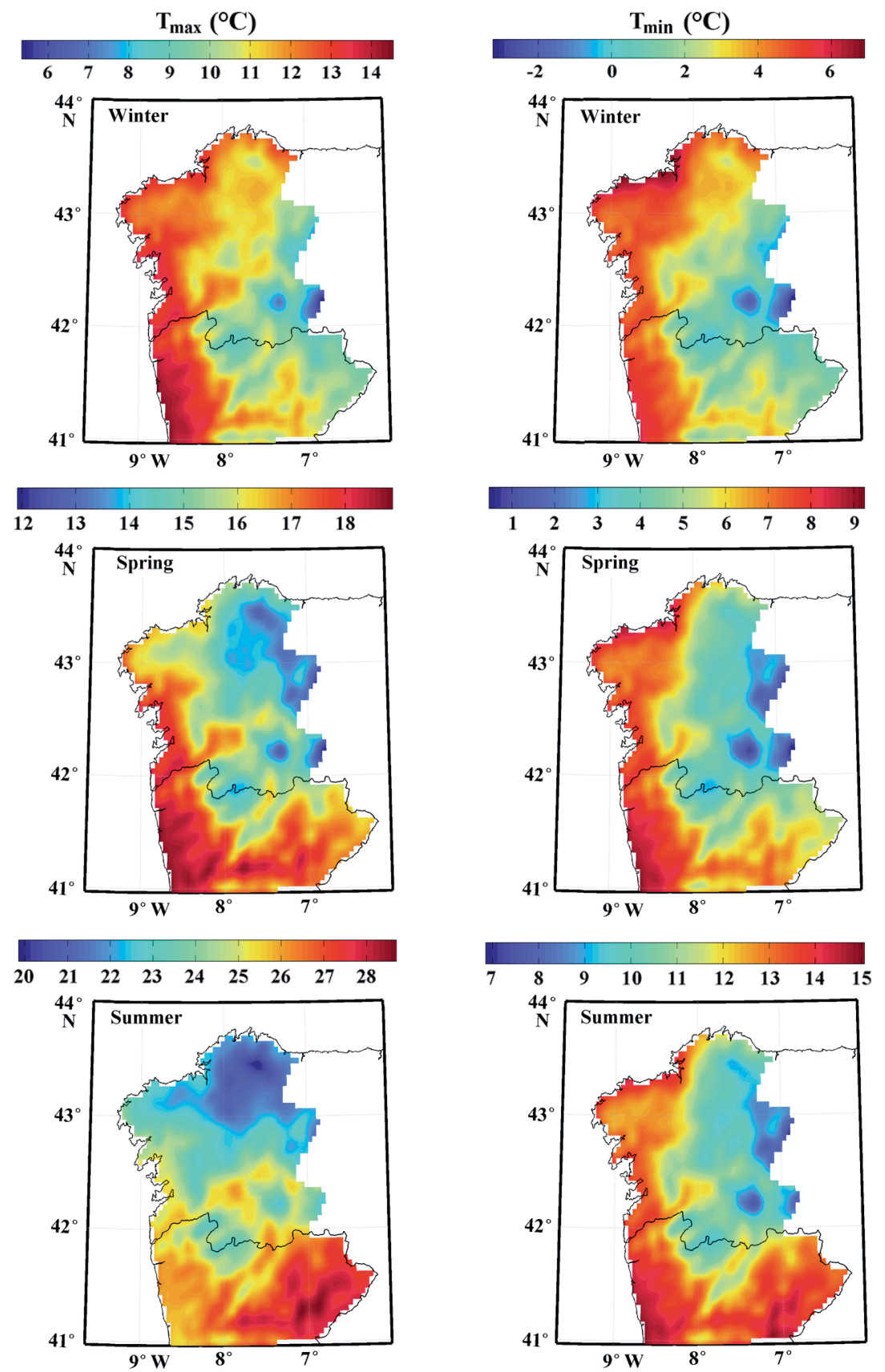

$0.83^{\circ} \mathrm{C}$ decade $^{-1}$. This positive trend at the annual scale can be analyzed in more detail by means of seasonal trends (Table 2). Increases in maximum temperature were highest in spring, followed by summer and winter, with no apparent trend seen in autumn. A similar pattern can be observed for the minimum temperature values. Once again, the annual trend for the period 1974 to 2006 was positive at all stations (Table 2). Seasonally, summer and spring showed the highest increase in minimum temperature (Table 2). Most of the trends were within the interval 0.5 to $1.1^{\circ} \mathrm{C}$ decade $^{-1}$ during these seasons. The trend in winter was more moderate than the one observed for maximum temperature (Table 2). Most of the stations showed a trend lower than $0.25^{\circ} \mathrm{C}$ decade $^{-1}$. Finally, the trend in autumn was higher than the one observed for maximum temperatures.

Besides demonstrating a clear temperature increase during the last 3 decades, we also analyzed extreme temperatures. Table 3 shows the 1974-2006 trends for seasonal TX90 (hot days) and TX10 (cold days). A positive significant trend was found at all stations. The TX90 trend was significant at the $5 \%$ level at $\sim 36 \%$ of the stations in winter, $\sim 91 \%$ in spring, $\sim 73 \%$ in summer and $0 \%$ in autumn. Both in spring and summer most of the trends ranged from 3 to $6 \mathrm{~d}_{\text {decade }}{ }^{-1}$. In summary, the warming trend associated with an increasing trend in TX90 appeared mainly between March and August.

Negative trends were found in TX10 (Table 3) at all stations, which is consistent with the positive trend observed for TX90. Seasonally, the most coherent pattern appeared in spring, when all stations, except one located at the southern part of the region, showed a Csignificant trend. In summer, only $\sim 55 \%$ of the stations showed a significant

Fig. 2. Seasonal maps of maximum ( $T_{\max }$ left column) and minimum ( $T_{\min }$ right column) temperature for the period 1961-2006. Winter: DJF; spring: MAM; summer: JJA; autumn: SON. Note that colour scales differ between panels 


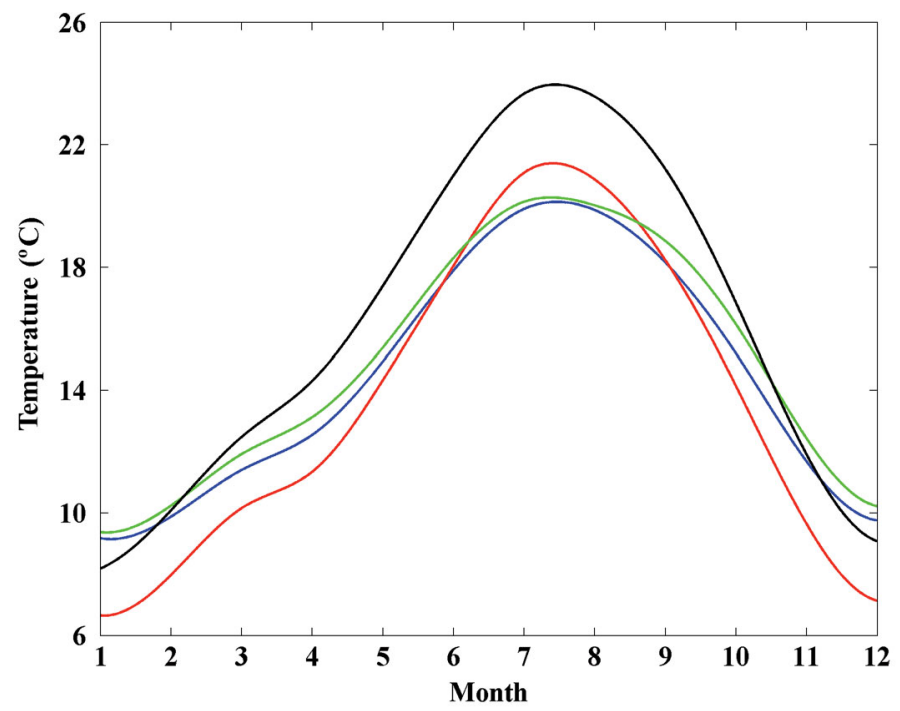

Fig. 3. Comparison between the annual temperature cycle at Galicia coastal (blue line) and interior (red line) stations and Portugal coastal (green line) and interior (black line) stations averaged for the period 1961 to 2006 trend, and this number diminished to $\sim 45 \%$ and $\sim 27 \%$ in autumn and winter, respectively. In autumn, the stations with a significant trend were located to the north. Overall, trends of increasing number of days with extreme temperatures were greater for TX90 than for TX10 (Table 3).

The most marked trends for extreme temperatures were obtained for TN90, the index associated with hot nights, as shown in Table 3. These trends were observed in spring and summer at all stations. In particular, values ranging from 3.5 to $9 \mathrm{~d}$ decade $^{-1}$ were found in spring and from 3 to $15.5 \mathrm{~d} \mathrm{decade}^{-1}$ in summer. In winter, only 1 station showed a significant trend, while in autumn, 6 ( $55 \%)$ showed a significant trend. Compared with the trends for TX90, a larger warming trend exists in the night index than in the day index, suggesting a negative trend in mean diurnal temperature range. Warming was mainly observed in spring and summer, both for days and nights, in good agreement with the values observed in Table 2 .

The TN10 index, associated with cold nights, showed a decreasing trend at all stations (Table 3), which indicates a warming similar to the one observed for the other indices. Significant trends were found for almost all the stations in spring, summer and autumn whereas only 2 stations displayed significant trends in TN10 in winter. The negative trends for cold nights can be observed to be similar to the ones obtained for cold days, although considerably lower in absolute value, than the TN90.

In general, the T10 values were always lower in absolute value than their T90 counterparts. This fact, which has been previously pointed out by Klein Tank et al. (2006), is expected when the Gaussian-shaped temperature distribution shifts toward higher temperatures.

\section{PRECIPITATION}

\subsection{Methods}

As in Section 3 for temperature, we used observational data sets from the Portuguese and Spanish databases to reflect the spatial variability of precipitation patterns. Although precipitation is gauged at points in typically sparse networks, for many environmental studies it can be useful to interpolate these records as a continuous surface, represented by isohyets. At mid-latitudes, most studies have
Fig. 4. Land stations considered in the present study (black squares), set of 25 points selected to calculate sea surface temperature (SST) trends along the coastal area (blue dots), and set of 8 points selected to calculate SST at ocean locations around the study area (red numbers with dots) 


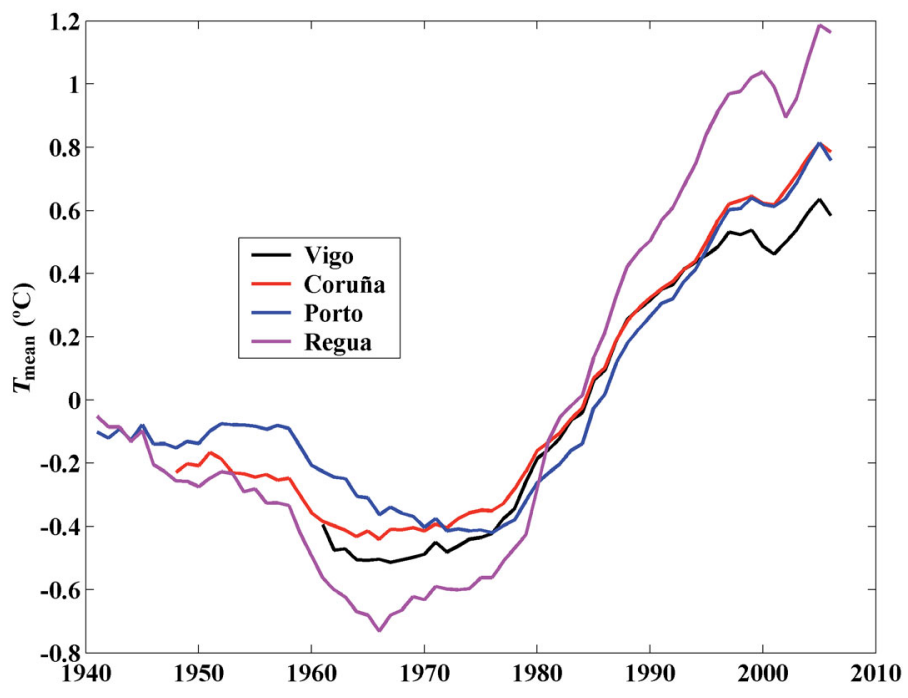

Fig. 5. Land temperature evolution for different gauge stations scattered over the study area. $T_{\text {mean }}$ mean temperature found that a simple linear model seems to fit the observed data well, at least for extended time periods and over relatively small areas (e.g. Brunsdon et al. 2001). Thus, maps for precipitation $(P)$ were created following a methodology similar to the one described for temperature:

$$
P_{i, j}=\frac{\sum_{k=1}^{\mathrm{N}} C_{h}\left(h_{k}-h_{i, j}\right) \mathrm{e}^{-\left(d_{i, j}^{k} / \sigma\right)^{2}} P_{k}}{\sum_{k=1}^{\mathrm{N}} \mathrm{e}^{-\left(d_{i, j}^{k} / \sigma\right)^{2}}}
$$

Here, the parameter $C_{h}$ depended on altitude, the month of the year, and the area (Martínez Cortizas \& Pérez Alberti 2000). Precipitation distribution in the IP is highly variable depending on the season, which is reflected both in quantity and in typology. Thus, for example, winter precipitation is characterized by frontal rainfall while summer rain is mainly convective. On the other hand, the intensity of precipitation is

Table 2. Annual and seasonal trends $\left({ }^{\circ} \mathrm{C}\right.$ decade $\left.^{-1}\right)$ of maximum and minimum temperatures for the period 1974-2006. $(-)$ points without statistical significance (i.e. $p>0.05$ ) at a $95 \%$ confidence level were removed

\begin{tabular}{|c|c|c|c|c|c|c|c|c|c|c|}
\hline \multirow[b]{2}{*}{ Weather station } & \multicolumn{2}{|c|}{ Annual } & \multicolumn{2}{|c|}{ Winter (DJF) } & \multicolumn{2}{|c|}{ Spring (MAM) } & \multicolumn{2}{|c|}{ Summer (JJA) } & \multicolumn{2}{|c|}{ Autumn (SON) } \\
\hline & Max & Min & Max & Min & $\operatorname{Max}$ & Min & Max & Min & Max & Min \\
\hline A Coruña & 0.41 & 0.41 & 0.21 & 0.22 & 0.73 & 0.58 & 0.47 & 0.51 & 0.24 & 0.33 \\
\hline As Pontes & 0.72 & 0.41 & 0.37 & 0.14 & 1.25 & 0.58 & 0.91 & 0.48 & 0.33 & 0.42 \\
\hline Santiago & 0.54 & 0.35 & 0.31 & 0.09 & 1.02 & 0.55 & 0.66 & 0.5 & 0.19 & 0.26 \\
\hline Vigo & 0.41 & 0.33 & - & 0.08 & 0.77 & 0.6 & 0.46 & 0.42 & - & 0.21 \\
\hline Sarria & 0.51 & 0.73 & 0.73 & 0.51 & 1.07 & 1.03 & 0.17 & 0.79 & - & 0.58 \\
\hline Pobra do Brollón & 0.46 & 0.56 & 0.76 & - & 0.67 & 0.66 & 0.25 & 0.85 & - & 0.53 \\
\hline Braga & 0.35 & 0.77 & 0.19 & 0.22 & 0.66 & 0.96 & 0.49 & 0.96 & - & 0.84 \\
\hline Bragança & 0.47 & 0.26 & 0.27 & - & 0.84 & 0.49 & 0.86 & 0.37 & - & 0.19 \\
\hline Montalegre & 0.83 & 0.35 & 0.62 & 0.07 & 1.19 & 0.75 & 0.87 & 0.48 & 0.28 & 0.22 \\
\hline Porto & 0.42 & 0.56 & 0.24 & 0.23 & 0.76 & 0.74 & 0.61 & 0.67 & - & 0.59 \\
\hline Régua & 0.44 & 0.88 & 0.38 & 0.43 & 0.91 & 1 & 0.52 & 1.14 & - & - \\
\hline
\end{tabular}

Table 3. Seasonal trends for TX90 (hot days), TX10 (cold days), TN90 (hot nights), and TN10 (cold nights) (see Seciton 3.1 for definitions) for the period 1974-2006. (-) points without statistical significance (i.e. p > 0.05) at a $95 \%$ confidence level were removed

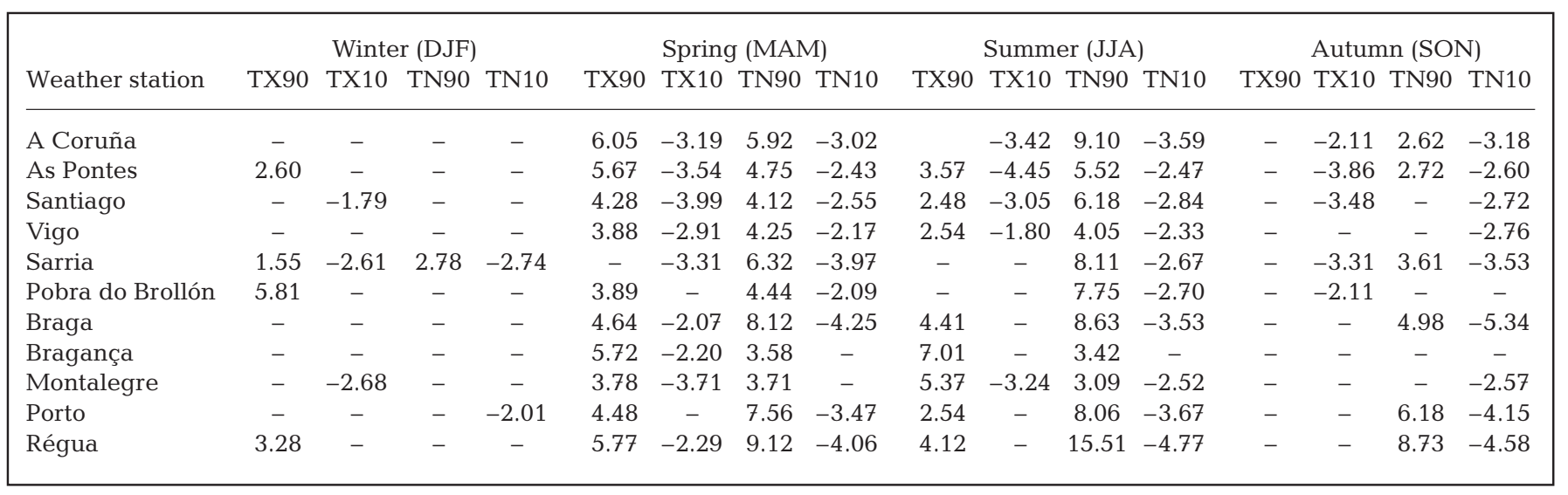




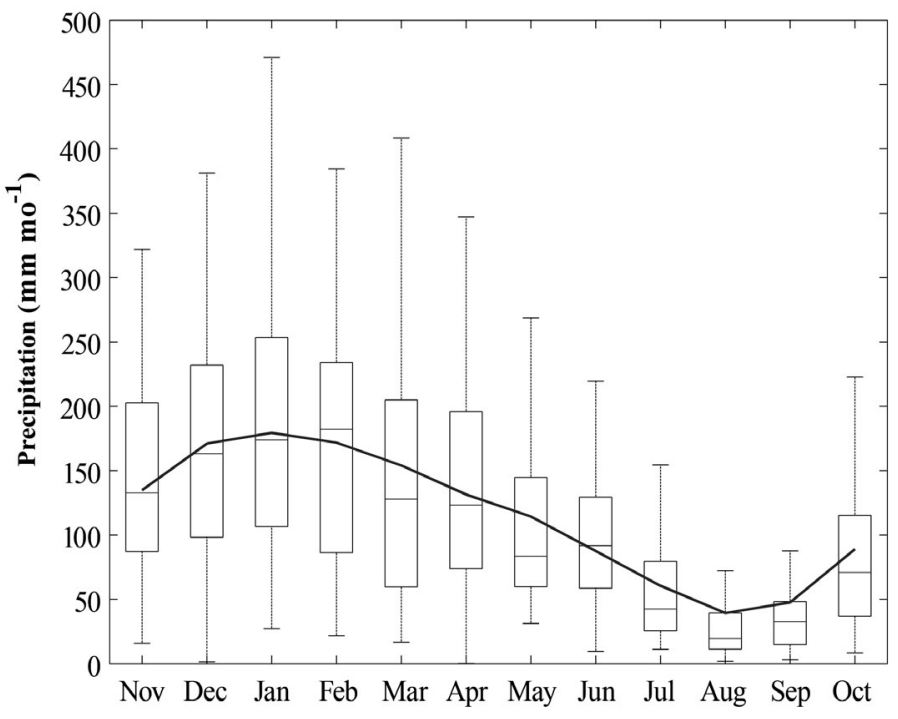

Fig. 6. Annual hydrologic cycle variability for the monthly average precipitation from 1961-2006. Curve: monthly average; line inside box: median; lower and upper box limits: first and third quartiles, respectively; lower and upper whiskers: minimum and maximum precipitaion, respectively clearly influenced by local orography. This gives rise to precipitation with a strong gradient increasing from the coastal areas to the mountains. Thus, the 34 stations under study were grouped into 7 clusters (as shown in Table 1) labeled from A to F following previous work carried out in the region (Martínez Cortizas \& Pérez Alberti 2000) and also applying a $k$-means clustering (Trauth 2006). Data were linearly fitted for the stations inside each cluster to obtain the dependence of precipitation on altitude $C_{h}(m, C L)$ where $m$ refers to the month and $C L$ to the cluster. Data were gridded with a $0.01^{\circ} \times 0.01^{\circ}$ mesh.

\subsection{Results}

Fig. 6 shows the hydrological year for the study region. This figure was created by averaging the monthly rainfall measured at the stations labeled A to F in Table 1 from 1961 to 2006. The maximum monthly precipitation ( 150 to $200 \mathrm{~mm} \mathrm{mo}^{-1}$ ) was observed in December, January, and February. Minimum values
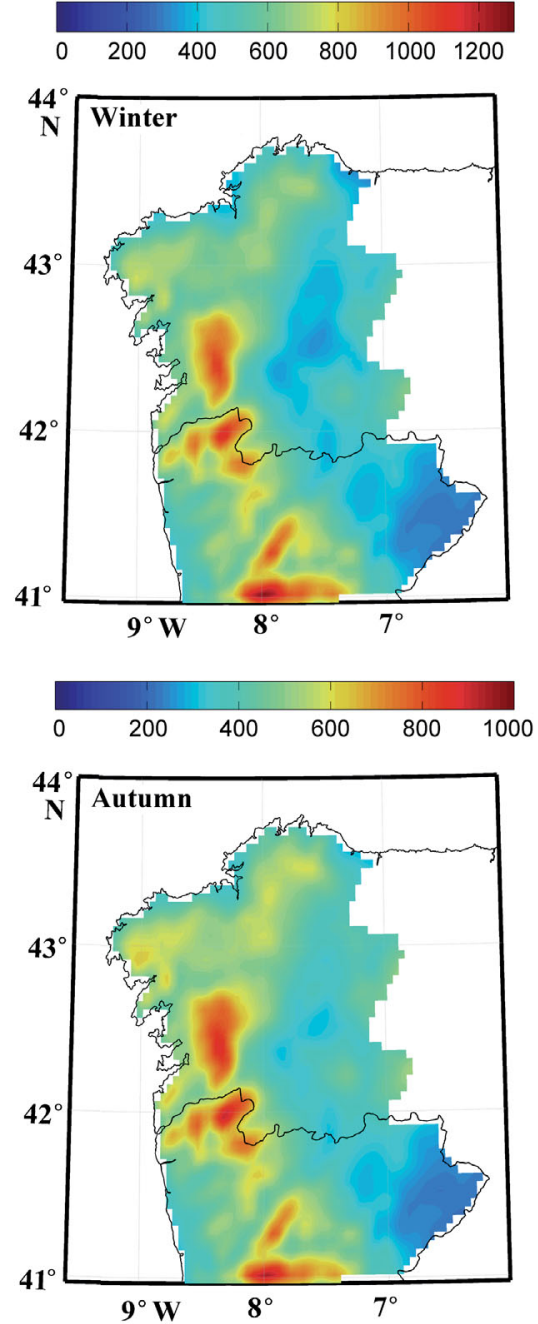
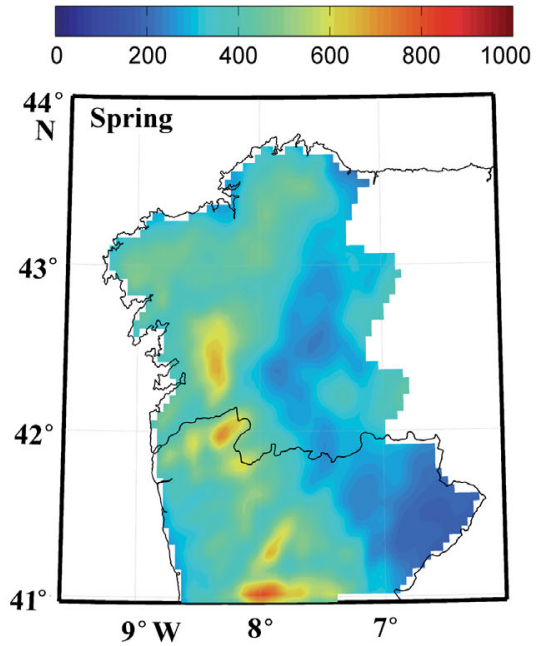

0200400600800100012001400160018002000

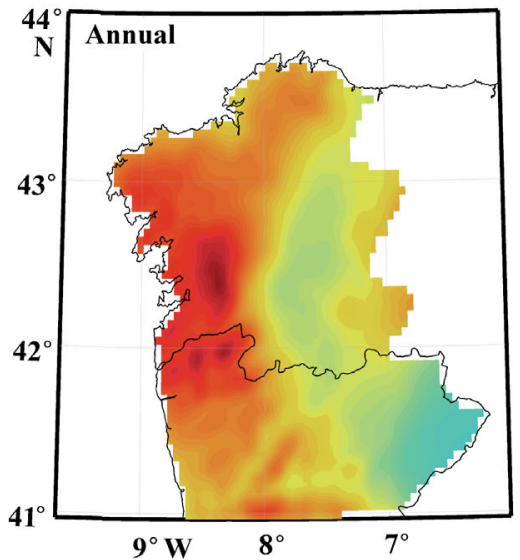

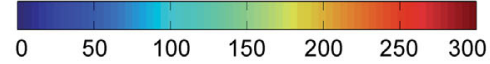

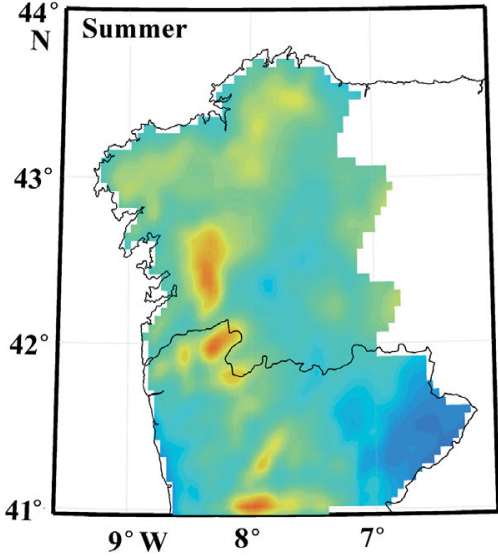

Fig. 7. Mean seasonal and annual accumulated precipitation (mm) for 1961-2006. Winter: DJF, spring: MAM, summer: JJA, autumn: SON. Note that colour scales differ between panels 
( $<50 \mathrm{~mm} \mathrm{mo}^{-1}$ ) were observed in July, August, and September. A high inter-annual variability can also be observed; see for example January, where the minimum and maximum discharges, represented with whiskers, ranged from $\sim 25$ to $475 \mathrm{~mm} \mathrm{mo}^{-1}$.

The seasonal accumulated precipitation averaged for 1961 to 2006 is shown in Fig. 7. In general, moderate precipitation values were observed at coastal locations and low values in the interior regions. Maximum values were observed along the Galician ridge in the northern part of the area and along the Xures/Geres and Marão mountain ranges in the southern part. These mountains act as barriers that hinder the track of fronts to the interior areas, causing orographic precipitation with a strong gradient that increases from the coastal areas to the high mountains. Seasonally, the highest precipitation values were observed in autumn and winter (Fig. 7), reaching values close to 1000 and $1200 \mathrm{~mm}$ season $^{-1}$ respectively, in good agreement with the annual cycle shown in Fig. 6. Minimum values $<300$ mm season $^{-1}$ were observed in summer.

The same overall behavior is observed in Fig. 7 at the annual scale. The mean annual accumulated precipitation is around $1300 \mathrm{~mm}$, although rainfall can reach values close to $2000 \mathrm{~mm} \mathrm{yr}^{-1}$ along the mountain chains. In the interior valleys, the precipitation values are around $650 \mathrm{~mm} \mathrm{yr}^{-1}$ in the southern section and around $1000 \mathrm{~mm} \mathrm{yr}^{-1}$ in the northern section. In general, a smooth increasing gradient, south to north, can be observed both in coastal and inland areas. However, the most important gradient is in an eastwest direction, which marks the transition between an

Table 4. Annual and seasonal trends of accumulated precipitation (mm decade ${ }^{-1}$ ) for the period 1961-2006. (-) points without statistical significance at a $95 \%$ confidence level were removed

\begin{tabular}{|lccccr|}
\hline Weather station & Annual & $\begin{array}{c}\text { Winter } \\
\text { (DJF) }\end{array}$ & $\begin{array}{c}\text { Spring } \\
\text { (MAM) }\end{array}$ & $\begin{array}{c}\text { Summer } \\
\text { (JJA) }\end{array}$ & $\begin{array}{c}\text { Autumn } \\
\text { (SON) }\end{array}$ \\
\hline Fene-Maniños & 4.19 & -12.22 & 6.09 & 2.28 & 20.62 \\
As Pontes & 2.28 & -19.74 & 7.08 & - & 20.69 \\
Betanzos & 3.75 & -8.86 & - & 1.25 & 20.79 \\
A Coruña-Estación & - & -14.03 & - & - & 15.89 \\
Montaos-Ordes & 4.36 & -17.54 & 6.84 & 1.75 & 26.38 \\
Santiago 'Labacolla' & -3.64 & -40.93 & - & -1.06 & 23.50 \\
Salcedo & 3.75 & -27.46 & 7.77 & 1.80 & 32.88 \\
Vigo 'Peinador' & -3.76 & -42.59 & - & - & 25.25 \\
Sarria 'Barreiros' & -2.74 & -24.29 & -2.65 & 5.91 & 10.08 \\
Pobra do Brollon & -2.95 & -17.82 & -4.75 & 1.90 & 8.89 \\
Allariz & - & -11.53 & -2.70 & 4.84 & 7.69 \\
Pnteareas-Canedo & 3.38 & -26.55 & 10.42 & - & 29.82 \\
Xinzo de Limia & -6.25 & -25.48 & -2.77 & -3.68 & 6.79 \\
Montalegre & - & -103.24 & - & -6.34 & 59.81 \\
Bragança & 1.16 & -17.71 & 11.57 & -7.14 & 27.20 \\
Braga & - & -90.78 & 26.30 & -4.77 & 51.64 \\
Régua & -1.71 & -48.44 & - & -5.39 & 30.59 \\
Porto-Serra Pilar & - & -45.44 & - & 4.18 & 46.64 \\
\hline
\end{tabular}

oceanic precipitation regime near the coast and a continental one in interior areas.

The trends in precipitation at the annual scale for the period 1961 to 2006 are shown in Table 4. No clear, spatially consistent pattern was observed at the annual scale, since the trends were strongly dependent on the station under study. Seasonally, no clear trend was observed in spring or summer (Table 4). In spring, the change in precipitation tended to be positive at coastal areas and negative at interior areas. However, precipitation trends were clearly negative in winter and positive in autumn (Table 4). In particular, an extreme decrease $\left(\sim 100 \mathrm{~mm}^{\text {decade }}{ }^{-1}\right)$ was observed in winter and a similar increase ( 60 mm decade $\left.{ }^{-1}\right)$ was observed at 2 stations in autumn.

\section{SEA SURFACE TEMPERATURE}

\subsection{Methods}

We used 2 global gridded temperature data sets to create a representative picture of the area since the available long-term observational data sets for the coastal area are not sufficiently homogeneous in time and space without application of additional statistical treatment to identify and correct biases.

The first database is characterized by a high spatial resolution $(4 \times 4 \mathrm{~km})$ and contains weekly mean SST data obtained from night-time measurements carried out by the Advanced Very-High Resolution Radiometer (AVHRR) onboard of NOAA series satellites (http:// poet.jpl.nasa.gov) between 1985 and 2006 . For our purposes, the area from $40^{\circ} \mathrm{N}, 11^{\circ} \mathrm{W}$ to $44^{\circ} \mathrm{N}, 7^{\circ} \mathrm{W}$, which corresponds to the northwestern part of the IP, was extracted from the global data set. The protocol applied is described in detail by deCastro et al. (2009).

A total of 25 points (blue dots in Fig. 4) were selected to calculate SST trends along the coastal area. Discretization effects were smoothed by calculating the SST values at each point as the average of its nearest neighbors (separated by $4 \mathrm{~km}$ in the original data set). Finally, SST trends were analyzed using the anomalies from the annual cycle obtained from the $22 \mathrm{yr}$ (1985 to 2006) monthly means.

The second database is the extended reconstructed SST (ERSST) version 3 provided by the NOAA/OAR/ESRL PSD (www. cdc.noaa.gov), with a coarser spatial resolution $\left(2^{\circ} \times 2^{\circ}\right.$ grid) but longer temporal coverage (extending back to 1854). Details on the 
reconstruction procedure can be found in Smith et al. (1996, 2008) and Smith \& Reynolds (2002, 2003, 2004, 2005).

In order to study oceanic SST trends, 8 points, all at open sea locations, without continental influence, were considered (red numbers in Fig. 4). The point-to-point correlation was observed to be $>0.98$ in all cases. This fact justifies the analysis in terms of a unique mean series, which was calculated by averaging the series corresponding to the 8 points. Since monthly patterns are highly noisy, short-term fluctuations were smoothed out by means of a running average $( \pm 10 \mathrm{yr})$ in order to highlight any large-scale warming and cooling periods.
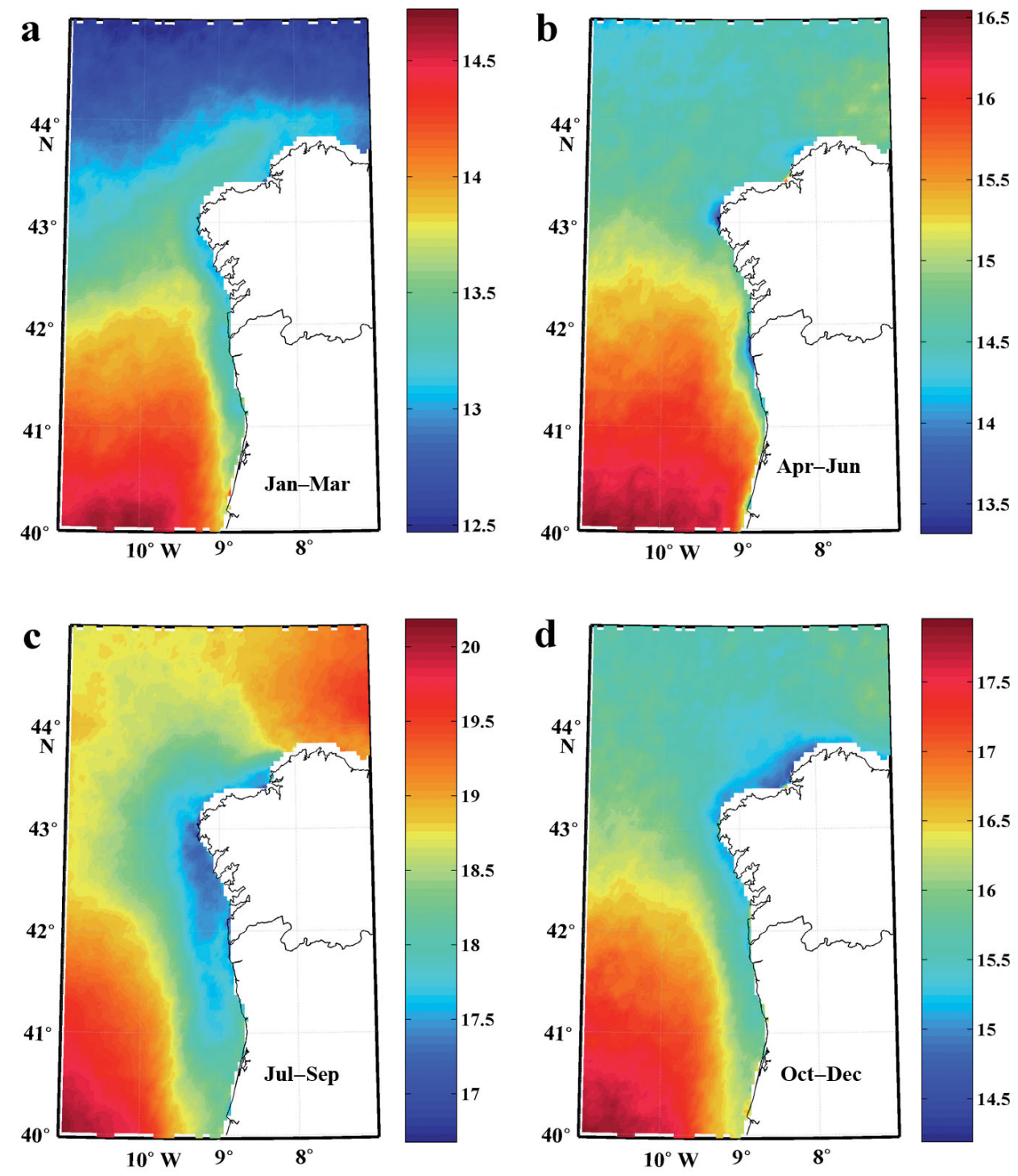

Fig. 8. Seasonal sea surface temperature $\left({ }^{\circ} \mathrm{C}\right)$ from 1985-2006 for (a) winter (JFM), (b) spring (AMJ), (c) summer (JAS), and (d) autumn (OND). Note that colour scales differ between panels

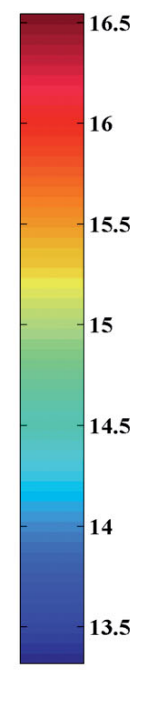

\subsection{Results}

Mean seasonal SSTs were calculated using data from the AVHRR for the 4 hydrological seasons-winter (JFM), spring (AMJ), summer (JAS), and autumn (OND) — for the period 1985 to 2006 (Fig. 8).

Each SST field is characterized by a different pattern, with both longitudinal and latitudinal temperature gradients evident. Winter (Fig. 8a) shows a maximum latitudinal gradient of $2^{\circ} \mathrm{C}$ across open sea locations, ranging from $14.5^{\circ} \mathrm{C}$ at $40^{\circ} \mathrm{N}$ to $12.5^{\circ} \mathrm{C}$ at $45^{\circ} \mathrm{N}$. A longitudinal gradient was also observed west of the IP. Close to the coast, there was an almost continuous band of colder water that developed in shallow waters at the end of autumn when the ocean begins to cool as a result of net heat loss from the surface (Fiuza 1983, Deschamps et al. 1984). Spring (Fig. 8b) showed a similar latitudinal gradient of $\sim 2.5^{\circ} \mathrm{C}$ in open sea locations, ranging from $16.5^{\circ} \mathrm{C}$ at $40^{\circ} \mathrm{N}$ to $14^{\circ} \mathrm{C}$ at $45^{\circ} \mathrm{N}$, whereas the longitudinal gradient produced by cold water nearshore decreased both in extent and in intensity. During summer (Fig. 8c), the longitudinal gradient west of the IP was also present. In addition, important changes in SST patterns can be observed. On the one hand, there was a broad band of colder water west of the IP coast generated by the prevailing favorable upwelling conditions (Wooster et al. 1976, Nykjaer \& Van Camp 1994, Alvarez et al. 2005, 2008a, Santos et al. 2005, Gomez-Gesteira et al. 2006). Traces of these upwelling events can also be observed in the spring and autumn SST fields, although to a lesser extent. On the other hand, a mass of warm water occurred in the Cantabrian Sea as previously described (Pingree \& Le Cann 1989, Koutsikopoulos \& Le Cann 1996, deCastro et al. 2009, Goikoetxea et al. 2009). Autumn (Fig. 8d) also showed the latitudinal gradient observed all year long and the relaxation of the longitudinal gradient previously detected west of the IP. 
Considerable warming of SSTs has occurred globally over the last century according to both data sets used here. Similar trends of the warming ocean have been reported by other authors (e.g. Levitus et al. 2000). In addition, SST trends coincide with global trends in wind speed and direction (Gillett \& Thompson 2003, Chelton et al. 2004; Global Wave Climatology Atlas data available at www.knmi.nl/waveatlas), cloud coverage (Roderick \& Farquhar 2002, Wiley et al. 2002), and humidity (Flohn et al. 1990). Global warming, however, is not uniformly distributed over the world's oceans. The Atlantic Ocean contributes most to the increase in the heat content (Levitus et al. 2000). For our study area, SST increases of 0.25 to $0.35^{\circ} \mathrm{C}$ can be observed between the baseline period 1961-1990 and the period 1977-2006 (Fig. 9).

The monthly evolution of SST (Fig. 10a) showed a clear seasonal cycle, with minimum values from January to April and maximum values from July to September. The thermal amplitude of the SST cycle was $\sim 7^{\circ} \mathrm{C}$, with a minimum $\left(\sim 12.5^{\circ} \mathrm{C}\right)$ in February-March and a maximum $\left(\sim 19^{\circ} \mathrm{C}\right)$ in August. The error bars were calculated as the standard deviation of the monthly data $(\sigma[\mathrm{SST}])$. The signal-to-noise ratio $(100 \times \sigma[\mathrm{SST}] /$ $<$ SST [mean]) does not exceed $10 \%$, showing the periodic nature of the signal. This seasonal pattern of SST is also depicted in Fig. 10b, which shows monthly SST evolution from 1854 to 2007. Different modulations in SST can be observed. In particular, the width of the

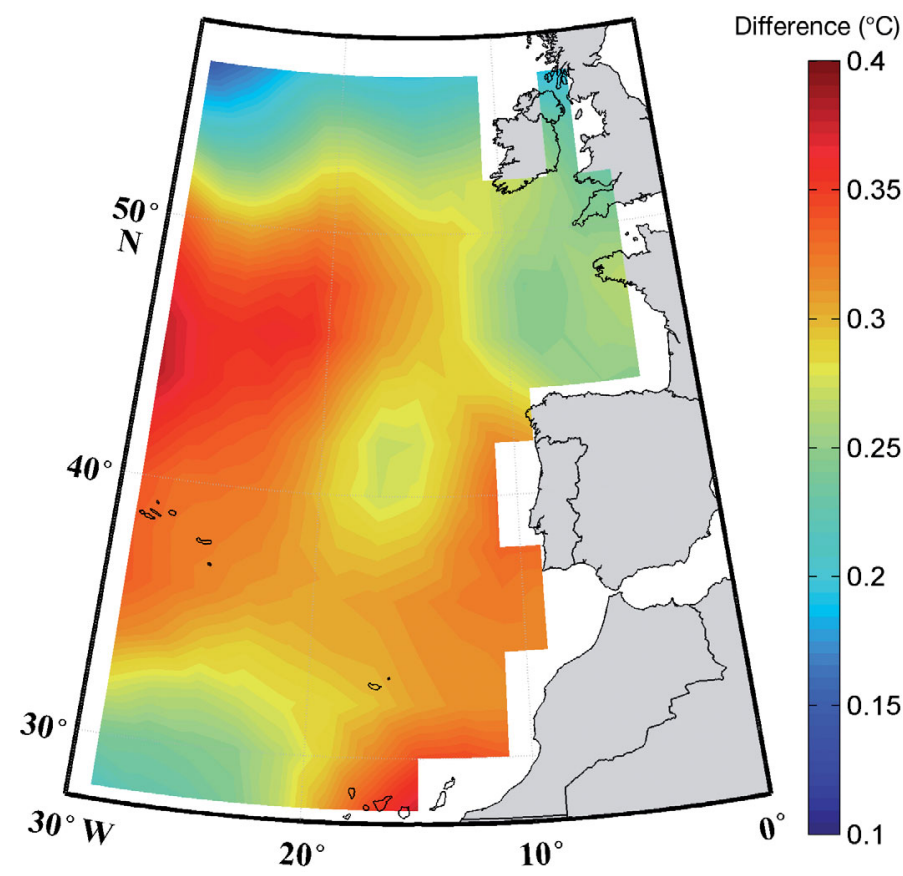

Fig. 9. Sea surface temperature difference in the eastern North Atlantic between the period 1977-2006 and the baseline period 1961-1990. Data were retrieved from the ERSST v. 3 database
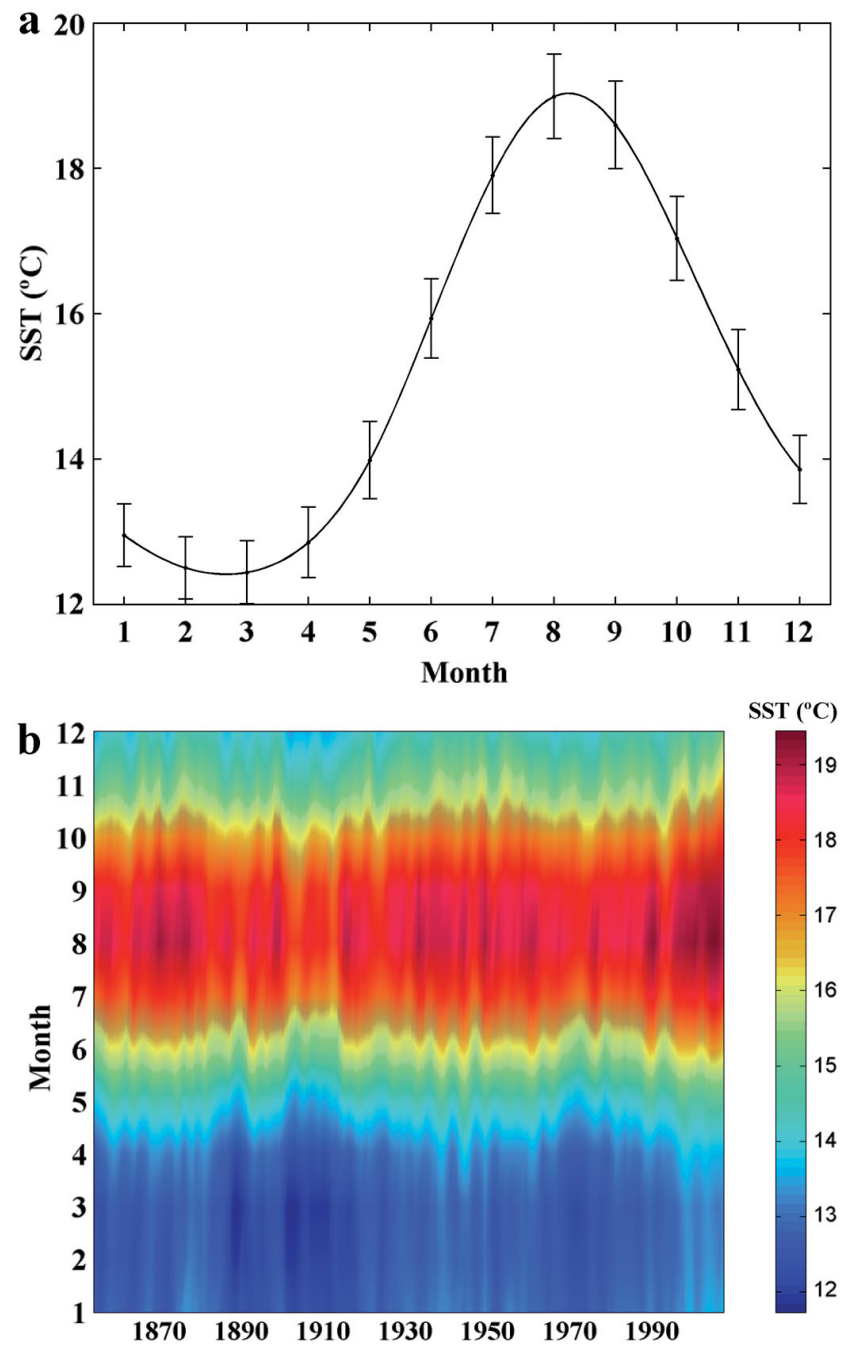

Fig. 10. (a) Annual sea surface temperature (SST; 1854-2007) cycle averaged for the study area (see sampling points in Fig. 4). Error bars represent standard deviation of the monthly data. (b) Monthly evolution of SST from 1854 to 2007. Data were retrieved from the ERSST v. 3 database

summer band $\left(16.5^{\circ} \mathrm{C} \leq \mathrm{SST} \leq 18.5^{\circ} \mathrm{C}\right)$ reached a minimum around 1910 and a maximum during the last decade.

The inter-annual variation in SST anomaly $\left(\mathrm{SST}_{\mathrm{a}}\right)$ was calculated using the annual cycle obtained from the 154 yr monthly means (grey line in Fig. 11). This monthly pattern is highly variable, with peak values on the order of $\pm 1.5^{\circ} \mathrm{C}$ and standard deviations of $\pm 0.5^{\circ} \mathrm{C}$. Short-term fluctuations were smoothed out (thick black line in Fig. 11) by means of a running average ( $\pm 10 \mathrm{yr})$ in order to highlight the long-term periods. Two consecutive warming-cooling cycles can be observed in $\mathrm{SST}_{\mathrm{a}}$ with cooling trends being less intense than warming trends (Table 5).

The 2 consecutive warming-cooling phases indicate the existence of natural oscillations as suggested by 


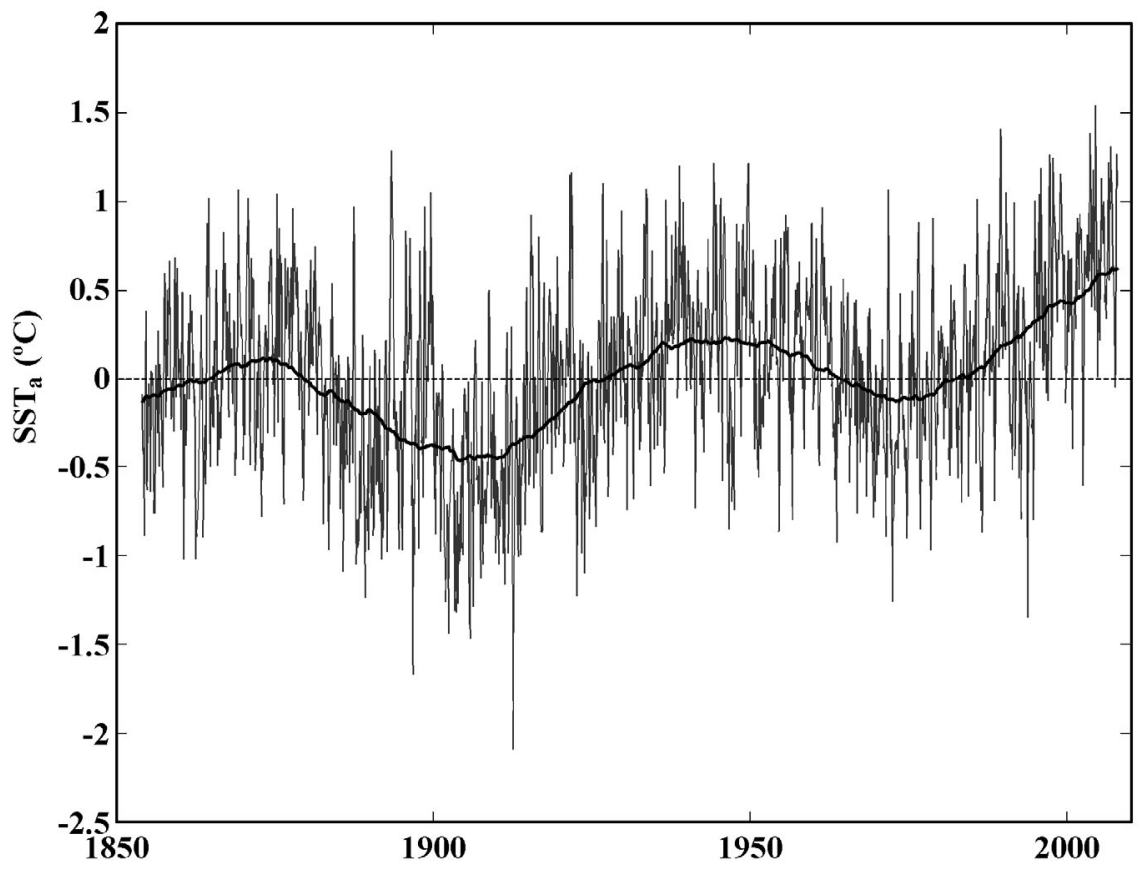

Fig. 11. Evolution of anomalies in sea surface temperature $\left(\mathrm{SST}_{\mathrm{a}}\right)$ for the period 1854-2007. Monthly means (grey line) and running average (thick black line) are shown. Two consecutive warming-cooling cycles can be observed

Michel et al. 2009). The existence of the observed warming-cooling cycles has been attributed by some authors (Swanson \& Tsonis 2009) to climate shifts that occurred during the last century.

The previous analysis (Figs. 8-11) was focused on ocean values following the coarse grid provided by ERSST v. 3. However, the near-shore SSTs can reflect the varying influences of Ekman transport, river discharge, and shallowness of the area.

The trend of a coastal SST anomaly along the coast of NW Iberia for the period 1985 to 2005 is shown in Fig. 12. A coastal SST anomaly trend $\left(\Delta \mathrm{SST}_{\mathrm{a}}\right)$ was calculated at each point along the coast by fitting the monthly anomaly to a straight line. A running average to the 9 nearest spatial neighbors was used prior to representation. Only points with significance $(\mathrm{p}<0.1)$ in the $t$-test were considered. Positive $\Delta \mathrm{SST}_{\mathrm{a}}$ values were observed along the coast, although with noticeable changes depending on the position of the gauge station. The an-

Southward \& Boalch (1994) and Planque et al. (2003), using the COADS records from 1844 to 2000. The present warming period is on the same order of magnitude although slightly more intense than the one observed from 1908 to 1945. This fact does not permit determining the possible anthropogenic influence on the present-day warming, which still remains an open question.

In spite of the marginal location of the area (IP), the observed large-scale trends are consistent with previous studies (e.g. Gomez-Gasteira et al. 2008). In particular, the warming observed in the area for the period 1854 to $2007\left(0.044^{\circ} \mathrm{C}\right.$ decade $\left.^{-1}\right)$ is consistent with the ones observed in the Northern Hemisphere by Rayner et al. (2003, 2006). Similar results were observed in nearby areas, such as the Bay of Biscay (Garcia-Soto et al. 2002, deCastro et al. 2009, Goikoetxea et al. 2009,

Table 5. Increment of sea surface temperature anomaly $\left(\Delta \mathrm{SST}_{\mathrm{a}},{ }^{\circ} \mathrm{C}\right.$ decade $\left.^{-1}\right)$ for each warming-cooling period from 1854-2007 and for the whole period

\begin{tabular}{|lr|}
\hline Period & $\Delta \mathrm{SST}_{\mathrm{a}}$ \\
\hline $1874-1908$ & -0.18 \\
$1908-1945$ & 0.21 \\
$1945-1974$ & -0.15 \\
$1974-2007$ & 0.24 \\
$1854-2007$ & 0.04 \\
\hline
\end{tabular}

nual $\Delta \mathrm{SST}_{\mathrm{a}}$ decreased by 0.13 to $0.2^{\circ} \mathrm{C}_{\text {decade }}$ deuth- $^{-1}$ sout ward from station to station (Fig. 12), similar to results by Gomez-Gesteira et al. (2008). A similar overall pattern is observed at the seasonal scale in spring and summer (Fig. 12), the maximum increment being close to $0.4^{\circ} \mathrm{C}$. The trend in autumn is slightly negative and the winter one slightly positive but not statistically significant. Table 6 summarizes the mean annual and seasonal $\Delta \mathrm{SST}_{\mathrm{a}}$ and their standard deviation.

\section{EKMAN TRANSPORT}

\subsection{Methods}

Upwelling is a frequent phenomenon along the western coast of the IP $\left(\sim 36^{\circ} \mathrm{N}\right.$ to $\left.44^{\circ} \mathrm{N}\right)$ during the spring and summer months (Wooster et al. 1976, Fraga 1981, Blanton et al. 1984, Tenore et al. 1984, AlvarezSalgado et al. 1993, Pérez et al. 1995, Gomez-Gesteira et al. 2006). Although southerly winds favorable for downwelling prevail in wintertime (Wooster et al. 1976, McClain et al. 1986), the occurrence of upwelling can also be observed during this period (Santos et al. 2001, 2004, Alvarez et al. 2003, Borges et al. 2003, deCastro et al. 2006b, 2008b, Prego et al. 2007).

Ekman transport has been classically calculated from wind or pressure field data (Bakun 1990). This method has also been the most commonly used in the 

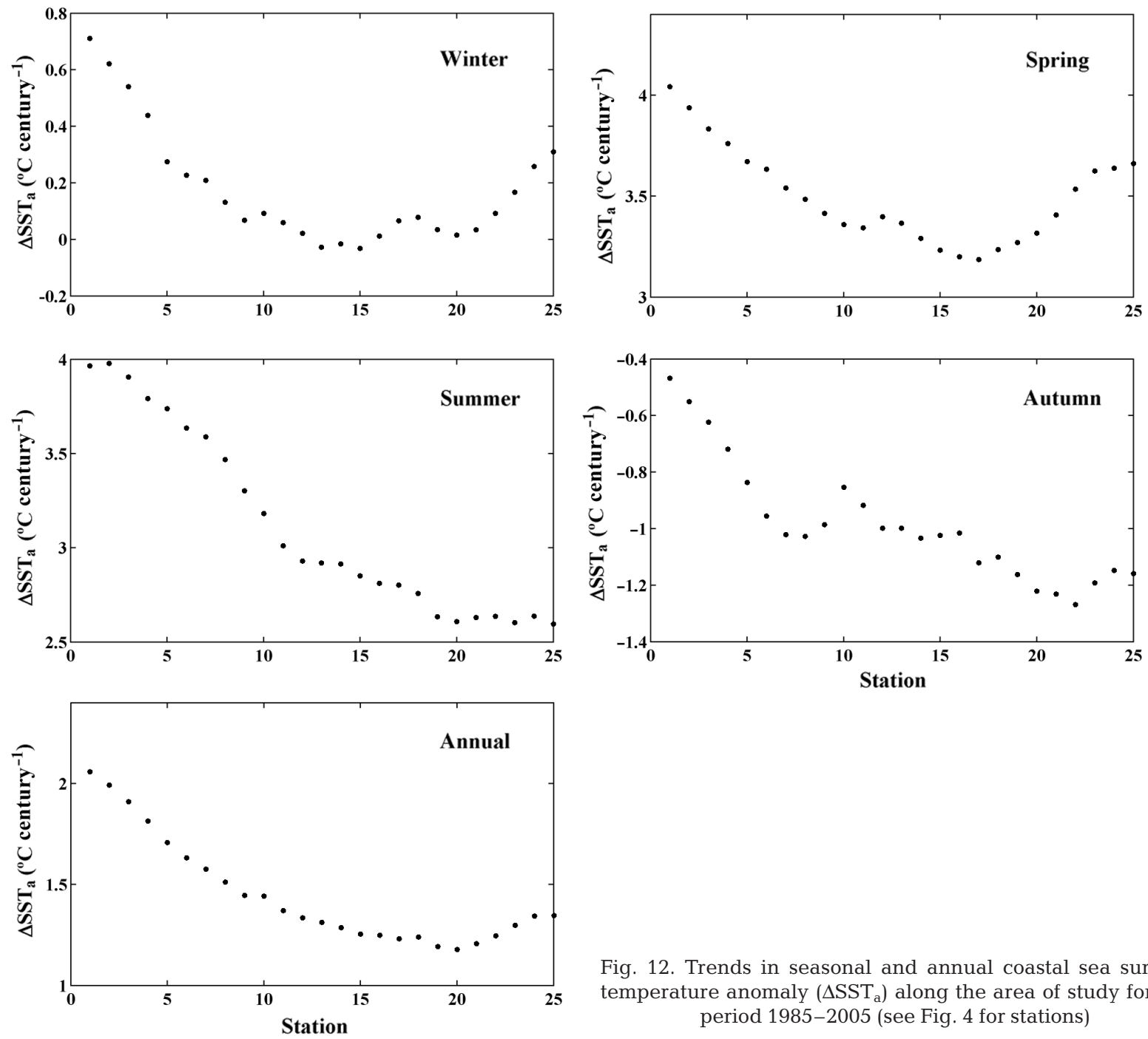

Fig. 12. Trends in seasonal and annual coastal sea surface temperature anomaly $\left(\Delta \mathrm{SST}_{\mathrm{a}}\right)$ along the area of study for the period 1985-2005 (see Fig. 4 for stations)

area under study (Alvarez-Salgado et al. 1993, Tilstone et al. 1994, Alvarez et al. 2003, 2005, 2008b, GomezGesteira et al. 2006). Here, the surface wind fields used to calculate Ekman transport were obtained from the QuikSCAT satellite, which has data available from July 1999. Wind data were retrieved from the Jet Propulsion Laboratory website (http://podaac.jpl.nasa. gov/DATA_CATALOG/quikscatinfo.html). A detailed

Table 6. Annual and seasonal increment of coastal sea surface temperature anomaly $\left(\Delta \mathrm{SST}_{\mathrm{a}},{ }^{\circ} \mathrm{C}\right.$ decade $\left.^{-1}\right) . \quad \sigma$ : standard deviation

\begin{tabular}{|lcc|}
\hline Season & $\Delta \mathrm{SST}_{\mathrm{a}}$ & $\sigma\left(\Delta \mathrm{SST}_{\mathrm{a}}\right)$ \\
\hline Annual & 0.15 & 0.03 \\
Spring & 0.35 & 0.02 \\
Summer & 0.31 & 0.05 \\
Autumn & -0.10 & 0.02 \\
Winter & 0.02 & 0.02 \\
\hline
\end{tabular}

description of the database is in Alvarez et al. (2008b). It is necessary to take into account the fact that wind data close to the coast $(\sim 25 \mathrm{~km})$ are not available owing to the existence of a small land mask. This mask makes the study difficult in the inner $75 \mathrm{~km}$ and prevents the analysis of orographic effects nearer to the shoreline. Nevertheless, a study carried out by Gomez-Gesteira et al. (2006) using modeled wind data around the Galician coast showed that along the western coast (41 to $43^{\circ} \mathrm{N}$ ) from the shoreline to around $75 \mathrm{~km}$, the wind direction presents a constant pattern, with small differences in the amplitude of the values. On the other hand, the lack of real, simultaneous wind measurements (e.g. buoy data and meteorological stations) along the coast makes the analysis of wind patterns difficult near the shoreline.

The precision of QuikSCAT data was previously analyzed along the Galician coast for the period 2002 to 2005. A statistical comparison between satellite wind 
measurements and high-resolution numerical models was carried out by Penabad et al. (2008), revealing similar results between models and satellite data. A statistical analysis based on mean errors, root mean square errors, and complex correlation was performed on spatial, temporal, and directional scales. Highresolution numerical model results compared to satellite wind estimations showed a pattern within the confidence limits of the satellite scatterometer.

Ekman transport $(Q)$ was calculated using the wind speed at $10 \mathrm{~m}$ above sea level $(W)$, seawater density $\left(\rho_{W}=1025 \mathrm{~kg} \mathrm{~m}^{-3}\right)$, a dimensionless drag coefficient $\left(C_{d}=1.4 \times 10^{-3}\right)$, and air density $\left(\rho_{a}=1.22 \mathrm{~kg} \mathrm{~m}^{-3}\right)$ by means of:

$$
\begin{aligned}
& Q_{X}=\frac{\rho_{a} C_{d}}{\rho_{W} f}\left(W_{X}^{2}+W_{Y}^{2}\right)^{1 / 2} W_{Y} \\
& Q_{Y}=-\frac{\rho_{a} C_{d}}{\rho_{W} f}\left(W_{X}^{2}+W_{Y}^{2}\right)^{1 / 2} W_{X}
\end{aligned}
$$

where $f$ is the Coriolis parameter defined as twice the vertical component of the Earth's angular velocity $(\Omega)$ about the local vertical or $f=2 \Omega \sin (\theta)$ at latitude $\theta$. Finally, the $x$ subscript corresponds to the zonal component and the $y$ subscript to the meridional one. Discretization effects were smoothed by calculating Ekman transport values at each point as the average of its nearest neighbors.

The upwelling index calculated from wind data (UI ${ }^{\mathrm{W}}$ ) can be defined as the fraction of the Ekman transport perpendicular to the coast (Nykjaer \& Van Camp 1994). This index is calculated as the component of Ekman transport in the direction perpendicular to the shoreline by means of $\mathrm{UI}^{\mathrm{W}}=Q_{\perp}=-\sin (\theta) Q_{\mathrm{X}}+\cos (\theta) Q_{\mathrm{Y}}$ where $\theta=\pi+\varphi$ and $\varphi$ is the angle of the unitary vector perpendicular to the shoreline pointing landward (Gomez-Gesteira et al. 2006). Positive UI ${ }^{\mathrm{W}}$ values mean favorable upwelling conditions and negative values mean unfavorable conditions.

Additional data were obtained from the Pacific Fisheries Environmental Laboratory (PFEL) (www.pfel. noaa.gov), which is associated with the US Navy's Fleet Numerical Meteorology and Oceanography Centre (FNMOC). For our purposes, monthly data for $\mathrm{UI}^{\mathrm{W}}$ were considered at 3 points located west of the IP coast (at about $10.5^{\circ} \mathrm{W}$; black squares in Fig. 13) on an approximately $1^{\circ} \times 1^{\circ}$ grid from 1967 to 2008 .

The upwelling index can also be calculated as the difference between the SST value at a coastal location and the SST value at an oceanic location with the same latitude $\left(\mathrm{UI}^{\mathrm{SST}}\right)$ following the method described in deCastro et al. (2008a). We calculated UI ${ }^{\mathrm{SST}}$ from coastal data at about $15-20 \mathrm{~km}$ from the coast and oceanic data at $500 \mathrm{~km}$ from the coast. SST at each point was was calculated as described in Section 5.1. The 20 pairs of points considered in the present study

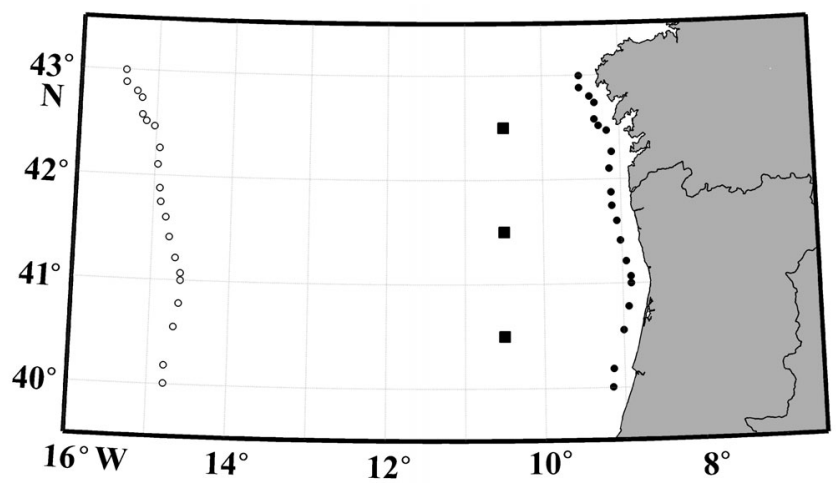

Fig. 13. Set of points selected from different databases to calculate the upwelling index from wind data $\left(\mathrm{UI}^{\mathrm{W}}\right)$ in front of the Iberian coast ( $\square$ : Pacific Fisheries Environmental Laboratory database points), and set of 20 pairs of points selected to calculate the upwelling index from the difference between sea surface temperature (SST) at a coastal $(\bullet)$ and an oceanic location $(\mathrm{O})$ at the same latitude $\left(\mathrm{UI}^{\mathrm{SST}}\right)$

are depicted in Fig. 13 (filled and unfilled dots). Negative and positive $\mathrm{UI}^{\mathrm{SST}}$ values translate respectively into favorable and unfavorable upwelling conditions.

\subsection{Results}

Fig. 14 shows the Ekman transport calculated from QuikSCAT data for the wet season for the period 1999 to 2008. The season (November to March) was defined according to previous studies carried out in the same area (Gomez-Gesteira et al. 2006, Alvarez et al. 2008b). The observed pattern was strongly dependent on the year in question. Along the western coast, some years (e.g. 1999, 2003, 2005, and 2007) were clearly favorable for upwelling, with Ekman transport pointing seaward. Other years (e.g. 2000, 2002, and 2006) were characterized by Ekman transport pointing southward, which corresponds to neutral conditions from the point of view of upwelling. Along the northern coast, during the last decade the Ekman transport tended to be mainly landward (unfavorable for upwelling). This pattern was especially intense in 2000, 2002, 2006, and 2007.

Fig. 15 shows the Ekman transport calculated from QuikSCAT data over the dry season during the period 1999 to 2008. Once again, the extent of the season was defined in previous studies (Gomez-Gesteira et al. 2006, Alvarez et al. 2008b). Here, Ekman transport pointing seaward (favorable upwelling conditions) tended to be prevalent along the western coast. Small inter-annual differences can be observed in the intensity of the transport, although the values ranged from 800 to $1200 \mathrm{~m}^{3} \mathrm{~s}^{-1} \mathrm{~km}^{-1}$ during the period of study. The situation is not so clear along the northern coast, where 

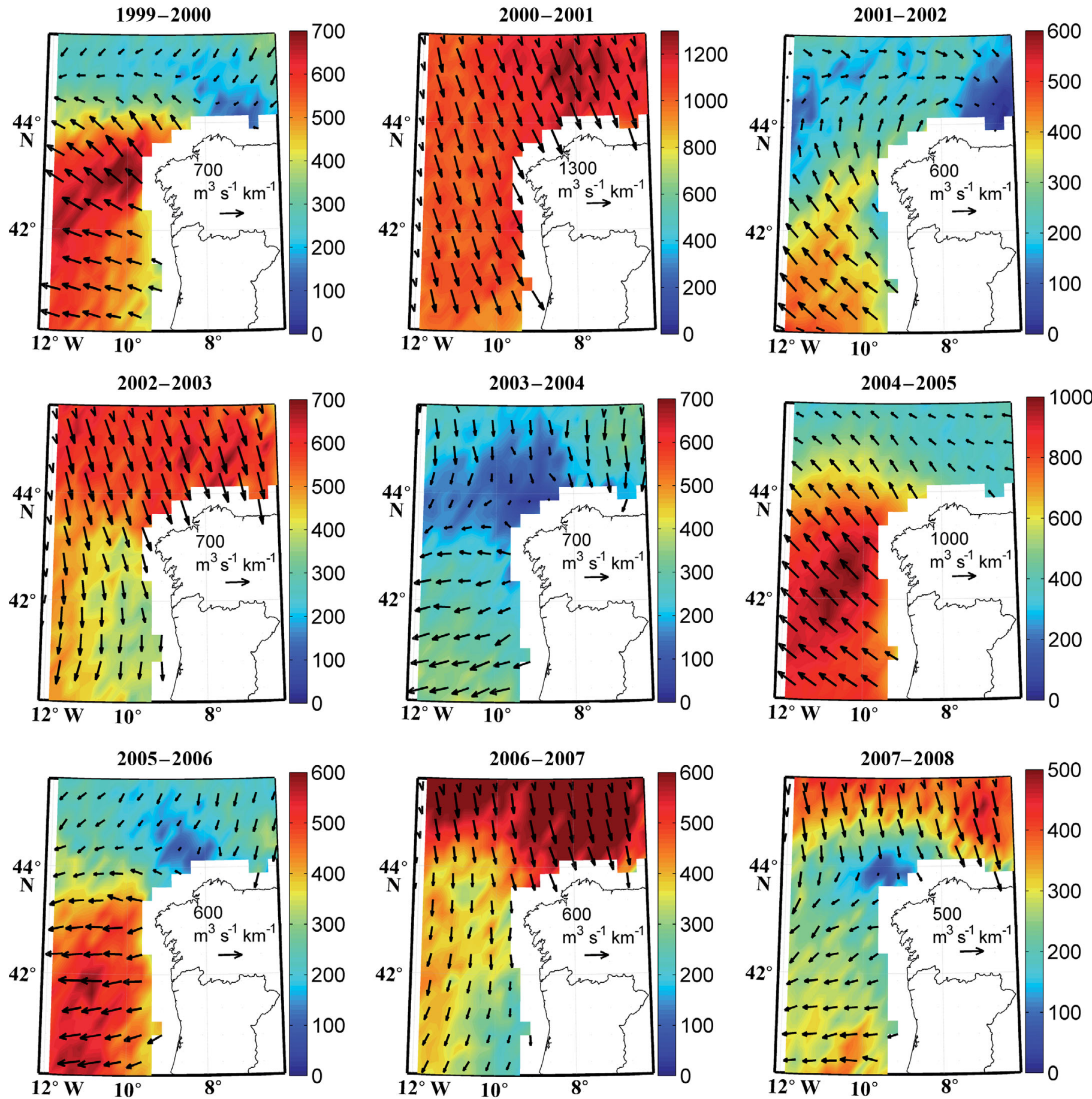

Fig. 14. Direction (arrows) and intensity $\left(\mathrm{m}^{3} \mathrm{~s}^{-1} \mathrm{~km}^{-1}\right)$ of Ekman transport calculated during the wet season (November to March) from 1999 (top left) to 2008 (lower right)

the intensity of the transport was considerably lower, with important inter-annual variations.

In general, the patterns along the western coast tend to be more persistent, with lesser inter-annual differences during the dry season than during the wet one. This is mainly due to the influence of the Azores High along the coast, which generates northerly winds.
Thus, inter-annual differences during the wet season only affect the intensity of the transport pattern.

As we mentioned in Section 6.1, an upwelling index can be calculated in different ways (see UI ${ }^{\mathrm{SST}}$ and UI ${ }^{\mathrm{W}}$ definitions). Here we will describe the evolution of UI both in space and time using both definitions. The evolution of $\mathrm{UI}^{\mathrm{SST}}$ from 1985 to 2006 along the western 

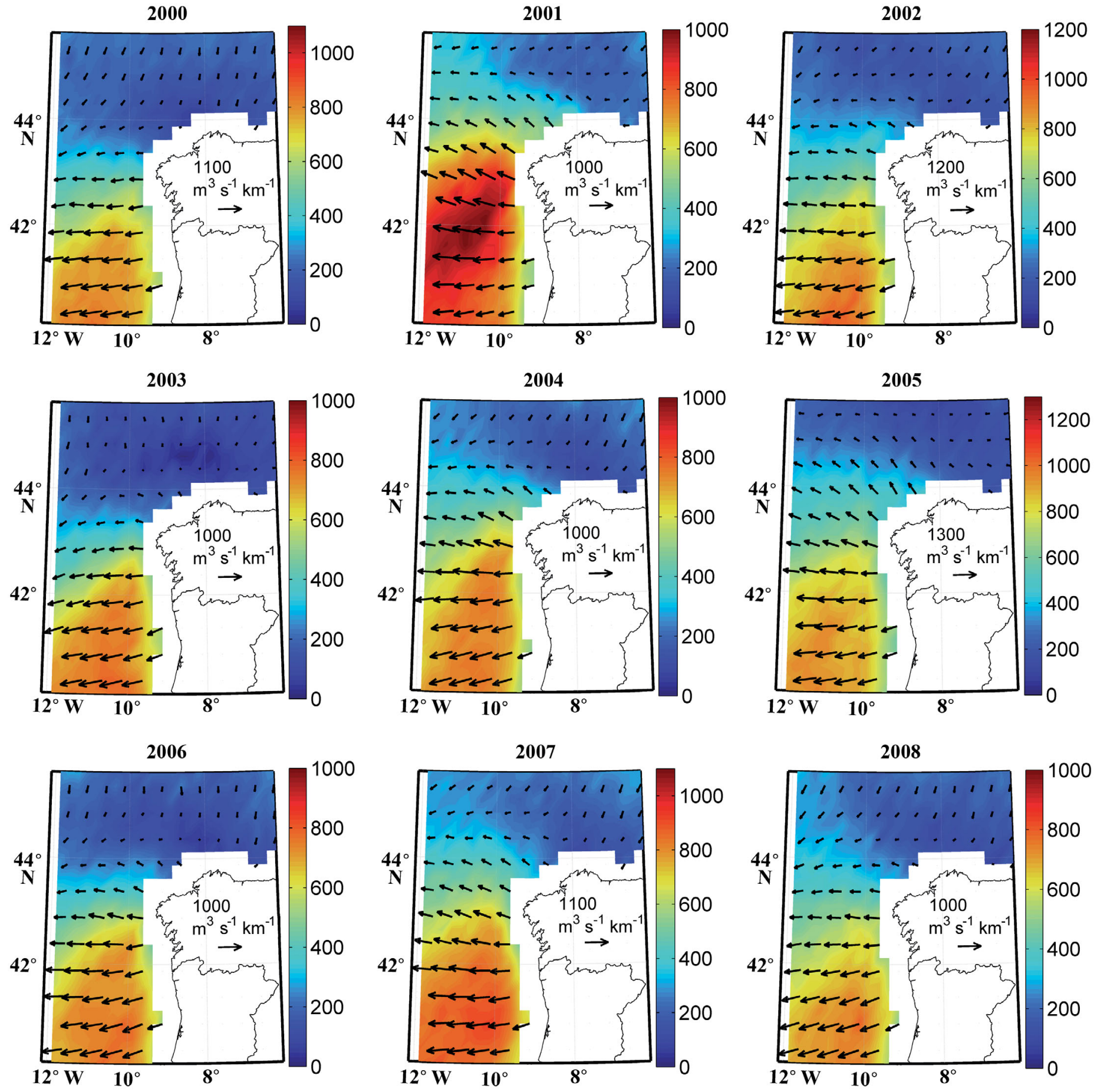

Fig. 15. Direction (arrows) and intensity $\left(\mathrm{m}^{3} \mathrm{~s}^{-1} \mathrm{~km}^{-1}\right)$ of Ekman transport calculated during the dry season (May to September) from 2000 (top left) to 2008 (lower right)

coast is shown in Fig. 16. The density plot in Fig. 16a shows the annual periodicity of the upwelling index signal from 40 to $43^{\circ} \mathrm{N}$. Note that according to the definition, the more negative the $\mathrm{UI}^{\mathrm{SST}}$ values are, the more favorable are the upwelling conditions.

The annual cycle can be determined by averaging $\mathrm{UI}^{\mathrm{SST}}$ over time from 1985 to $2006\left(<\mathrm{UI}^{\mathrm{SST}}>_{\mathrm{t}}\right)$ (Fig. 16b).
The most negative values were observed from July to October (upwelling season), being practically equal at all latitudes. The existence of an upwelling season during summer associated with persistent northerly winds blowing along the coastal shelf is consistent with previous research (Alvarez et al. 2005, Santos et al. 2005, Gomez-Gesteira et al. 2006, Borja et al. 2008). Less- 

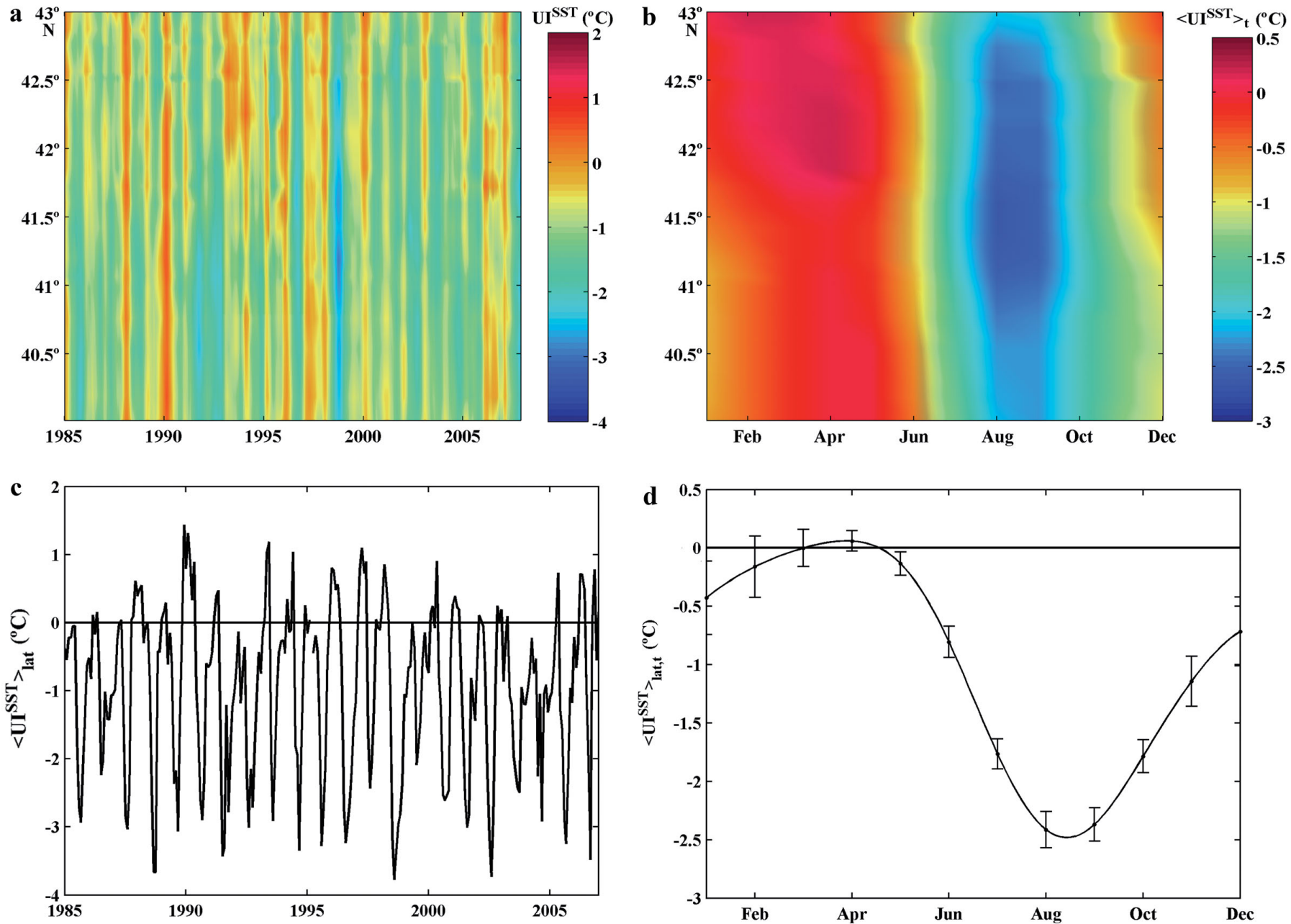

Fig. 16. (a) Interannual evolution of the upwelling index calculated from the difference between sea surface temperature (SST) at a coastal location and SST at an oceanic location at the same latitude (UI ${ }^{\text {SST }}$ ) from 1985-2006. (b) The 22 yr (1985-2006) mean of the annual evolution of time-average UI ${ }^{\mathrm{SST}}$. (c) Interannual evolution of the meridional average of UI ${ }^{\mathrm{SST}}$ from 1985-2006. (d) Annual cycle calculated by meridional- and time-averaging of UI ${ }^{\mathrm{SST}}$ from $1985-2006$. Error bars were calculated using $\sigma\left(\mathrm{UI}^{\mathrm{W}}\right) / \sqrt{N}$, where $\sigma\left(\mathrm{UI}^{\mathrm{W}}\right)$ is the standard deviation of the monthly data and $N$ the number of years

negative values (unfavorable upwelling conditions) were detected along the entire coast from January to May, reaching a maximum in March-April. Fig. 16c is the latitudinal average $\left(\langle\mathrm{UI}\rangle_{\text {lat }}\right)$ of data depicted in Fig. 16a. The signal from 1985 to 2006 was irregular, showing years with a strong upwelling season (e.g. 1988, 1998, and 2002) and years with a weak upwelling season (e.g. 1986, 1997, and 1999). The signal did not show any clear trend indicative of weakening or strengthening of upwelling during the $22 \mathrm{yr}$ under study. The index averaged in time and latitude $\left.\left(<\mathrm{UI}^{\mathrm{SST}}\right\rangle_{\mathrm{t}, \text { lat }}\right)$ is shown in Fig. 16d. Less-negative values were observed from December to May, with the maximum value occurring during March and April. Negative values were observed from July to October, reaching a maximum during August and September. Values near $0^{\circ} \mathrm{C}$ were observed during June and November, which can be considered transition months.
A similar behavior can be observed using UI ${ }^{\mathrm{W}}$ (Fig. 17). Fig. 17 a shows the inter-annual evolution of $\mathrm{UI}^{\mathrm{W}}$, which is characterized by a marked annual cycle, with maximum values (favorable upwelling conditions) in July-August and minimum values in DecemberJanuary. The monthly average of $\mathrm{UI}^{\mathrm{W}}$ from 1967 to 2006 (Fig. 17b) shows positive values from March to October, with maximum values in July $\left(800 \mathrm{~m}^{3} \mathrm{~s}^{-1}\right.$ $\mathrm{km}^{-1}$ ). These maximum values were observed at all latitudes, although $\mathrm{UI}^{\mathrm{W}}$ was slightly higher from 39.5 to $40.5^{\circ} \mathrm{N}$. For the rest of the year, UI ${ }^{\mathrm{W}}$ showed negative or practically negligible values, reaching a minimum in December and January.

The inter-annual evolution of the meridional average of UI ${ }^{\mathrm{W}}$ (Fig. 17c) showed a pattern with maximum values in July and August and minimum values in December-January. The signal tended to be displaced toward positive values, although it is possible to observe some 

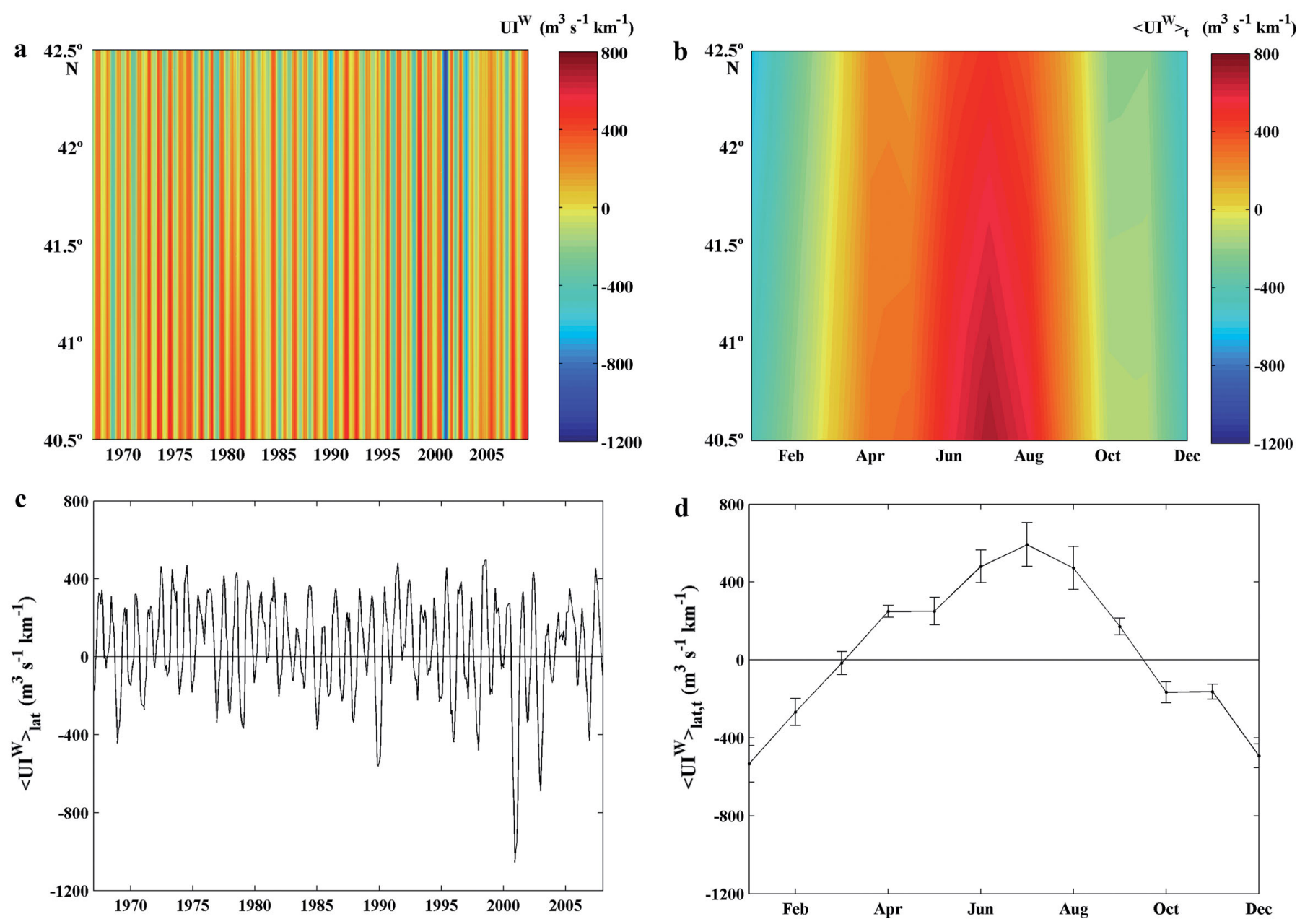

Fig. 17. (a) Interannual evolution of the upwelling index calculated from wind data (UI ${ }^{\mathrm{W}}$ ) from 1967-2008. (b) The 42 yr (1967-2008) mean of the annual evolution of UI ${ }^{\mathrm{W}}$. (c) Interannual evolution of the meridional average of UI ${ }^{\mathrm{W}}$ from $1967-2008$. (d) Annual cycle calculated by meridional- and time-averaging of $\mathrm{UI}^{\mathrm{W}}$ from 1967-2008. Error bars were calculated using $\sigma\left(\mathrm{UI}^{\mathrm{W}}\right) / \sqrt{N}$, where $\sigma\left(\mathrm{UI}^{\mathrm{W}}\right)$ is the standard deviation of the monthly data and $N$ the number of years

years with strong negative values, which reveals significant differences among years. Thus, the minimum amplitude was much higher at the end of 2000 and at the beginning of 2001 than for the remaining years.

The index averaged in time and latitude is represented in Fig. 17d. Positive values were observed from April to September, with the maximum value $>600 \mathrm{~m}^{3}$ $\mathrm{s}^{-1} \mathrm{~km}^{-1}$ in July. Negative values were observed for the rest of the year, showing unfavorable upwelling conditions during winter. SEs were negligible compared to the amplitude of the annual cycle.

$\mathrm{UI}^{\mathrm{SST}}$ lagged behind $\mathrm{UI}^{\mathrm{W}}$. In particular, the most favorable upwelling conditions were observed in July for $\mathrm{UI}^{\mathrm{W}}$ and August for $\mathrm{UI}^{\mathrm{SST}}$. This lag had previously been noted by Fiuza et al. (1982) off Portugal, by Nykjaer \& Van Camp (1994) in a larger area covering NW Africa and Portugal, and by Alvarez et al. (2008a) along the western coast of the IP. In particular, Nykjaer \& Van Camp (1994) proposed that factors other than the winds should be considered when analyzing the temporal variability of coastal upwelling. In addition, Cabanas \& Alvarez (2005) showed in a local study carried out at $43^{\circ} \mathrm{N}, 11^{\circ} \mathrm{W}$ that the best correlation between $\mathrm{UI}^{\mathrm{W}}$ and $\mathrm{UI}^{\mathrm{SST}}$ is obtained when $\mathrm{UI}^{\mathrm{SST}}$ lags $\mathrm{UI}^{\mathrm{W}}$ by 1 or 2 mo.

Table 7 shows the annual and seasonal $\mathrm{UI}^{\mathrm{W}}$ trends expressed in $\mathrm{m}^{3} \mathrm{~s}^{-1} \mathrm{~km}^{-1}$ decade $^{-1}$ for the period 1975 to 2008, which coincides with the last warming period.

Table 7. Annual and seasonal upwelling trends calculated from wind data $\left(\mathrm{UI}^{\mathrm{W}}\right)$ for the period $1975-2008$

\begin{tabular}{|lcc|}
\hline Season & $\begin{array}{c}\mathrm{UI}^{\mathrm{W}} \\
\left(\mathrm{m}^{3} \mathrm{~s}^{-1} \mathrm{~km}^{-1} \text { decade }^{-1}\right)\end{array}$ & $\begin{array}{c}\text { Confidence } \\
\text { level }(\%)\end{array}$ \\
\hline Annual & -15.1 & 95 \\
Dry season (AMJJAS) & -8.4 & 85 \\
Wet season (ONDJFM) & -22.8 & 90 \\
\hline
\end{tabular}


Two seasons were defined according to Fig. 17d, namely, a dry season (AMJJAS) and a wet season (ONDJFM). Data were smoothed out by means of a running-average filter $( \pm 2 \mathrm{yr})$ prior to fitting to a straight line. This procedure effectively dampens inter-annual variations. A significant decrease in upwelling intensity was observed both at the annual scale $\left(-15.1 \mathrm{~m}^{3} \mathrm{~s}^{-1} \mathrm{~km}^{-1}\right.$ decade $\left.^{-1}\right)$ and during the wet season $\left(-22.8 \mathrm{~m}^{3} \mathrm{~s}^{-1} \mathrm{~km}^{-1}\right.$ decade $\left.^{-1}\right)$. This decrease was also observed during the dry season $\left(-8.4 \mathrm{~m}^{3} \mathrm{~s}^{-1} \mathrm{~km}^{-1}\right.$ decade $\left.^{-1}\right)$ but was not statistically significant ( $p>0.1$ ). The decrease is especially remarkable during the wet season, where the observed decadal change is close to $10 \%$ of the absolute value of the index during that period. The decadal changes during the dry season are only on the order of $5 \%$.

Changes observed in wind cannot be linked to those observed in SST since there is a complicated interplay between wind stress and the generation of SST anomalies (Brahmananda Rao et al. 2008). Also, Schwing \& Mendelssohn (1997) observed that long-term SST trends related to global warming can mask the cooling effect of increased seasonal upwelling.

\section{RIVER DISCHARGE}

\subsection{Methods}

River discharges considered in the present study were obtained from these 3 sources: Rios-Barja \& Rodríguez-Lestegás (1992), the OSPAR commission (www.ospar.org), and the Confederación Hidrográfica del Norte. Discharge data from the Douro River at Régua, which was provided by INAG Instituto de Água I.P. (http://snirh.pt/), was also considered for comparison purposes only.

The Miño River, located in the northwest corner of the IP, rises in Serra Meira (Galicia) and acts as a natural border between Spain and Portugal over its last $75 \mathrm{~km}$, flowing into the Atlantic Ocean between A Guarda (Spain) and Caminha (Portugal). The length of the river is $\sim 307.5 \mathrm{~km}$. The present study focused on this river because it is the most important of the area with a mean runoff at least 4 times higher than the rest. Monthly river-discharge data from October 1970 were provided by the Confederación Hidrográfica del Norte at a gauge station situated in Frieira, close to the river mouth. The river basin has an area of $\sim 15864 \mathrm{~km}^{2}$. Monthly data is the most useful frequency when describing river runoff since the presence of dams can distort the results at daily or weekly time scales. For example, the DJF precipitation spatially integrated over the Miño River basin and DJF river flow are strongly correlated (correlation coefficient $=0.85$, deCastro et al. 2006a).

\subsection{Results}

The annual variability of the hydrologic cycle for the Miño River is shown in Fig. 18 using monthly average river-discharge data for the period 1970 to 2008. The mean monthly flow oscillated between maximum runoff during the wet season (DJF), and minimum runoff occurring in the dry season (JAS). The interannual variability was high during autumn-winter and low during spring-summer.

The correlation between DJF precipitation (wet season) integrated over the Miño River basin and river flow was studied from 1976 to 1997 (Fig. 19). In order to facilitate a visual comparison, both variables were normalized: $x_{\text {in }}=\left(x_{i}-<x>\right) / \sigma(x)$, where $x_{\text {in }}$ refers to the normalized values, and $\langle x\rangle$ and $\sigma(x)$ to the mean value and to the standard deviation of variable $x_{i}$ respectively. Both variables show great similarity from 1976 to 1983 and from 1989 to 1997 . From 1984 to 1988 they are not as strongly correlated but follow a similar trend. The correlation coefficient between river flow and precipitation is 0.88 (confidence level 99\%). In order to analyze the time lag between the DJF precipitation and the Miño River flow, the data were temporally averaged for different time lags. Fig. 20 shows for example that with time lags of 0,1 , and even $2 \mathrm{mo}$, precipitation (in DJF) and river discharge (in JFM) correlation coefficient is close to 0.9 . This coefficient drops to values $<0.6$ for time lags $>3$ mo. The highest coefficient was found for a lag of $1 \mathrm{mo}$, although it was only slightly higher than for lag 0 .

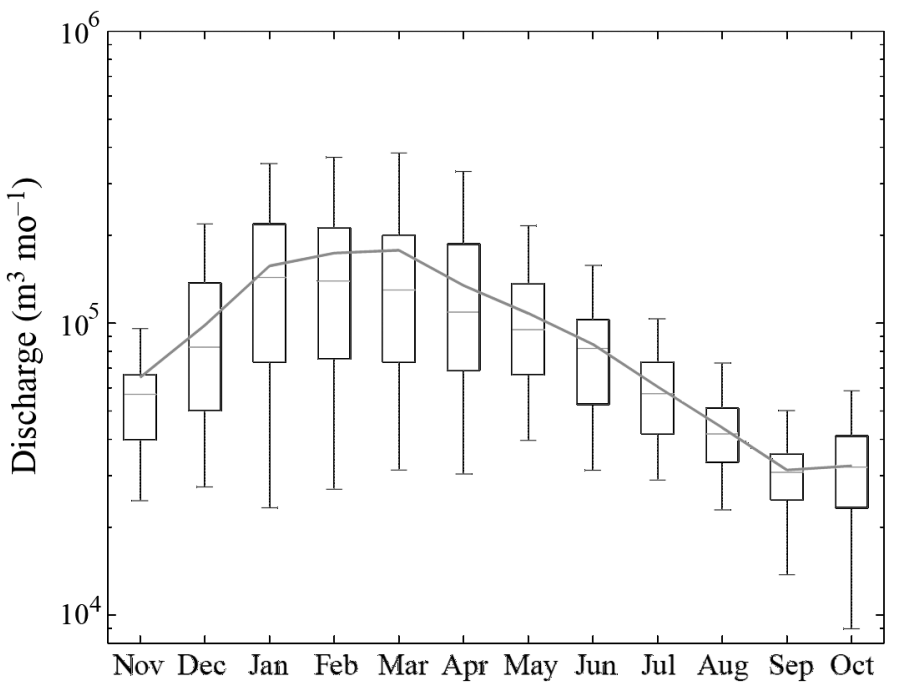

Fig. 18. Annual hydrologic cycle variability for the monthly average Miño River flow from 1970-2008. Curve: monthly average; line inside each box: mean value for each month; lower and upper whiskers: minimum and maximum river flow, respectively; lower and upper box limits: first and third quartiles, respectively 


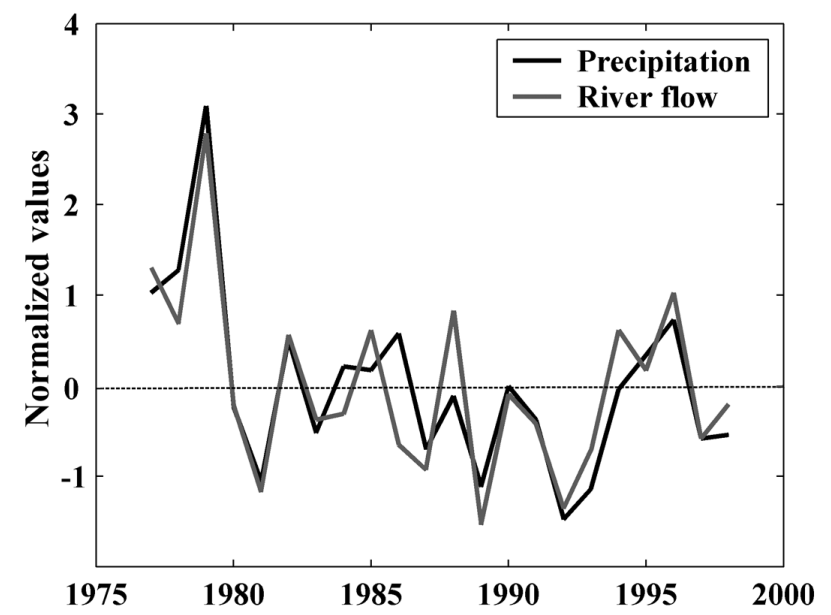

Fig. 19. Inter-annual variability of DJF precipitation (spatially integrated over the Miño River basin; black line) and DJF river flow (grey line) from October 1976 to September 1997. Precipitation and river flow data were normalized in order to facilitate visual comparison (see Section 7.2)

Trends in Miño River discharge were calculated for the period 1971 to 2008 (Fig. 21). First, data were averaged at an annual scale. As the resulting pattern was still too variable (grey curve in Fig. 21), a running average of \pm 2 yr was used to remove high-frequency variations (black curve in Fig. 21). Apart from a decreasing trend, the pattern shows an oscillation with a periodicity of $\sim 20 \mathrm{yr}$. However, the extent of the series is too short to elucidate whether there is some physical reason behind this oscillation or it is just an artifact. Data were then fitted to a straight line, showing a decreasing trend on the order of $-18 \mathrm{~m}^{3} \mathrm{~s}^{-1}$ decade $^{-1}$. This decrease is relatively important, since it constitutes $\sim 15 \%$ of the mean river runoff $\left(375 \mathrm{~m}^{3} \mathrm{~s}^{-1}\right)$ for the

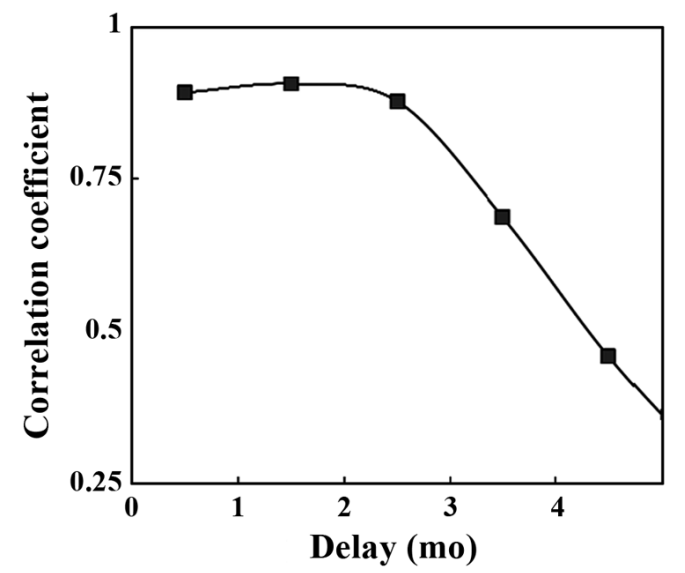

Fig. 20. DJF precipitation (spatially integrated over the Miño River basin) correlation with river flow (temporally averaged for different time periods) from 1976-1997. Zero corresponds to the DJF river-flow period, 1 to the JFM period, and so on. Only results with a significance level of $p<0.05$ are presented

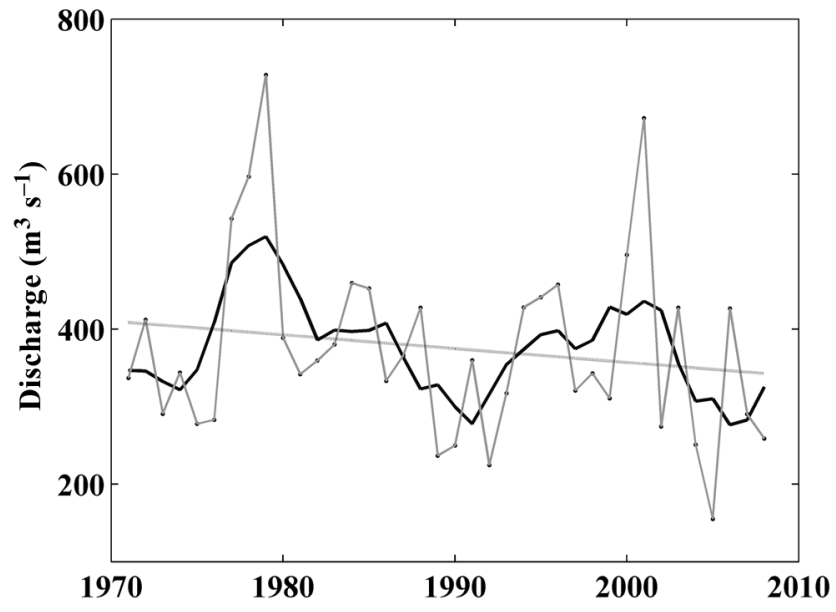

Fig. 21. Trend in Miño river discharge for 1971-2008 (straight line). Annual averaged raw data (grey) and data with a \pm 2 yr running average (black) are shown

28 yr under study. This decrease is similar to the one we found for the Douro River at the Régua gauge station in Portugal for the period 1974 to 2008. The observed trend in that case was $-13 \mathrm{~m}^{3} \mathrm{~s}^{-1}$ decade $^{-1}$ with a river runoff of $376 \mathrm{~m}^{3} \mathrm{~s}^{-1}$.

The decrease observed in river discharge is much more marked than the one described for precipitation in Section 4. Apart from a certain decrease in precipitation, the existence of an increasing number of dams and water uses therefore seem to play an important role in the runoff decrease, since irrigation and power production have intensified during the last few decades.

\section{SEA LEVEL RISE}

\subsection{Methods}

Mean sea level is related to climate change and can represent a valuable indicator of global warming. Changes in sea level are due to multiple factors, as stated in the last IPCC report (IPCC 2007), although there are 2 main causes of the observed SLR: thermal expansion of the oceans (which has contributed to $\sim 5 \%$ ), and the melting of glaciers and ice caps (with a contribution of $\sim 28 \%$ ). The remaining contribution is mainly due to losses from the polar ice sheets. It is commonly accepted that the global sea level has been rising at a rate of 1.5 to $2.0 \mathrm{~cm}$ decade $^{-1}$ during the last century (e.g. $1.84 \pm 0.35$ [SD] cm decade ${ }^{-1}$; Peltier 2001).

Since 1943, the Instituto Español de Oceanografía has managed a network of permanent tide gauges to monitor sea-level measurements relative to a common tide gauge zero (TGZ). This network has been previ- 
ously used by different authors to identify sea level patterns around the IP (Cabanas et al. 2003, Marcos et al. 2005, Rosón et al. 2009). In the present study we used the gauges located at Coruña and Vigo harbors.

García-Lafuente et al. (2004) analyzed seasonal sealevel variations. According to their research for lowfrequency variability (after removing diurnal, semidiurnal, and high-frequency tides as well as short-term meteorological fluctuations), the remaining signal can be decomposed into the following terms

$$
h(t)=H+c t+h_{\mathrm{m}}(t)+h_{\mathrm{s}}(t)+h_{\mathrm{o}}(t)+h_{\mathrm{r}}(t)
$$

where $h(t)$ represents the observed sea level, $H$ the mean sea level, $c t$ the possible sea level trend, $h_{\mathrm{m}}(t)$ and $h_{\mathrm{s}}(t)$ the meteorological and steric contributions respectively, while $h_{0}(t)$ accounts for other contributions and $h_{\mathrm{r}}(t)$ includes inter-annual variability and noise. In the particular case of Galician harbors, the term $h_{\mathrm{m}}(t)$ accounts for $\sim 80 \%$ of the variability, suggesting a strong response to meteorological forcing (wind setup and inverted barometer response), especially to winds (García-Lafuente et al. 2004). In addition, the term $h_{\mathrm{s}}(t)$ is small, since the area is characterized by intense summer upwelling, which reduces the amplitude of the thermal cycle and hence decreases steric effects.

The steps followed in the present analysis can be summarized as follows. Hourly data were averaged to a daily scale, neglecting non-complete days. Gaps in the data, $<2.5 \%$ of the total data set, were interpolated by means of a spline method. Then, a running average $( \pm 15$ d) was considered as a filter to eliminate or, at least, to smooth out daily variability. Other authors (Cabanas et al. 2003, Rosón et al. 2009) preferred to work with monthly averages, but the results obtained following our approach are identical, so proving that the observed trends are completely independent of the particular features of the method used to compute them.

We linearly fitted the observed sea level for the whole period under study (1943 to 2005 for Vigo and 1943 to 2008 for Coruña).

Finally, we removed the crust movement for a better estimation of the long-term sea-level changes. Due to the lack of additional detailed information about the stations under study, only the post-glacial rebound (PGR) signal was removed by using the corrections given by the Geodynamic Model (Peltier 2001). These values are -0.13 and $-0.27 \mathrm{~cm} \mathrm{decade}^{-1}$ for Coruña and Vigo stations respectively.

\subsection{Results}

In order to compare our results with others described in the literature, the data were linearly fitted for differ- ent time periods. Table 8 summarizes the main findings of this preliminary analysis. The results were independent of the fitting method used by the different authors. The values observed for Vigo were larger than those reported in previous studies (Douglas 2001, Peltier 2001) at other stations located in the northeast Atlantic Ocean: $1.45 \mathrm{~cm}$ decade $^{-1}$ in Newlyn (Great Britain), $1.04 \mathrm{~cm}$ decade ${ }^{-1}$ in Brest (French Britanny), $1.89 \mathrm{~cm} \mathrm{decade}{ }^{-1}$ in Cascais (Portugal), and $1.70 \mathrm{~cm}$ decade $^{-1}$ in Lagos (southern coast of Portugal). However, the result for Vigo was close to the one obtained for Santander $\left(2.12 \mathrm{~cm}\right.$ decade $\left.^{-1}\right)$ by Marcos et al. (2005). The reason for the observed discrepancies should be analyzed in detail. Results reported by Douglas (2001) and Peltier (2001) were calculated with records covering a period of $80 \mathrm{yr}$, spanning from the first decades of the 20th century to the beginning of the 1990s, while results in Spain were calculated from Instituto Español de Oceanografía records covering around 60 yr since 1943. Thus, results can be sensitive both to the length of the record and to the particular time period under study.

Given the short distance between Coruña and Vigo $(\sim 100 \mathrm{~km})$, the difference in SLR between both stations seems rather large. Marcos et al. (2005) examined the trends calculated at both stations and at the neighboring station of Santander. They observed the existence of a jump in the reference sea level at Coruña during the period 1955 to 1965 . In addition, they also identified a data gap of $70 \mathrm{~d}$ starting in June 1963. Thus, data were corrected to fill the gaps by means of an empirical orthogonal function technique involving these stations to obtain a corrected trend of $2.12 \mathrm{~cm} \mathrm{decade}^{-1}$ in Santander, $2.91 \mathrm{~cm}$ decade $^{-1}$ in Vigo, and $2.51 \mathrm{~cm}$ decade $^{-1}$ in Coruña. Note that the correction only slightly modifies the trend in Vigo but it produces a remarkable effect in Coruña.

Fig. 22 shows the 10 yr moving average of sea level recorded at Coruña (grey line) and Vigo (black line) stations and also depicts the anomaly relative to the period 1943 to 2004. Note that the years before 1948

Table 8. Comparison of sea level rise calculated in the present study and in previous studies. Note that results from Marcos et al. (2005) correspond to the study of raw data, without correcting the series by interpolating data

\begin{tabular}{|lccc|}
\hline \multirow{2}{*}{ Source } & \multicolumn{3}{c}{ Sea level rise $\left(\mathrm{cm}\right.$ decade $\left.^{-1}\right)$} \\
& Period & Coruña & Vigo \\
\hline Cabanas et al. (2003) & $1943-1999$ & 1.45 & 2.88 \\
Present study & & 1.56 & 2.84 \\
Rosón et al. (2009) & $1943-2004$ & 1.52 & 2.90 \\
Present study & & 1.67 & 2.89 \\
Marcos et al. (2005) & $1943-2001$ & 1.59 & 2.84 \\
Present study & & 1.57 & 2.85 \\
\hline
\end{tabular}


and after 1999 were discarded since they were not central to a whole decade of data. Both patterns showed an overall increase in sea level, which was more marked in the case of Vigo and in good agreement with the results shown above. Some authors (e.g. Marcos et al. 2005) have related this increase to water-volume expansion due to the increasing heat content of the ocean (Levitus et al. 2000), although the correlation between both signals is far from being perfect, especially when comparing the sharp increases observed in the series.

The decadal variability of sea level was analyzed in terms of the trend computed for $10 \mathrm{yr}$ periods centered on every year of the entire record (Fig. 23). Once again, the years before 1948 and after 2003 in Coruña and after 1999 in Vigo were discarded since they were not central to a whole decade of data. In addition, a running average involving the previous and next period was used to smooth data. There was a marked variability, with values ranging from ca. -4.5 to $9 \mathrm{~cm} \mathrm{decade}^{-1}$ in Coruña (grey line in Fig. 23) and

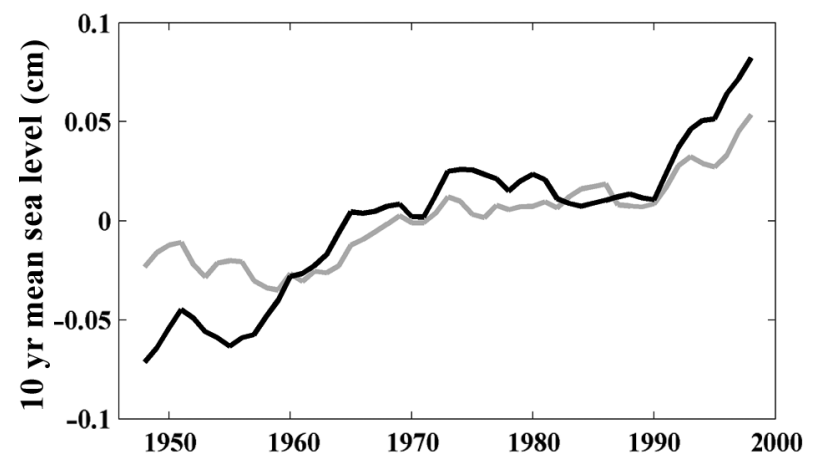

Fig. 22. Anomaly relative to the period 1943-2004 of the $10 \mathrm{yr}$ moving average of sea level at the Coruña (gray) and Vigo (black) stations

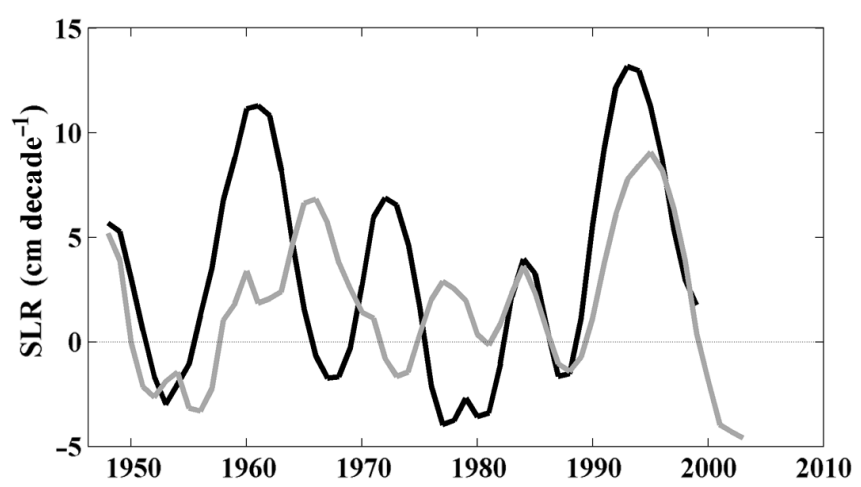

Fig. 23. Decadal variability in sea level rise (SLR) in terms of the trend computed for $10 \mathrm{yr}$ periods centered on every year of the entire record for the Coruña (gray) and Vigo (black) stations from ca. -4.0 to $13 \mathrm{~cm}$ decade ${ }^{-1}$ in Vigo (black line in Fig. 23). The correlation between trends was moderate $(\mathrm{R}=0.47)$ although, visually, one can observe how both series were in phase from the beginning of the record to the mid-1960s and again from 1980 on. Note that the highest SLR was observed during the 1990s for both stations, although the rate has decreased during the last decade. In addition, the average trend was $1.61 \pm 0.46 \mathrm{~cm} \mathrm{decade}^{-1}$ in Coruña and $3.25 \pm 0.69 \mathrm{~cm}$ decade $^{-1}$ in Vigo. Marcos et al. (2005) have compared mean sea level and mean North Atlantic temperature (derived by Levitus et al. 2000) and found them to be similar. Nevertheless, the comparison between the series shows the similarities and discrepancies. In particular, the main discrepancy is the time lag between the sharp increases observed in both signals (Marcos et al. 2005).

\section{SYNOPTIC SYSTEMS}

At mid-latitudes, the variability of weather and climate is related to moving low-pressure systems, which sometimes are diverted from their regular path by the presence of persistent and quasi-stationary highpressure systems. Both systems are expected to shape some of the characteristics and variability of the analyzed region.

Thus, extra-tropical cyclones have a strong influence on local weather, as their passage is related to strong winds, precipitation, and temperature variations that occasionally produce destructive flooding (e.g. Ulbrich et al. 2009). In summer, however, quasi-stationary cyclones positioned over heated land masses are mostly dominant over Iberia, bringing little precipitation (e.g. Trigo et al. 1999). In contrast, blocking activity interrupts the normal progression of extratropical cyclone systems and - for typically 1 to $2 \mathrm{wk}-$ suppresses the mid-latitude westerly winds, which are replaced by meridional flows (e.g. Barriopedro et al. 2010). Therefore, persistent anomalous temperatures and a marked redistribution of precipitation over large areas of middle and high latitudes, including NW Iberia, are typical fingerprints of blocking patterns (Trigo et al. 2004a, García-Herrera et al. 2007).

The results presented in this section are based on objective detection schemes of these specific synoptic systems by means of automatic algorithms applied to gridded data, taking advantages of the following reanalyses: the European Centre for Medium-Range Weather Forecasts (ECMWF) ERA-40 reanalysis project (Uppala et al. 2005) and the National Center for Environmental Prediction and National Center for Atmospheric Research (NCEP/NCAR) reanalysis (Kalnay et al. 1996, Kistler et al. 2001). 


\subsection{Cyclone climatology}

\subsubsection{Methods}

Cyclone activity can be inferred from either Eulerian or Lagrangian methods (see e.g. Ulbrich et al. 2009). The analysis of cyclones presented herein is of Lagrangian nature and follows the scheme by Trigo (2006), which is based on $1000 \mathrm{hPa}$ geopotential height fields (6-hourly) from the ERA-40 reanalysis for the period 1959 to 2001 at the highest resolution available (ca. $1.125^{\circ} \times 1.125^{\circ}$ ).

The method we used to analyze cyclones consists of the detection of sea-level pressure minima that are eligible for possible storm centers according to a set of conditions and their subsequent tracking by looking for the nearest neighbor in consecutive charts within a given distance. The lifecycle of the storm must exceed $24 \mathrm{~h}$, to eliminate weak systems with little impact on local weather.

As NW Iberia is frequently affected by cyclones originating in the North Atlantic, changes in cyclone activity over the region west of the IP region are expected to be strongly related to those in the North Atlantic. Therefore, the analyses of cyclone variability and trends described herein will be performed for 2 regions: (1) the North Atlantic sector encompassing the area $30-50^{\circ} \mathrm{N}, 0-20^{\circ} \mathrm{W}$; and (2) a smaller area (40$46^{\circ} \mathrm{N}, 5-15^{\circ} \mathrm{W}$ ) embedded in the North Atlantic sector but centered on NW Iberia. As already mentioned by Trigo et al. (1999), the monthly distributions of cyclogenesis activity in the Mediterranean indicate the existence of 3 main overlapping seasons: extended winter (NDJFM), spring (MAMJ), and summer (JJAS), whereas the conventional autumn months (SON) correspond to transitions between summer and winter regimes. These seasonal definitions have been adopted here.

\subsubsection{Results}

The annual mean spatial distribution of cyclones for the western Europe sector is presented in Fig. 24. (Note that each cyclone is identified by its minimum central pressure [i.e. just 1 grid point] but the same cyclone is counted more than once in a given day, as the temporal resolution is $6 \mathrm{~h}$.) The IP is one of the most favorable areas for the location of minimum central pressures over the Mediterranean. The relative maximum of cyclonic activity over the IP exhibits a strong annual cycle and it is mostly due to summer activity of the Iberian thermal low (Trigo et al. 1999), a quasistationary signature that rarely brings precipitation. In winter, however, most of the cyclones travel along the northern Atlantic or, secondarily, through the Azores-
Mediterranean axis. Although the tracks delineated by the cyclone centers are displaced slightly from the region under scope, it is important to notice that an extratropical cyclone often reaches 1500 to $2000 \mathrm{~km}$ in diameter (Longshore 2000) and that frontal precipitation associated with extratropical cyclones typically occurs south of the low-pressure center. Therefore, the target region is mainly affected by low-pressure systems to the north, thus justifying the analysis of cyclone changes over a larger area than the one under scope.

Fig. 25 shows annual and seasonal decadal trends of the percentage of cyclone number aggregated in $\sim 9^{\circ} \times$ $9^{\circ}$ cells centered over each grid point for the 19592001 period. Two bands with opposite signs were observed (Fig. 25a): the one with positive trends was located in northern latitudes, mainly northern UK, and the one with a decline in the number of cyclones was centered at southern latitudes, over the IP. Although seasonal trends exhibited strong spatial variability, annual signatures, especially the decreasing trends, seemed to arise from the winter season, whose pattern suggests a northward shift of the storm tracks in the eastern Atlantic/Western Europe sector (e.g. Trigo 2006). Recent studies also show evidence of a decline in winter cyclone density during the second half of the 20th century (e.g. Raible et al. 2008), especially in middle (but not high) latitudes of the North Atlantic, with a resulting northward shift of the mid-latitude storm tracks (e.g. Gulev et al. 2001, Trigo 2006) that amounts to $180 \mathrm{~km}$ (Wang et al. 2006). These changes have been partially associated with decadal variability in the North Atlantic, and in particular, with a predomi-

\section{Events per grid box}

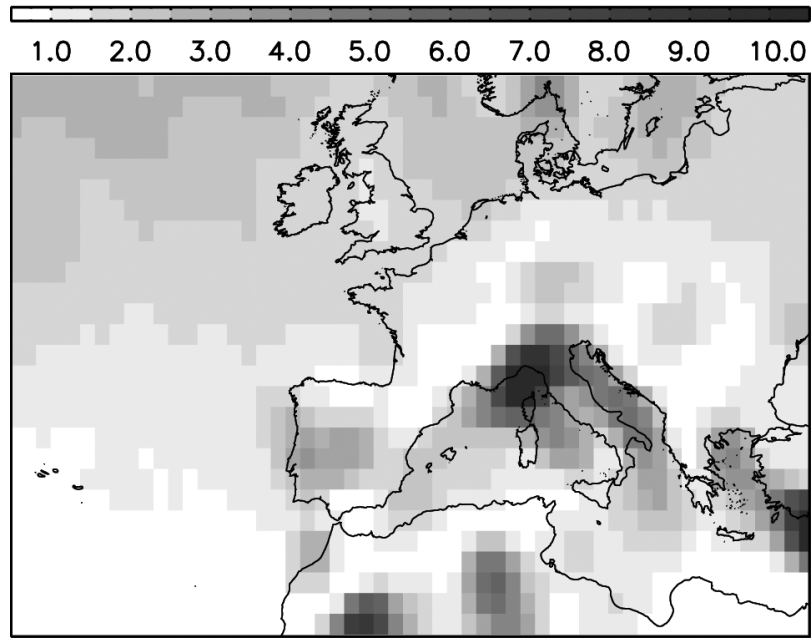

Fig. 24. Spatial distribution of the positions where lows reach their minimum central pressure (1959-2001) using the 6hourly database of the ERA-40 reanalysis and the cyclone tracking method of Trigo et al. (1999). The values correspond to the average number of events detected per $1.125^{\circ} \times 1.125^{\circ}$ grid box 

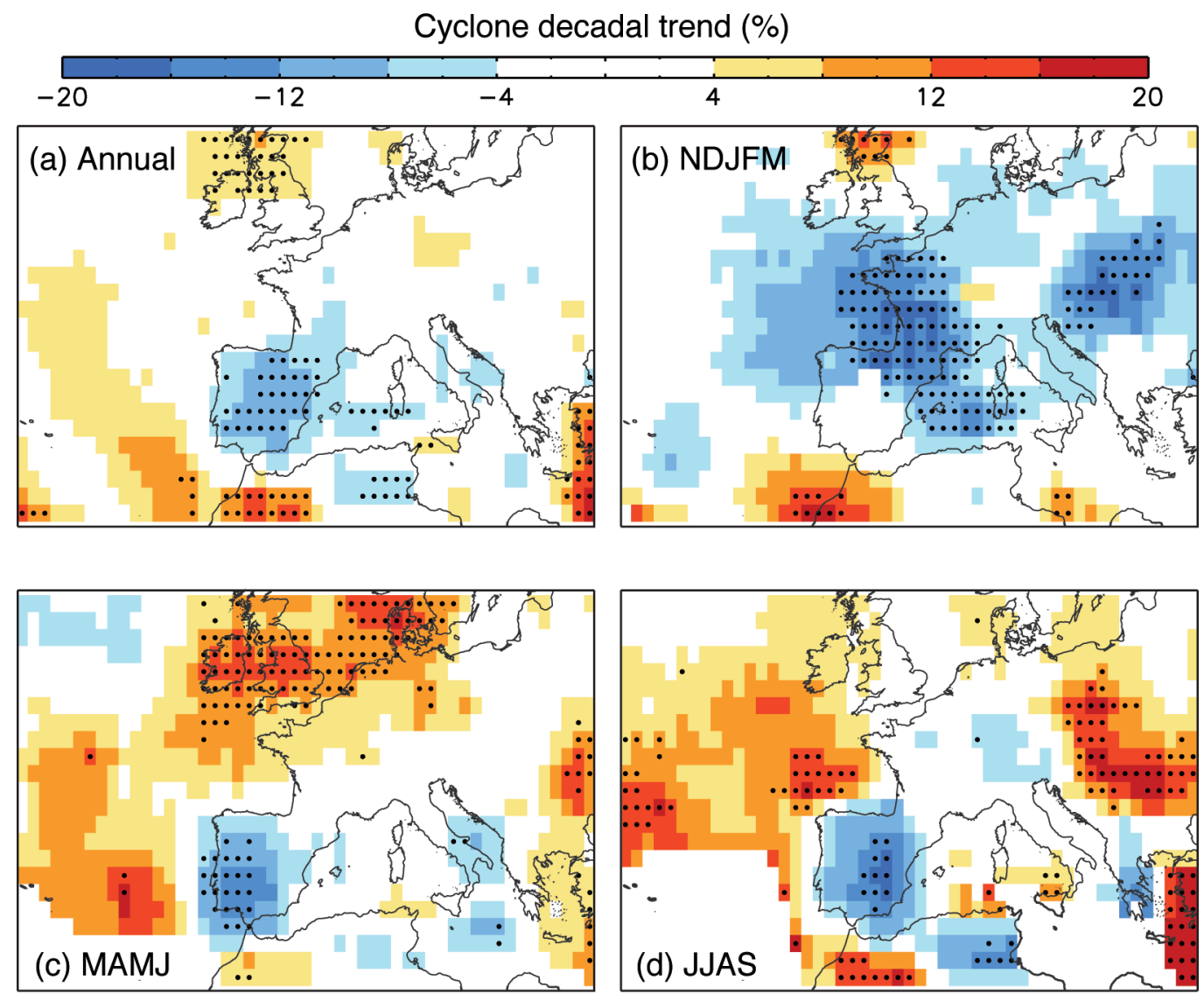

Fig. 25. Decadal trend of (a) annual and (b-d) seasonal cyclone numbers aggregated in grid boxes of $\sim 9^{\circ} \times 9^{\circ}$ for $1959-2001$. Significant trends $(\mathrm{p}<0.05)$ level with a Mann-Kendall test are marked $(\bullet)$. Grid boxes with aggregated cyclone density below $\sim 10$ counts $100 \mathrm{~km}^{-2}$ on average were omitted

nantly positive phase of the NAO through most of the 1990s (e.g. Hurrell 1995; see also Section 10). These trends in extra-tropical cyclones have significant impacts in the associated precipitation field. Thus, the significant decrease in winter cyclones and wind patterns over the western Mediterranean and an increase over Greenland and Scandinavia in the 1960-2000 period matches those patterns observed in precipitation and the height of waves and with concurrent decreases of precipitation in Iberia and increases in the UK, particularly acute in February and March (Trigo et al. 2008).

Focusing on NW Iberia, there are no substantial changes in cyclone frequency (only marginally significant in certain grid boxes), but it is surrounded by areas with significant decreases that spread throughout most of (and north of) the IP. Averaging cyclone activity over the western Europe region as a whole gives a non-significant trend of $-0.62 \%$ decade $^{-1}$. This almost zero annual decrease, however, masks seasonal changes of opposite signs, mostly dominated by a decline in winter cyclones of $-5.20 \%$ decade $^{-1}$ (months:
NDJFM) (confidence level 99\%), which corresponds to one of the seasons with a higher amount of precipitation in the region. The winter decrease in cyclones is in agreement with a widespread decline in winter precipitation over NW Iberia (see Table 4 \& Section 4). During the rest of the year, a meridional dipole in cyclone trends also emerges, but with NW Iberia lying in between, which may partially explain the sparse distribution of the precipitation trends reported in Section 4 .

\subsection{Blocking}

\subsubsection{Methods}

Blocking patterns are characterized by an appreciable mass difference between high and middle latitudes and anomalous easterly winds in typical latitudes of the westerlies, both signatures being typically employed in blocking-detection methods (e.g. Tibaldi \& Molteni 1990). The blocking index used herein (Barriopedro et al. 2006) is a modified version of the Tibaldi \& 
Molteni (1990) index that allows for tracking and a 2-D description of the blocked flows, which are identified as regions of at least $12.5^{\circ}$ in longitude with zonal wind reversals around the typical latitude of the jet stream $\left(\sim 50^{\circ} \mathrm{N}\right)$ during $5 \mathrm{~d}$ or more. The database was obtained from daily geopotential height fields at $500 \mathrm{hPa}$ from the NCEP/NCAR reanalysis for 1948-2008.

To quantify blocking occurrence in NW Iberia, 2 parameters of blocking activity were derived, namely, the number of blocking events and the number of blocked days that affected any longitude of the 0$20^{\circ} \mathrm{W}$ region. A blocking event is said to affect this sector when at least one of its blocked longitudes falls within the area at any time of its life cycle. The second parameter is computed as the frequency of days when any longitude of the area was blocked by the presence of a blocking event. As blocking events exhibit a wide range of duration and the same blocking event can influence the same region for several days, both parameters provide additional information.

\subsubsection{Results}

Fig. 26 displays the longitudinal distribution of the annual averaged frequency of blocking days for the whole period. Two main sectors with a high tendency for blocking can be distinguished over the eastern sides of both oceans, with a secondary center of action over Eurasia. The region of interest (delimited by vertical lines in Fig. 26) was frequently affected by eastern Atlantic/western Europe blocking, especially during winter and spring, whereas in summer, blocking activity was rare. In the period of study, a total of 625 block-

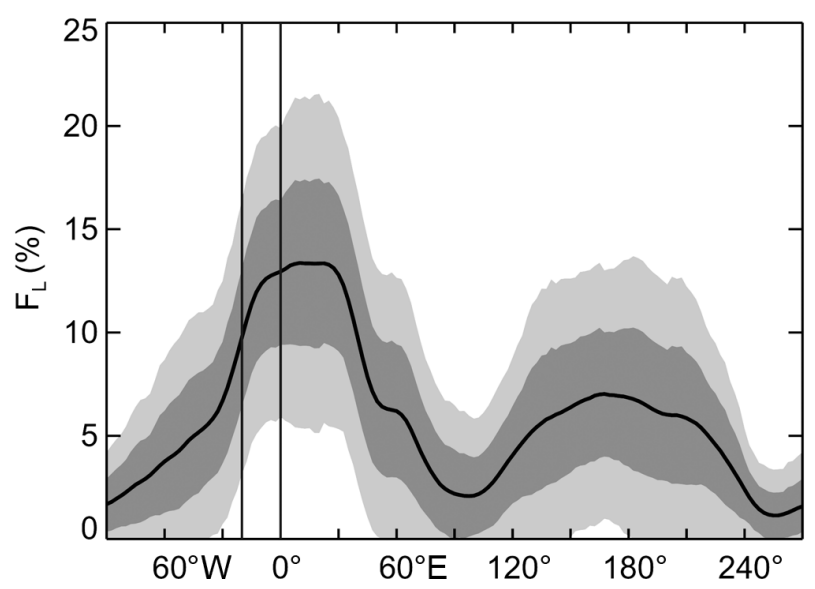

Fig. 26. Annually averaged frequency distribution of blocked longitudes $\left(\mathrm{F}_{\mathrm{L}}\right.$, in \% of the total number of days; black line). Light and dark shaded areas represent the $2 \sigma$ and $1 \sigma$ deviation, respectively. Vertical bars show the longitudinal limits of the region of interest ing events led to a flow reversal within the target region, giving an annual mean of about 10 episodes. On average, the region was blocked $65 \mathrm{~d} \mathrm{yr}^{-1}$ (i.e. $17 \%$ of the time). That means that each blocking event impinged on the target region for $6.5 \mathrm{~d}$ on average. As the mean persistence of the blocking events of the region was $9.9 \mathrm{~d}$, each blocking event that reached NW Iberia persisted therein for $>60 \%$ of its entire life cycle.

On average, annual blocking activity in the Atlantic/ Europe region has decreased during the analyzed period (Fig. 27). A significant fraction of the annual trend arises from late winter and early spring (near $5 \%$ decade $^{-1}$, confidence level 99\%), which is in agreement with the reported decreased trend in the Atlantic winter-blocking activity during the second half of the 20th century (Barriopedro et al. 2006, Croci-Maspoli et al. 2007a).

A longitude-time Hovmöller diagram of the local trends in the frequency of blocking days confirms the presence of regional decreases in the frequency of blocking days in the region, mostly confined to winter and early spring (Fig. 28). Additional analyses (not shown) showed that there were periods during the winters of the 1970s and 1990s that were characterized by less blocking activity, coinciding with upward trends towards positive phases of the NAO index (Section 10), which has been shown to be strongly related to blocking activity in the Atlantic sector (e.g. Barriopedro et al. 2006, Croci-Maspoli et al. 2007b).

Attributing regional changes such as large-scale circulation anomalies to a small region like NW Iberia is not straightforward, as local factors are expected to play a significant role. However, the spatial homo-

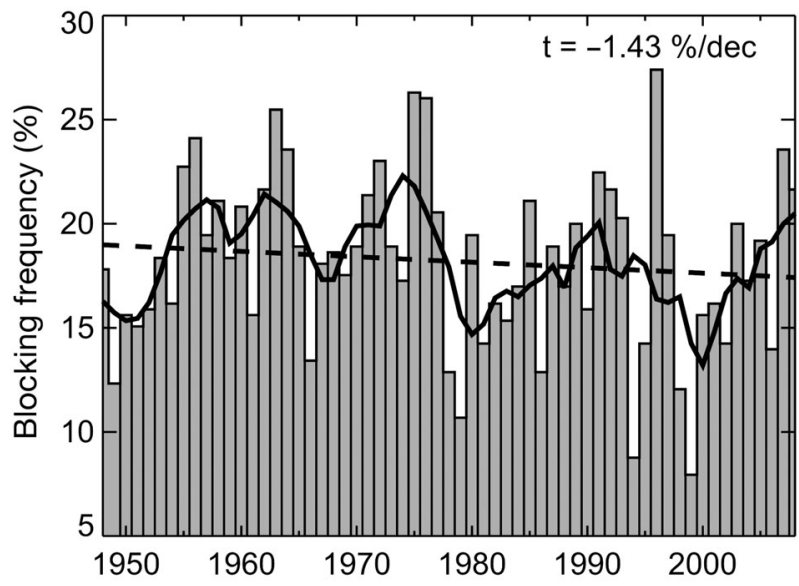

Fig. 27. Annual times series of the frequency of blocking days in the area (vertical bars) (i.e. the frequency of days when a longitude of the region of interest was blocked), expressed as a percentage of total days of the year. Linear regression (dashed line) was performed to estimate the linear trend (upper right corner). Solid line: running average 


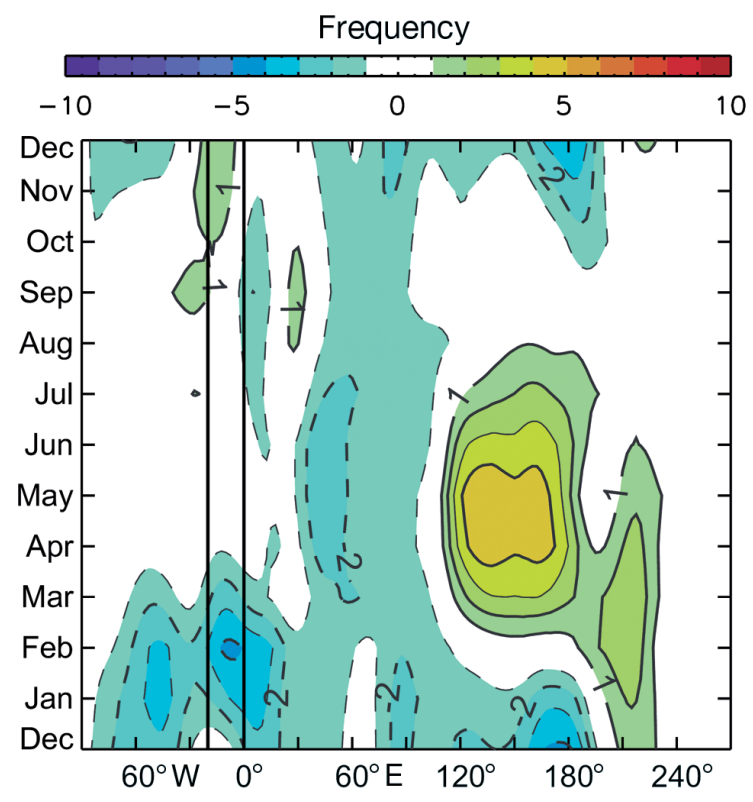

Fig. 28. Longitudinal-time Hovmöller diagram indicating trends (d decade ${ }^{-1}$ ) in the frequency of blocking days (expressed as a percentage of the total number of days in a given month). Solid vertical lines demarcate the analyzed area

geneity in the sign of temperature trends across a region with a large diversity of conditions suggests a possible large-scale influence. Blocking occurrence in eastern Atlantic/western Europe favors below-normal temperatures and enhanced precipitation over southern Europe, including Iberia (Trigo et al. 2004a). The results reported herein are therefore in agreement with the temperature trends obtained in Section 3.2. The decrease in blocking is expected to have contributed to a reduction of persistent winter and spring cold periods in NW Iberia, which is in agreement with the increasing temperature trends reported in NW Iberia (Table 2; Section 3.2) and with the reduction in cold days and nights (Table 3; Section 3.2). The periods of strongest blocking decreases (1970s and 1990s) also agree with the maximum increases in temperature (Fig. 5; Section 3.2). Blocking impacts are also related to a deflection of cyclones to the south and precipitation increases over western Iberia. Accordingly, the blocking decrease mirrors the decreasing winter trend in cyclone activity over latitudes of NW Iberia (Fig. 25; Section 9.1.2). The reduction in blocking also implies a decrease in the frequency of northerly and easterly flows over NW Iberia, which seems to be in agreement with the reduced regional coastal upwelling in the wet seasons (Section 6).

Since the occurrence of blocking simultaneously involves lower-than-normal temperatures and abovenormal cloud conditions over western Iberia, the impacts on maximum temperatures are expected to be particularly pronounced, the corresponding decreases in minimum temperatures being partially offset by the radiative nighttime warming associated with cloud conditions. Consistently, some of the strongest warming over the analyzed region has occurred in spring (Table 2; Section 3), although local and regional changes have likely contributed to shape and modulate the magnitude and spatial variations across the region. Temperature changes in other seasons besides winter and spring are most probably unconnected to blocking.

\section{TELECONNECTION PATTERNS}

\subsection{Methods}

Teleconnection patterns are often the phenomena responsible for abnormal weather patterns occurring simultaneously over seemingly vast distances. Previous studies (Rodríguez-Puebla et al. 1998, Lorenzo \& Taboada 2005, deCastro et al. 2006a, Ramos et al. 2010) have considered that the most representative regional patterns of atmospheric variation in the Northern Hemisphere, with some influence on the eastern North Atlantic region, are: NAO, EA, SCAND, EA-WR, and Europe Polar/Eurasia pattern (POL). These atmospheric circulation patterns exhibit largescale decadal change and play a key role in the longterm variability of winds across the North Atlantic, affecting the circulation of atmospheric weather systems and coastal upwelling intensity.

The teleconnection indices were obtained from the Climate Prediction Center (CPC) of the NOAA (www.cpc.noaa.gov) at monthly time scales from 1950 to 2005. A detailed description of the atmospheric modes and the procedure followed is described in deCastro et al. (2008a).

Although the NAO index has been the most commonly studied mode in the IP (Rodríguez-Puebla et al. 1998, 2001, Trigo et al. 2004b, Santos et al. 2005), several studies (e.g. Lorenzo \& Taboada 2005, deCastro et al. 2006a) have shown the need to consider additional modes to explain the variable structure of winter rainfall and river flow in Galicia. Similar results were obtained to explain the variability of upwelling both in Galicia (deCastro et al. 2008b) and in the Bay of Biscay (Borja et al. 2008). In the latter case, Borja et al. (2008) showed that $55 \%$ of the anchovy catch variability is explained by upwelling over the spawning area, which is related to the EA pattern. Finally, several studies have indicated the influence of the main atmospheric circulation modes on weather type frequency and drought occurrence in Spain (Rodó et al. 1997, Rodríguez-Puebla et al. 1998, Pozo-Vázquez et al. 2005, Ramos et al. 2010). Monthly precipitation data 
from 1976 to 1997 were obtained from the 22 rain gauge stations distributed throughout the Miño River basin (see stations labeled from A to F in Table 1). Only stations with $>80 \%$ of the monthly precipitation data processed were considered in order to avoid bias in the results. Although orography and distance are not likely to alter conditions from one station to another due to the limited extent of the Miño River basin, data were spatially integrated over the basin by means of a weighted-average procedure following Alexander \& Jones (2000). Monthly river-discharge data for a gauge station situated in Frieira were obtained from the Confederación Hidrográfica del Norte for the period October 1970 to September 2005 as mentioned in Section 7.1. Precipitation data, river discharge, and monthly teleconnection indices were averaged for the winter period (DJF) corresponding to the wet season during hydrological years (October to September).

\subsection{Results}

According to the results obtained in Sections 4 and 7 , the months with the highest precipitation and hence river discharge are December, January, and February. Thus this section focuses on those teleconnection modes that influence precipitation and discharge during these months.

The lagged correlation coefficients between the major winter atmospheric indices and river flow are presented in Fig. 29. The EA index reveals a correlation

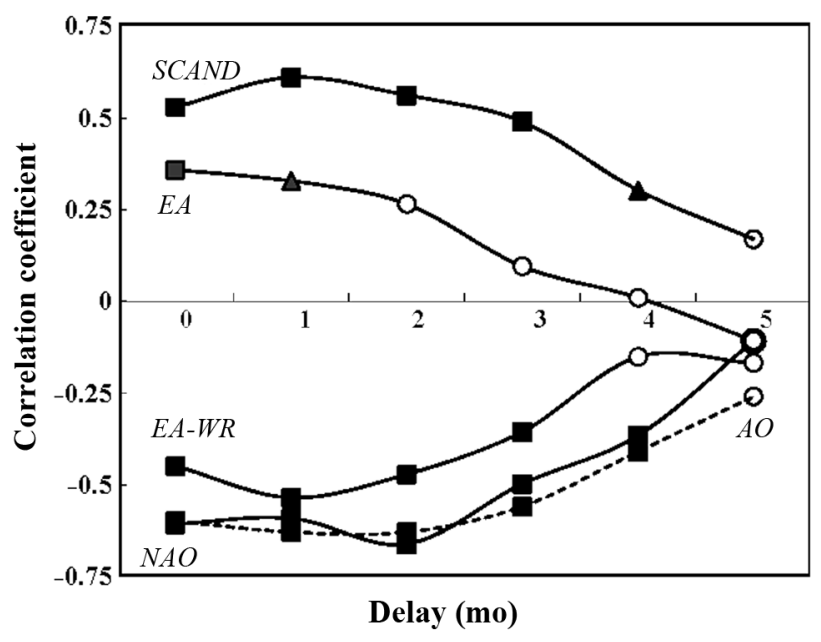

Fig. 29. DJF atmospheric pattern correlations with river flow (temporally averaged for different time periods) from 19761997. Zero corresponds to the DJF river flow period, 1 to the JFM period, and so on. Results are shown with a significance

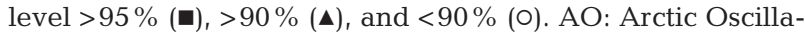
tion, EA: Eastern Atlantic pattern, EA-WR: Eastern AtlanticWestern Russia pattern, NAO: North Atlantic Oscillation, SCAND: Scandinavia pattern coefficient close to 0.4 . This correlation coefficient drops continuously for increasing time lags. The correlation coefficients between river discharge and the SCAND and EA/WR indices show a different behavior. In these 2 cases, the highest correlation coefficients ( 0.61 and -0.54 respectively) are achieved at a lag of 1 mo (river flow averaged for the period JFM). In contrast, the correlation coefficient between river flow and the NAO index achieves its maximum value of -0.66 at a time lag of 2 mo. This result contrasts with that obtained by Trigo et al. (2004b) for other Iberian rivers flowing into the Atlantic. In their results, the correlation between the DJF NAO index and river flow peaked at a time lag of 1 mo.

The correlations between the teleconnection indices and precipitation were also analyzed at each rain gauge station for the Miño River basin from 1976 to 1997 (Fig. 30). The highest correlations were obtained for the NAO index, ranging from -0.48 to -0.71 . This result coincides with the one found by Queralt et al. (2009), who reported that negative winter NAO phases also favor the frequency of extreme precipitation events in Galicia, particularly the intensity of total and extreme precipitation events, suggesting that the relatively wet regions of the IP significantly reflect the intensity rather than the number of days with precipitation. The correlation coefficients between rainfall and the EA-WR index range from -0.2 to -0.6 and between rainfall and the EA and SCAND indices range from 0.25 and 0.6 , showing a similar influence of the 3 teleconnection indices on precipitation patterns. Finally, no correlation between POL and rainfall was observed.

Table 9 summarizes the influence of the atmospheric patterns on precipitation at each gauge station. These correlations are significant for the NAO, SCAND, EA-WR, and EA indices (confidence level 95\%). These results reveal some of the features mentioned in Section 10.1, namely that the NAO index has the strongest influence on precipitation for this region. The remaining indices, SCAND, EA-WR, and EA, reveal a lower although significant correlation with precipitation.

The weather in Galicia is characterized by the passage of cold fronts associated with lows travelling across the North Atlantic. The storm track in this area depends strongly on the particular NAO state during the winter, which will make the passage of cold fronts easier or more difficult. On the other hand, the action centers of the north-south dipole of the EA are located southwest of the NAO dipole. Considering that Galicia is strongly influenced by the NAO, but at a latitude where influences pass from positive to negative correlations, it is clear that the EA must have an important influence on winter rainfall as well. A positive EA pattern means that subtropical high and lows in the North 

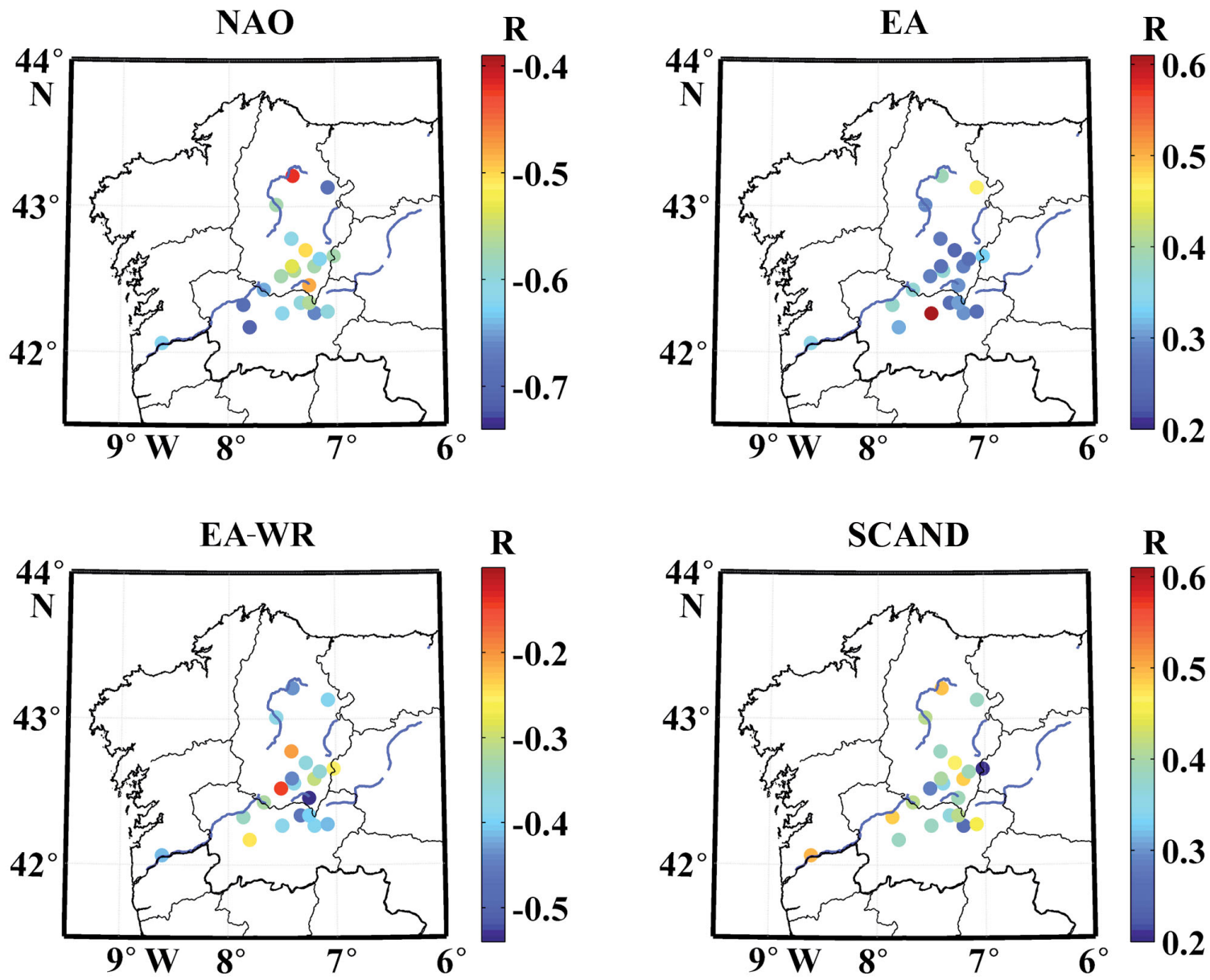

Fig. 30. Correlation coefficients between DJF teleconnection indices (NAO, EA, EA-WR, and SCAND; see Fig. 29 caption for abbreviations) and DJF precipitation at each rain gauge station from October 1976 to September 1997

Atlantic are stronger. The northern part of the dipole is located in a latitude band between Newfoundland and Ireland in the North Atlantic. Therefore, a positive EA pattern implies that low pressure will dominate this area, and in this situation, more cold fronts will reach the Galician coast during the winter. In addition, the positive state of the east-west dipole of SCAND produces a negative pressure center over the IP, forcing the storm track along the same line of latitude as Galicia (forming a crossroads between Atlantic and conti-

Table 9. Correlation coefficients between DJF rainfall and DJF atmospheric patterns calculated at each rain-gauge station from 1976 to 1997. POL: Europe Polar/Eurasia pattern. See Fig. 29 caption for other abbreviations

\begin{tabular}{|lc|}
\hline Index & Correlation coefficient $($ mean $\pm \mathrm{SD})$ \\
\hline NAO & $-0.59 \pm 0.02$ \\
SCAND & $0.39 \pm 0.02$ \\
EA-WR & $-0.36 \pm 0.02$ \\
EA & $0.33 \pm 0.02$ \\
POL & $-0.053 \pm 0.02$ \\
\hline
\end{tabular}

nental influences), even if NAO or EA do not favor this trajectory. The EA-WR features in their positive phases imply the existence of high pressure located over Europe mainly to the north of the IP. This location prevents the jet stream from traversing southward toward Galicia, typically passing to the north or to the south, leading to more precipitation in Scandinavia and the Canary Islands and dry conditions over the IP, which explains the negative correlation with winter rainfall in Galicia. On the other hand the POL represents a northsouth dipole, as with the NAO and EA, but with the centers of action located further north than the NAO centers. This location shows that variations in this index structure do not favor a correlation in regions located below $40^{\circ} \mathrm{N}$.

The influence of the atmospheric indices on precipitation variability can also be found in the flow of Iberian rivers. For example, Trigo et al. (2004b) found correlation coefficients between the DJF averaged NAO index and the JFM averaged river flow for the period 1923 to 1998 of -0.55 for the Douro River, -0.52 for the Tagus River, and -0.69 for the Guadiana River. 
The correlation coefficients are stronger from south to north according to other research (Rodó et al. 1997, Rodríguez-Puebla et al. 1998, 2001), where the highest correlation coefficients between the December NAO index and the annual precipitation were observed in the southwestern corner of the IP. The correlations are considerably larger when the period 1973 to 1998 is considered: -0.76 for the Douro River, -0.77 for the Tagus River, and -0.79 for the Guadiana River, which shows the non-stationarity of the correlation (Goodess \& Jones 2002). In the particular case of the Miño River, several modes have been described as having a nonnegligible influence on river discharge and hence on precipitation (deCastro et al. 2006a).

In order to compare the correlation between the NAO index and the river flow for the Miño River with other Atlantic-draining Iberian Rivers, we used the same period of time (from 1973 to 1998) as Trigo et al. (2004b). The results show correlation coefficients of: -0.65 for the NAO and Arctic Oscillation indices, 0.64 for the SCAND, -0.50 for the EA-WR, 0.44 for the EA, and -0.13 for the POL index. The correlation coefficient obtained between the Miño River flow and the NAO index was smaller than the one obtained for the Douro River, which follows the tendency for correlations to diminish from south to north over the region. In this case the highest correlation between the NAO index and river flow was achieved for a time lag of 2 mo, which contrasts with the results obtained by Trigo et al. (2004b), where the highest correlation was obtained for a time lag of $1 \mathrm{mo}$. This is possibly due to the orographic constraints and the high density of dams located in the Miño River basin compared to the rest of Iberian rivers.

The non-stationarity of the atmospheric indices becomes more apparent when comparing the correlation with river flow for both analyzed time periods. An increase in the SCAND and EA correlation coefficients and a decrease in the EA-WR correlations are observed when passing from the 1976-1997 data set to the 1973-1998 data set. In contrast, correlation coefficients with the NAO index remain nearly constant over time. Therefore, the atmospheric patterns evolve temporally with a different structure, in such a way that the most prevalent pattern depends on the chosen period of time. The time evolution of the correlation coefficients between the atmospheric indices (NAO, EA, EA-WR, and SCAND) and river flow averaged for 22 yr periods (record length limited by the precipitation data) from 1970 to 2005 are presented in Fig. 31. The mean and standard deviation of these correlation coefficients are summarized in Table 10. Both Fig. 31 and Table 10 show the significance of the NAO, SCAND, EA-WR, and EA atmospheric patterns in explaining the inter-annual variability of the Miño River flow. In particular, it is clear that the NAO pattern had the greatest influence on Miño River flow from successive periods beginning in 1970-1991 and ending 1976-1997, with correlation coefficients close to -0.7 . Afterwards, the correlation coefficient decreased, reaching values below -0.4 for the last 5 periods. On the other hand, the correlation coefficient between the SCAND pattern and Miño River flow increased during the entire time period, reaching the highest correlation values (close to 0.7 ) for the last 5 periods.

In addition, the results show how the decrease in the NAO correlation coefficient also coincides temporally with the decrease in the EA-WR and EA correlation coefficients. The winter NAO exhibited significant multi-decadal variability, where the negative phase of the NAO (which is the phase with the most influence on the Miño River basin) dominated the

Table 10. Correlation coefficient (simultaneous [lead $=0$ ] and with lead, mean $\pm \mathrm{SD}$ ) between the DJF atmospheric patterns and Miño River flow averaged for 22 yr periods from 19702005. See Fig. 29 caption for abbreviations

\begin{tabular}{|lrrr|}
\hline Index & \multicolumn{2}{c}{ Correlation coefficient } & \multicolumn{2}{c|}{$\begin{array}{c}\text { Lead } \\
\text { Lead }=0\end{array}$} & \multicolumn{1}{c}{ With lead } & \\
& & & \\
\hline NAO & $-0.51 \pm 0.04$ & $-0.54 \pm 0.05$ & $2(\mathrm{FMA})$ \\
SCAND & $0.54 \pm 0.02$ & $0.63 \pm 0.01$ & 1 (JFM) \\
EA-WR & $-0.39 \pm 0.02$ & $-0.46 \pm 0.02$ & $1(\mathrm{JFM})$ \\
EA & $0.40 \pm 0.02$ & $0.40 \pm 0.02$ & $0(\mathrm{DJF})$ \\
\hline
\end{tabular}

Fig. 31. Time evolution of correlation coefficients between DJF atmospheric patterns (NAO, EA, EA-WR, and SCAND; see Fig. 29 caption for abbreviations) and the Miño River flow, averaged for 22 yr periods from 1970-2005. A river flow time lag of 0 (EA), 1 (SCAND and EA-WR), and 2 (NAO) months were considered depending on the atmospheric pattern

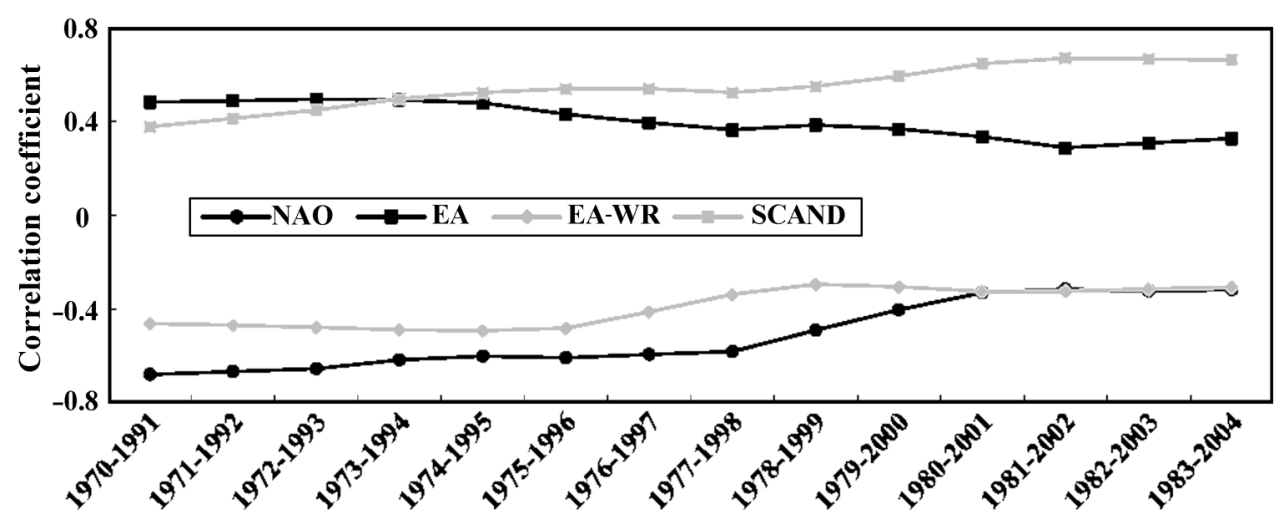


circulation from the mid-1950s through the 1978-79 winter (Hurrell 1995). During this 24 yr interval, there were 4 prominent periods, of at least $3 \mathrm{yr}$ each, in which the negative phase was dominant and the positive phase was notably absent. In fact, during the entire period, the positive phase was observed in the seasonal mean only 3 times, and never in 2 consecutive years. This explains the high correlation coefficient between the NAO pattern and Miño River flow and the relatively small influence of the SCAND pattern. An abrupt transition to recurring positive phases of the NAO occurred during the 1979-80 winter, with the atmosphere remaining locked near these index values until the 1994-95 winter season. During this $15 \mathrm{yr}$ interval, a substantial negative phase of the pattern appeared only twice (in the winters of 1984-85 and 1985-86). Thus the NAO positive phase shows less influence on precipitation in Galicia and consequently on the Miño River flow, with SCAND becoming the circulation pattern of most relevant influence.

\section{CONCLUDING REMARKS}

In the present study, the state of climate in NW Iberia was analyzed by means of different atmospheric and oceanographic variables. In this section, we consider a treatment of uncertainty slightly different from the one used by the IPCC (2007). Instead of considering different grades (virtually certain: $>99 \%$; extremely likely: $>95 \%$; very likely: $>90 \%$; likely: $>66 \%$ ), here we only distinguish between very likely $(>90 \%)$ and without statistical significance. The main findings of the present study can be summarized as follows:

- It is very likely that both maximum and minimum land temperature have increased at the annual scale since 1974 at a mean rate on the order of $0.5^{\circ} \mathrm{C}$ decade $^{-1}$. This behavior is especially marked for maximum temperature in spring and summer, and for minimum temperature in spring, summer and autumn.

- It is very likely that cold days and cold nights have become less frequent over NW Iberia since 1974. This decrease is especially remarkable for cold days in spring and for cold nights in spring, summer, and autumn.

- It is very likely that hot days and hot nights have become more frequent over NW Iberia since 1974. Trends are evident for hot days in spring and summer and for hot nights in spring, summer, and autumn.

- It is very likely that precipitation has decreased in winter and increased in autumn since 1974. No clear trend is observed during the other seasons and at an annual scale.
- It is very likely that coastal SST has increased at a mean rate of $\sim 0.15^{\circ} \mathrm{C}$ decade $^{-1}$ since 1985 . This behavior is especially noticeable in spring and summer, with increases at a mean rate of 0.35 and $0.30^{\circ} \mathrm{C}$ decade $^{-1}$ respectively.

- It is very likely that Atlantic SSTs have increased at a mean rate on the order of $0.24^{\circ} \mathrm{C}_{\text {decade }}{ }^{-1}$ since 1974 . This annual trend is mainly caused by spring and summer increases at a mean rate of 0.35 and $0.31^{\circ} \mathrm{C}$ decade $^{-1}$ respectively.

- It is very likely that several warming-cooling cycles in SST have occurred since 1874. The intensity of the present-day warming is similar although slightly higher than the one observed for the period 1908 to 1945.

- It is very likely that coastal upwelling along the western cost of NW Iberia has decreased during the period 1975 to 2008 both at the annual scale and during the wet season. The significance of the decrease observed during the dry season is lower.

- It is very likely that the discharge of the Miño River has decreased at a mean rate of $18 \mathrm{~m}^{3} \mathrm{~s}^{-1}$ decade $^{-1}$ since 1970. This decrease does not agree with precipitation results, suggesting that most of the observed decrease can be due to changes in water and land uses.

- It is very likely that sea level has risen by approximately $2 \mathrm{~cm}$ decade $^{-1}$ since 1943.

- It is very likely that winter cyclone frequency around western Europe has decreased for the period 1959 to 2001, which may have contributed to the decline in winter precipitation.

- It is very likely that blocking activity has decreased during winter and spring since 1948. This decrease was more pronounced during the 1970s and the 1990s and may have helped to amplify the increasing temperature trends by reducing the frequency of days with cold temperatures.

- Changes in circulation systems and their associated effects on temperature and precipitation are in broad agreement with a positive trend of the NAO in recent decades (until the 1990s), although other modes of variability also influence inter-annual variability of climate in NW Iberia.

The changes observed at a local scale (i.e. for NW Iberia) during the second half of the 20th century and beginning of the 21st century are consistent with those observed at the global scale (IPCC 2007). The possible persistence of these changes requires further study. In particular, the interaction of anthropogenic changes with internal climate variability is still an open question.

Acknowledgements. This work is supported by the Ministerio de Ciencia e Innovación under the FEDER-funded project CTM2007-62546-C03-03/MAR and under the projects CGL 2009-09143 and INCITE09383278PR. 


\section{LITERATURE CITED}

Alexander LV, Jones PD (2000) Updated precipitation series for the UK and discussion of recent extremes. Atmos Sci Lett 1:142-150

Alexander LV, Zhang X, Peterson TC, Caesar J and others (2006) Global observed changes in daily climate extremes of temperature and precipitation. J Geophys Res 111: D05109 doi:10.1029/2005JD006290

Alvarez I, deCastro M, Prego R, Gomez-Gesteira M (2003) Hydrographic characterization of a winter-upwelling event in the Ria of Pontevedra (NW Spain). Estuar Coast Shelf Sci 56:869-876

> Alvarez I, deCastro M, Gomez-Gesteira M, Prego R (2005) Inter- and intra-annual analysis of the salinity and temperature evolution in the Galician Rías Baixas-ocean boundary (northwest Spain). J Geophys Res 110:C04008 doi: 10.1029/2004JC002504

Alvarez I, Gomez-Gesteira M, deCastro M, Dias JM (2008a) Spatiotemporal evolution of upwelling regime along the western coast of the Iberian Peninsula. J Geophys Res 113: C07020 doi:10.1029/2008JC004744

- Alvarez I, Gomez-Gesteira M, deCastro M, Novoa EM (2008b) Ekman transport along the Galician Coast (NW, Spain) calculated from QuikSCAT winds. J Mar Syst 72: 101-115

Alvarez-Salgado XA, Roson G, Perez FF, Pazos Y (1993) Hydrographic variability off the Rias Baixas (NW Spain) during the upwelling season. J Geophys Res 98: 14447-14455

Araújo IB, Pugh DT (2008) Sea levels at Newlyn 1915-2005: analysis of trends for future flooding risks. J Coast Res 24: 203-212

Bakun A (1990) Global climate change and intensification of coastal upwelling. Science 247:198-201

Barriopedro D, Herrera RG, Lupo AR, Hernández E (2006) A climatology of Northern Hemisphere blocking. J Clim 19: 1042-1063

Barriopedro D, García-Herrera R, Trigo RM (2010) Application of blocking diagnosis methods to General Circulation Models. Part I: a novel detection scheme. Clim Dyn 35: 1373-1391

Blanton JO, Atkinson LP, Castillejo F, Montero AL (1984) Coastal upwelling of the Rias Bajas, Galicia, northwest Spain. I: Hydrographic studies. Rapp P-V Reùn Cons Int Explor Mer 183:179-190

Borges MF, Santos AMP, Crato N, Mendes H, Mota B (2003) Sardine regime shifts off Portugal: a time series analysis of catches and wind conditions. Sci Mar 67:235-244

> Borja A, Fontán A, Sáenz J, Valencia V (2008) Climate, oceanography and recruitment: the case of the Bay of Biscay anchovy (Engraulis encrasicolus). Fish Oceanogr $17: 477-493$

Brahmananda Rao V, Giarolla E, Monteiro do Espirito Santo C, Franchito SH (2008) Comparison of surface wind stress characteristics over the Tropical Atlantic $\left(10^{\circ} \mathrm{N}-40^{\circ} \mathrm{S}\right)$ in fields derived from the UWM/COADS, NCEP/NCAR and QuikSCAT datasets. J Oceanogr 64:551-560

Brunet M, Jones P, Sigró J, Saladié O and others (2007) Temporal and spatial temperature variability and change over Spain during 1850-2005. J Geophys Res 112:D12117 doi:10.1029/2006JD008249

Brunetti M, Colacino M, Maugeri M, Nanni T (2000) Trends in the daily intensity of precipitation in Italy from 1951 to 1996. Int J Climatol 20:1017-1031

> Brunsdon C, McClatchey J, Unwin DJ (2001) Spatial variations in the average rainfall-altitude relationship in
Great Britain: an approach using geographically weighted regression. Int J Climatol 21:455-466

Cabanas JM, Alvarez I (2005) Ekman transport patterns in the area close to the Galician coast (NW, Spain). J Atmos Ocean Sci 10:325-341

Cabanas JM, Lavin A, García MJ, Gonzalez-Pola C, Tel E (2003) Oceanographic variability in the northern shelf of the Iberian Peninsula (southern bay of Biscay), 1990-1999. ICES Mar Sci Symp 219:71-79

Castro M, Martín-Vide J, Alonso S (2005) The climate of Spain: past, present and scenarios for the 21st century. In: Moreno JM (ed) A preliminary assessment of the impacts in Spain due to the effects of climate change. Ministry of the Environment, Madrid, p 1-62

Chelton DB, Schlax MG, Freilich MH, Milliff RF (2004) Satellite measurements reveal persistent small-scale features in ocean winds. Science 303:978-983

Chust G, Caballero A, Marcos M, Liria P, Hernández C, Borja A (2010) Regional scenarios of sea level rise and impacts on Basque (Bay of Biscay) coastal habitats, throughout the 21st century. Estuar Coast Shelf Sci 87:113-124

> Croci-Maspoli M, Schwierz C, Davies HC (2007a) A multifaceted climatology of atmospheric blocking and its recent linear trend. J Clim 20:633-649

> Croci-Maspoli M, Schwierz C, Davies HC (2007b) Atmospheric blocking: space-time links to the NAO and PNA. Clim Dyn 29:713-725

deCastro M, Lorenzo N, Taboada JJ, Sarmiento M, Alvarez I, Gomez-Gesteira M (2006a) Influence of teleconnection patterns on precipitation variability and on river flow regimes in the Miño River basin (NW Iberian Peninsula). Clim Res 32:63-73

deCastro M, Dale AW, Gomez-Gesteira M, Prego R, Alvarez I (2006b) Hydrographic and atmospheric analysis of an autumnal upwelling event in the Ria of Vigo (NW Iberian Peninsula). Estuar Coast Shelf Sci 68:529-537

deCastro M, Gomez-Gesteira M, Lorenzo MN, Alvarez I, Crespo AJC (2008a) Influence of atmospheric modes on coastal upwelling along the western coast of the Iberian Peninsula, 1985 to 2005. Clim Res 36:169-179

deCastro M, Gomez-Gesteira M, Alvarez I, Lorenzo M, Cabanas JM, Prego R, Crespo AJC (2008b) Characterization of fall-winter upwelling recurrence along the Galician western coast (NW Spain) from 2000 to 2005: dependence on atmospheric forcing. J Mar Syst 72:145-158

deCastro M, Gomez-Gesteira M, Alvarez I, Gesteira JLG (2009) Present warming within the context of cooling-warming cycles observed since 1854 in the Bay of Biscay. Cont Shelf Res 29:1053-1059

$>$ Deschamps PY, Frouin R, Crepon M (1984) Sea surface temperatures of the coastal zones of France observed by the HCMM satellite. J Geophys Res Oceans 89:8123-8149

Douglas BC (2001) Sea level change in the era of the recording tide gauge. In: Douglas BC, Kearney MS, Leatherman SP (eds) Sea level rise: history and consequences. Academic Press, New York, NY, p 37-62

EEA (European Environment Agency) (2008) Impacts of Europe's changing climate-2008 indicator-based assessment. EEA Rep No 4/2008. EEA, Copenhagen. Available at: www.eea.europa.eu/publications/eea_report_2008_4

> Esteban-Parra MJ, Rodrigo FS, Castro-Díez Y (1998) Spatial and temporal patterns of precipitation in Spain for the period 1880-1992. Int J Climatol 18:1557-1574

Falkowski P, Scholes RJ, Boyle E, Canadell J and others (2000) The global carbon cycle: a test of our knowledge of Earth as a system. Science 290:291-296

Feldstein SB (2002) The recent trend and variance increase of 
the Annular Mode. J Clim 15:88-94

Fiuza AFG (1983) Upwelling patterns off Portugal. In: Suess E, Thiede J (eds) Coastal upwelling: its sediment record. Plenum Press, New York, NY, p 85-98

Fiuza AFG, Macedo ME, Guerreiro MR (1982) Climatological space and time variation of the Portugal coastal upwelling. Oceanol Acta 5:31-40

Flohn H, Kapala A, Knoche HR, Machel H (1990) Recent changes of the tropical water and energy budget and of midlatitude circulations. Clim Dyn 4:237-252

Fraga F (1981) Upwelling off the Galician coast, northwest Spain. In: Richards FA (ed) Coastal upwelling. American Geophysical Union, Washington, DC, p 176-182

$>$ Frouin R, Fiuza AFG, Ambar I, Boyd TJ (1990) Observations of a poleward surface current off the coasts of Portugal and Spain during winter. J Geophys Res Oceans 95:679-691

García JA, Serrano A, Cruz M (2002) A spectral analysis of Iberian Peninsula monthly rainfall. Theor Appl Climatol 71:77-95

García-Herrera R, Paredes D, Trigo RM, Trigo IF, Hernández E, Barriopedro D, Mendes MA (2007) The outstanding 2004/05 drought in the Iberian Peninsula: associated atmospheric circulation. J Hydrometeorol 8:483-498

García-Lafuente J, Del Río J, Álvarez-Fanjul E, Gomis D, Delgado J (2004) Some aspects of the seasonal sea level variations around Spain. J Geophys Res 109(C9):C09008 doi: 10.1029/2003JC002070

Garcia-Soto C, Pingree RD, Valdés L (2002) Navidad development in the southern Bay of Biscay: climate change and swoddy structure from remote sensing and in situ measurements. J Geophys Res Oceans 107(C8):3118

Gillett NP, Thompson DWJ (2003) Simulation of recent southern hemisphere climate change. Science 302:273-275

Goikoetxea N, Borja A, Fontan A, Gonzalez M, Valencia V (2009) Trends and anomalies in sea surface temperature, observed over the last 60 years, within the southeastern Bay of Biscay. Cont Shelf Res 29:1060-1069

Gomez-Gesteira M, Moreira C, Alvarez I, deCastro M (2006) Ekman transport along the Galician coast (northwest Spain) calculated from forecasted winds. J Geophys Res 111:C10005 doi:10.1029/2005JC003331

Gomez-Gesteira M, deCastro M, Alvarez I, Gomez-Gesteira JL (2008) Coastal sea surface temperature warming trend along the continental part of the Atlantic Arc (1985-2005). J Geophys Res 113:C04010 doi:10.1029/2007JC004315

- Goodess CM, Jones PD (2002) Links between circulation and changes in the characteristics of Iberian rainfall. Int J Climatol 22:1593-1615

Gulev SK, Zolina O, Grigoriev S (2001) Extratropical cyclone variability in the Northern Hemisphere winter from the NCEP/NCAR reanalysis data. Clim Dyn 17:795-809

> Haigh I, Nicholls R, Wells N (2009) Mean sea level trends around the English Channel over the 20th century and their wide context. Cont Shelf Res 29:2083-2098

- Haynes R, Barton ED (1990) A poleward flow along the Atlantic coast of the Iberian Peninsula. J Geophys Res 95: 11425-11441

Hurrell JW (1995) Decadal trends in the North Atlantic Oscillation: regional temperatures and precipitation. Science 269:676-679

IPCC (1990) Houghton JT, Jenkins GJ, Ephraums JJ (eds) Scientific assessment of climate change. Report of Working Group I. Cambridge University Press, Cambridge

IPCC (1996) Houghton JT, Meira Filho LG, Callender BA, Harris N, Kattenberg A, Maskell K (eds) Climate change 1995: the science of climate change. Contribution of Working Group I to the Second Assessment Report of the Inter- governmental Panel on Climate Change. Cambridge University Press, Cambridge

IPCC (2001) Houghton JT, Ding Y, Griggs DJ, Noguer M and others (eds) Climate change 2001: the scientific basis. Contribution of Working Group I to the Third Assessment Report of the Intergovernmental Panel on Climate Change. Cambridge University Press, Cambridge

IPCC (2007) Solomon S, Qin D, Manning M, Chen Z and others (eds) Climate change 2007: the physical science basis. Contribution of Working Group I to the Fourth Assessment Report of the Intergovernmental Panel on Climate Change. Cambridge University Press, Cambridge

$>$ Jones PD, New M, Parker DE, Martin S, Rigor IG (1999) Surface air temperature and its variations over the last 150 years. Rev Geophys 37:173-199

Kalnay E, Kanamitsu M, Kistler R, Collins W and others (1996) The NCEP/NCAR 40-year reanalysis project. Bull Am Meteorol Soc 77:437-471

Kistler R, Kalnay E, Collins W, Saha S and others (2001) The NCEP-NCAR 50-year reanalysis: monthly means CD-ROM and documentation. Bull Am Meteorol Soc 82: 247-268

> Klein Tank AMG, Können GP (2003) Trends in indices of daily temperature and precipitation extremes in Europe 1946-99. J Clim 16:3665-3680

Klein Tank AMG, Wijngaard JB, Können GP, Böhm R and others (2002) Daily dataset of 20th-century surface air temperature and precipitation series for the European Climate Assessment. Int J Climatol 22:1441-1453

Klein Tank AMG, Peterson TC, Quadir DA, Dorji S and others (2006) Changes in daily temperature and precipitation extremes in central and south Asia. J Geophys Res 111: D16105 doi:10.1029/2005JD006316

Koutsikopoulos C, Le Cann B (1996) Physical processes and hydrological structures related to the Bay of Biscay anchovy. Sci Mar 60:9-19

Levitus S, Antonov JI, Boyer TP, Stephens C (2000) Warming of the World Ocean. Science 287:2225-2229

Longshore D (2000) Encyclopedia of hurricanes, typhoons, and cyclones. Checkmark Books, New York, NY

> Lorenzo MN, Taboada JJ (2005) Influences of atmospheric variability on freshwater input in Galician Rias in winter. J Atmos Ocean Sci 10:377-387

Marcos M, Gomis D, Monserrat S, Álvarez-Fanjul E, Pérez B, García Lafuente J (2005) Consistency of long sea-level time series in the northern coast of Spain. J Geophys Res 110:C03008 doi:10.1029/2004JC002522

Martínez Cortizas A, Pérez Alberti A (2000) Atlas climático de Galicia Centro de información e tecnoloxía ambiental. Desenvolvemento sostible. Xunta de Galicia, Santiago de Compostela

> McClain CR, Chao S, Atkinson LP, Blanton JO, Castillejo F (1986) Wind-driven upwelling in the vicinity of Cape Finisterre, Spain. J Geophys Res 91:8470-8486

Michel S, Treguier AM, Vandermeirsch F (2009) Temperature variability in the Bay of Biscay during the past 40 years, from an in situ analysis and a 3D global simulation. Cont Shelf Res 29:1070-1087

> Moberg A, Jones PD, Barriendos M, Bergström H and others (2000) Day-to-day temperature variability trends in 160- to 275-year-long European instrumental records. J Geophys Res 105(D18):22849-22868

> Muñoz-Díaz D, Rodrigo FS (2004) Spatio-temporal patterns of seasonal rainfall in Spain (1912-2000) using cluster and principal component analysis: comparison. Ann Geophys 22:1435-1448

Nieto R, Gimeno L, de la Torre L, Ribera P and others (2005) 
Climatologies features of cut-off low systems in the Northern Hemisphere. J Clim 18:3085-3103

Nykjaer L, Van Camp L (1994) Seasonal and interannual variability of coastal upwelling along northwest Africa and Portugal from 1981 to 1991. J Geophys Res 99:14197-14208

Paredes D, Trigo RM, García-Herrera R, Trigo IF (2006) Understanding precipitation changes in Iberia in early spring: weather typing and storm-tracking approaches. J Hydrometeorol 7:101-113

Peltier WR (2001) Global glacial isostatic adjustment and modern instrumental records of relative sea level history. In: Douglas BC, Kearney MS, Leatherman SP (eds) Sea level rise: history and consequences. Academic Press, New York, NY, p 65-95

Penabad E, Alvarez I, Balseiro CF, deCastro M, Gomez B, Perez-Muñuzuri V, Gomez-Gesteira M (2008) Comparative analysis between operational weather prediction models and QuikSCAT wind data near the Galician coast. J Mar Syst 72:256-270

Pérez FF, Ríos AF, King BA, Pollard RT (1995) Decadal changes of the $\theta-S$ relationship of the Eastern North Atlantic Central Water. Deep-Sea Res I 42:1849-1864

> Peterson TC, Vose R, Schmoyer R, Razuvaev V (1998) Global historical climatology network (GHCN) quality control of monthly temperature data. Int J Climatol 18:1169-1179

Peterson TC, Folland C, Gruza G, Hogg W, Mokssit A, Plummer N (2001) Report on the activities of the Working Group on Climate Change Detection and Related Rapporteurs 1998-2001. Rep WCDMP-47 WMO-TD 1071. World Meteorological Organisation, Geneva

Pingree RD, Le Cann B (1989) Celtic and Armorican slope and shelf residual currents. Prog Oceanogr 23:303-338

Planque B, Beillois P, Jegou AM, Lazure P, Petitgas P, Puillat I (2003) Large scale hydroclimatic variability in the Bay of Biscay: the 1900s in the context of interdecadal changes. ICES Mar Sci Symp 219:61-70

> Pozo-Vázquez D, Gámiz-Fortis SR, Tovar-Pescador J, Esteban-Parra MJ, Castro-Díez Y (2005) El Niño-Southern Oscillation events and associated European winter precipitation anomalies. Int J Climatol 25:17-31

Prego R, Guzman-Zuñiga D, Varela M, deCastro M, GomezGesteira M (2007) Consequences of winter upwelling events on biogeochemical and phytoplankton patterns in a western Galician ria (NW Iberian Peninsula). Estuar Coast Shelf Sci 73:409-422

> Queralt S, Hernández E, Barriopedro D, Gallego D, Ribera P, Casanova C (2009) North Atlantic Oscillation influence and weather types associated with winter total and extreme precipitation events in Spain. Atmos Res 94: 675-683

Rahmstorf S (2007) A semi-empirical approach to projecting future sea-level rise. Science 315:368-370

Raible CC, Della-Marta P, Schwierz C, Wernli H, Blender R (2008) Northern hemisphere extratropical cyclones: a comparison of detection and tracking methods and different reanalyses. Mon Weather Rev 136:880-897

Ramos AM, Lorenzo MN, Gimeno L (2010) Compatibility between modes of low-frequency variability and circulation types: a case study of the northwest Iberian Peninsula. J Geophys Res 115:D02113 doi:10.1029/2009JD012194

Rayner NA, Parker DE, Horton EB, Folland CK and others (2003) Global analyses of sea surface temperature, sea ice, and night marine air temperature since the late nineteenth century. J Geophys Res 108:4407 doi:10.1029/2002JD 002670

Rayner NA, Brohan P, Parker DE, Folland CK and others (2006) Improved analyses of changes and uncertainties in sea surface temperature measured in situ since the midnineteenth century: the HadSST2 data set. J Clim 19: 446-469

Rios Barja F, Rodríguez-Lestegás F (1992) Os Ríos Galegos. Consello de Cultura Galega, Santiago de Compostela

Roderick ML, Farquhar GD (2002) The cause of decreased pan evaporation over the past 50 years. Science 298: 1410-1411

Rodó X, Baert E, Comin FA (1997) Variations in seasonal rainfall in southern Europe during the present century: relationships with the North Atlantic Oscillation and the El Niño-Southern Oscillation. Clim Dyn 13:275-284

> Rodrigo FS, Trigo RM (2007) Trends in daily rainfall in the Iberian Peninsula from 1951 to 2002. Int J Climatol 27:513529

> Rodrigo FS, Esteban-Parra MJ, Pozo-Vázquez D, Castro-Díez Y (1999) A 500-year precipitation record in Southern Spain. Int J Climatol 19:1233-1253

Rodríguez-Puebla C, Encinas AH, Nieto S, Garmendia J (1998) Spatial and temporal patterns of annual precipitation variability over the Iberian Peninsula. Int J Climatol 18: 299-316

> Rodríguez-Puebla C, Encinas AH, Sáenz J (2001) Winter precipitation over the Iberian Peninsula and its relationship to circulation indices. Hydrol Earth Syst Sci 5:233-244

Rosón G, Cabanas JM, Pérez FF, Herrera Cortijo JL and others (2009) Hidrografía e hidrodinámica. In: Evidencias e impactos do cambio climático en Galicia. Conselleria de Medio Ambiente de Desenvolvemento Sostible, Xunta de Galicia, Santiago de Compostela, p 287-302

Santos AM, Borges MF, Groom S (2001) Sardine and horse mackerel recruitment and upwelling off Portugal. ICES J Mar Sci 58:589-596

Santos AM, Peliz A, Dubert J, Oliveira PB, Angelico MM, Re $P$ (2004) Impact of a winter upwelling event on the distribution and transport of sardine (Sardina pilchardus) eggs and larvae off western Iberia: a retention mechanism. Cont Shelf Res 24:149-165

Santos AM, Kazmin AS, Peliz A (2005) Decadal changes in the Canary upwelling system as revealed by satellite observations: their impact on productivity. J Mar Res 63:359-379

Schwing FB, Mendelssohn R (1997) Increased coastal upwelling in the California Current System. J Geophys Res 102:3421-3438

- Serrano A, Garcia AJ, Mateos VL, Cancillo ML, Garrido J (1999) Monthly modes of variation of precipitation over the Iberian Peninsula. J Clim 12:2894-2919

> Smith TM, Reynolds RW (2002) Bias corrections for historical sea surface temperatures based on marine air temperatures. J Clim 15:73-87

Smith TM, Reynolds RW (2003) Extended reconstruction of global sea surface temperatures based on COADS data (1854-1997). J Clim 16:1495-1510

> Smith TM, Reynolds RW (2004) Improved extended reconstruction of SST (1854-1997). J Clim 17:2466-2477

> Smith TM, Reynolds RW (2005) A global merged land-airsea surface temperature reconstruction based on historical observations (1880-1997). J Clim 18:2021-2036

Smith TM, Reynolds RW, Livezey RE, Stokes DC (1996) Reconstruction of historical sea surface temperatures using empirical orthogonal functions. J Clim 9:1403-1420

Smith TM, Reynolds RW, Peterson TC, Lawrimore J (2008) Improvements to NOAA's historical merged land-ocean surface temperature analysis (1880-2006). J Clim 21: 2283-2296

Southward AJ, Boalch GT (1994) The effects of changing climate on marine life: past events and future predictions. In: 
Fisher S (ed) Man and the maritime environment. University of Exeter Press, Exeter, p 101-143

Swanson KL, Tsonis AA (2009) Has the climate recently shifted? Geophys Res Lett 36:1-4

Tenore KR, Cal RM, Hanson RB, Lopez-Jamar E, Santiago G, Tietjen JM (1984) Coastal upwelling off the Rias Bajas, Galicia, Northwest Spain. II Benthic studies. Rapp P-V Reùn Cons Int Explor Mer 183:91-100

Tibaldi S, Molteni F (1990) On the operational predictability of blocking. Tellus A 42:343-365

Tilstone GH, Figueras FG, Fraga F (1994) Upwelling-downwelling sequences in the generation of red tides in a coastal upwelling system. Mar Ecol Prog Ser 112:241-253

Trauth MH (2006) Matlab recipes for earth sciences. Springer, Berlin

Trigo IF (2006) Climatology and interannual variability of storm-tracks in the Euro-Atlantic sector: a comparison between ERA-40 and NCEP/NCAR reanalyses. Clim Dyn 26:127-143

Trigo RM, DaCamara CC (2000) Circulation weather types and their influence on the precipitation regime in Portugal. Int J Climatol 20:1559-1581

Trigo RM, Palutikof JP (2001) Precipitation scenarios over Iberia: a comparison between direct GCM output and different downscaling techniques. J Clim 14:4422-4446

Trigo IF, Davies TD, Bigg GR (1999) Objective climatology of cyclones in the Mediterranean region. J Clim 12: 1685-1696

Trigo RM, Osborn TJ, Corte-Real JM (2002) The North Atlantic Oscillation influence on Europe: climate impacts and associated physical mechanisms. Clim Res 20:9-17

Trigo RM, Trigo IF, DaCamara CC, Osborn TJ (2004a) Climate impact of the European winter blocking episodes from the NCEP/NCAR reanalyses. Clim Dyn 23:17-28

Trigo RM, Pozo-Vázquez D, Osborn TJ, Castro-Díez Y,

Submitted: April 29, 2010; Accepted: October 28, 2010
Gámiz-Fortis S, Esteban-Parra MJ (2004b) North Atlantic Oscillation influence on precipitation, river flow and water resources in the Iberian Peninsula. Int $\mathrm{J}$ Climatol 24: 925-944

Trigo RM, Valente MA, Trigo IF, Miranda PMA, Ramos AM, Paredes D, García-Herrera R (2008) The impact of North Atlantic wind and cyclone trends on European precipitation and significant wave height in the Atlantic. Ann NY Acad Sci (Spec Issue Trends Dir Clim Res) 1146:212-234

Tuomenvirta H, Alexandersson H, Drebs A, Frich P, Nordli PO (2000) Trends in nordic and Arctic temperature extremes and ranges. J Clim 13:977-990

Ulbrich U, Leckebusch GC, Pinto JG (2009) Extra-tropical cyclones in the present and future climate: a review. Theor Appl Climatol 96:117-131

Uppala SM, Kållberg PW, Simmons AJ, Andrae U and others (2005) The ERA-40 re-analysis. Q J R Meteorol Soc 131: 2961-3012

von Storch H, Zorita E, Cubasch U (1993) Downscaling of global climate change estimates to regional scales: an application to Iberian rainfall in wintertime. J Clim 6: 1161-1171

Wang XLL, Swail VR, Zwiers FW (2006) Climatology and changes of extratropical cyclone activity: comparison of ERA40 with NCEP-NCAR reanalysis for 1958-2001. J Clim 19:3145-3166

Wiley DP, Frey R, Zhang H, Menzel WP (2002) Extending HIRS high cloud trends with MODIS. MODIS Science Team Meeting. NASA, Greenbelt, MD

Wooster WS, Bakun A, McClain DR (1976) The seasonal upwelling cycle along the eastern boundary of the north Atlantic. J Mar Res 34:131-141

Zhu Y, Newell RE (1998) A proposed algorithm for moisture fluxes from atmospheric rivers. Mon Weather Rev 126: 725-735

Proofs received from author(s): August 16, 2011 